\title{
Effects of chlorine, peracetic acid and low-pressure ultra violet light on antibiotic resistant $E$. coli isolates with regards to their survival and changes in their antibiotic resistance profiles
}

\author{
By: Cameron Macdonell
}

\begin{abstract}
A thesis submitted to the Faculty of Graduate and Postdoctoral Affairs in partial fulfillment of the requirements for the degree

Masters of Applied Science

in

Environmental Engineering

Carleton University

Ottawa, Ontario
\end{abstract}

(C) Cameron Macdonell, 2019 


\begin{abstract}
Antibiotic resistance is a growing problem worldwide and poses a serious threat to human health. Overuse and misuse of antibiotics by the human health and animal livestock industries has contributed to the development of resistance to antibiotics that are vital for curing and preventing bacterial infections. Wastewater treatment plants play a key role in mitigating the propagation of antibiotic resistant bacteria because they are a collection point for all primary sources of antibiotic resistance. In this study, 97 Escherichia coli (E. coli) were isolated from secondary wastewater effluent and an analysis of their antibiotic resistance profiles against 7 antibiotics was conducted. Then, four selected E. coli test isolates and one control (ATCC 25922) were exposed to free chlorine ( $\mathrm{NaClO}$ ), peracetic acid (PAA) and lowpressure UV treatments. The $\log _{10} \mathrm{CFU}$ colony forming unit recoveries of the test isolates were compared to that of the control. The changes in antibiotic resistance for each isolate from before to after disinfection were analyzed. Finally incidents of change in Kirby Bauer resistance classification from before to after disinfection were analyzed. Disinfection is the final stage in the wastewater treatment process before discharge, and plays an important role in preventing the release of antibiotic resistant E. coli into the environment.
\end{abstract}




\section{Acknowledgements}

First and foremost I would like to thank Richard Kibbee for his help throughout the duration of this project. The work completed would not have been possible without his expertise. I would like to thank my supervisor, Professor Banu Ormeci for her support and motivation. I would also like to thank Emma for her encouragement, patience and understanding throughout this Masters program. 


\section{Table of Contents}

Abstract ......................................................................................................

Acknowledgements.......................................................................................... ii

Table of Contents .................................................................................................iv

List of Figures...................................................................................... viii

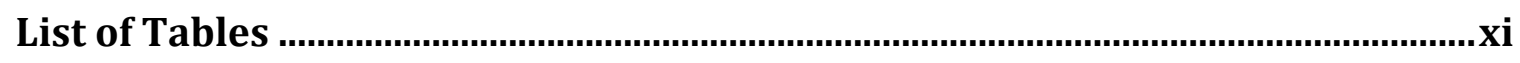

1 Introduction

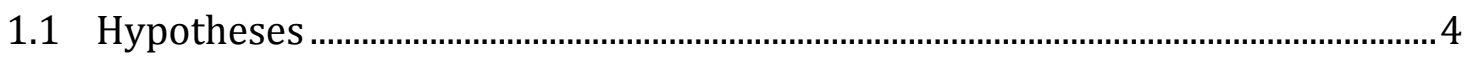

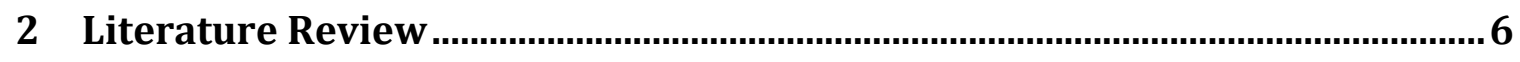

2.1 Antibiotic resistance a growing issue worldwide......................................................6

2.1.1 History of antibiotics and resistance ............................................................ 8

2.1.2 Antibiotics and antibiotic resistant bacteria ................................................11

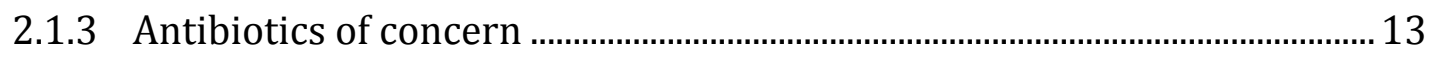

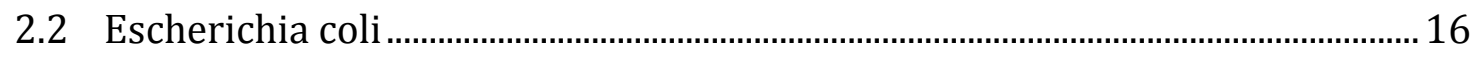

2.3 Wastewater treatment plants act as reservoirs for antibiotic resistance........17

2.4 Disinfection treatment technologies for water and wastewater ........................19

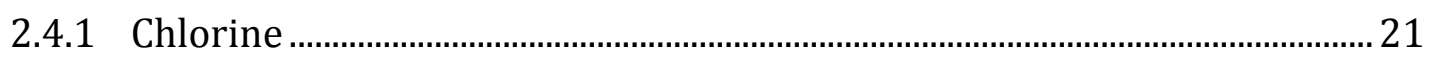

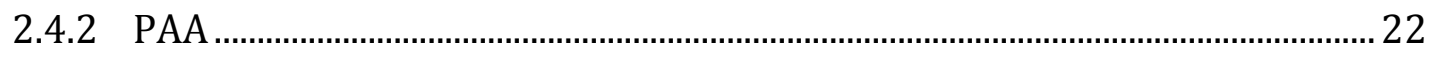

2.4.3 Low pressure ultra violet light .......................................................................... 23

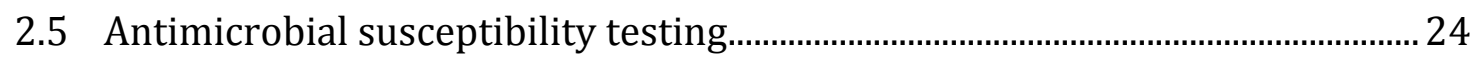

2.5.1 Broth dilution tests........................................................................................... 25 
2.5.2 Antimicrobial gradient method...................................................................25

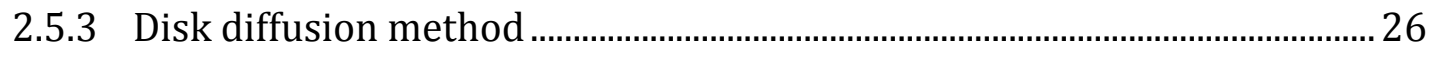

2.6 Antibiotic resistant E. coli in water and wastewater ………………………...... 27

2.7 Reduction of antibiotic resistant E. coli by disinfection treatments .................28

2.8 Changes in antibiotic resistance in bacteria after exposure to disinfection ..29

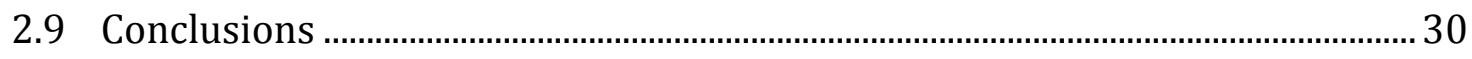

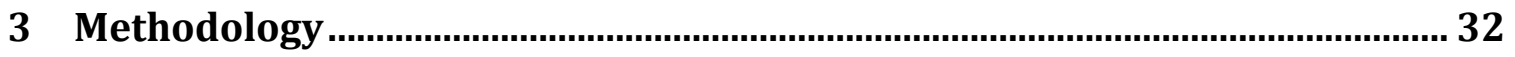

3.1 Assessing Prevalence of antibiotic resistant E. coli in secondary wastewater

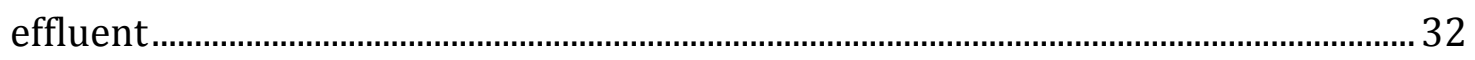

3.1.1 Sampling of secondary wastewater effluent.................................................. 32

3.1.2 Spread plating concentrated secondary wastewater effluent and

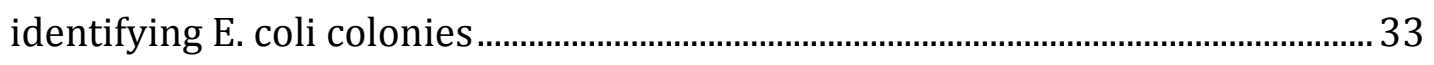

3.1.3 Picking E. coli colonies and streaking to isolate pure cultures ...................34

3.1.4 Selecting streaked E. coli colonies and growing them to optimal concentration 35

3.1.5 Swabbing E. coli cultures and placing antibiotic disks on to MuellerHinton agar plates for resistance profile determination ...........................................38

3.1.6 Kirby Bauer resistance profile determination and selection of E. coli isolates for disinfection treatments 40

3.1.7 Selecting for carbapenem resistant E. coli test isolates to add to study . 42

3.1.8 Preserving E. coli isolates and long term storage 43

3.2 Disinfection experiments and resistance profile analysis with control and E. coli test isolates. 43 
3.2.1 E. coli test isolates and experimental matrix

3.2.2 Chemical disinfection treatment by chlorine and PAA ...................................44

3.2.3 Low-pressure ultra violet disinfection 45

3.2.4 Filtration and enumeration of initial and disinfection-treated E. coli colonies 49

3.2.5 Kirby Bauer resistance profile comparison from pre to post disinfection 49

3.3 Statistical analysis 50

4 Results 52

4.1 Part 1: Prevalence of antibiotic resistant E. coli in secondary wastewater effluent. 53

4.2 Part 2: $\log _{10}$ CFU recovery of E. coli test isolates

4.2.1 Free chlorine 61

4.2.2 PAA 62

4.2.3 Low-pressure UV 65

4.2.4 Disinfection efficacy comparisons between free chlorine, PAA and lowpressure UV. 66

4.3 Part 3: Susceptibility changes in antibiotic resistance profiles. 68

4.3.1 Changes in E. coli antibiotic susceptibility versus disinfection treatment 68

4.3.2 Changes in E. coli antibiotic susceptibility versus E. coli test isolates .....71

4.3.3 Changes in E. coli antibiotic susceptibility versus antibiotics tested ....... 73 
4.4 Part 4: Reclassification of antibiotic resistance of post-disinfection E. coli picks

5 Discussion 78

5.1 Part 1: Prevalence of antibiotic resistant bacteria in secondary wastewater effluent. 78

5.2 Part 2: $\log _{10} \mathrm{CFU}$ inactivation of E. coli test isolates versus the control by free chlorine, PAA and low-pressure UV

5.3 Part 3: Susceptibility changes in antibiotic resistance profiles versus

disinfection treatment, E. coli test isolates and antibiotic..

5.4 Part 4: Significant susceptibility changes in post-disinfection E. coli picks causing reclassification of antibiotic resistance

6 Conclusions.

References. 


\section{List of Figures}

Figure 2.1: Wastewater treatment plants are sewage collection centers and therefore considered "hot spots" for antibiotic resistant bacteria and genes.......8

Figure 2.2: Developing antibiotic resistance: A timeline of key events...........................10

Figure 2.3: Three main methods of horizontal gene transfer: transformation,

transduction and conjugation ..................................................................................... 18

Figure 2.4: Frequently observed survival curves, linear, tailing and shouldering .....20

Figure 3.1: Spread plate technique for applying wastewater sample to $100 \times 15 \mathrm{~mm}$

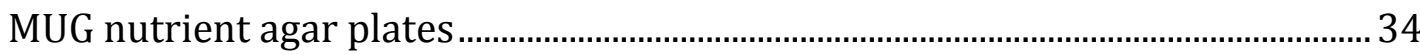

Figure 3.2: Streak plate method for isolating pure E. coli cultures ...................................36

Figure 3.3: Example of E. coli streaked on to 100x15mm MUG nutrient agar plate.. 37

Figure 3.4: Swabbing method for Kirby Bauer antibiotic resistance profile

determination

Figure 3.5: Antibiotic disk placement for Kirby Bauer disk diffusion method, with azithromycin (AZM) $(15 \mu \mathrm{g})$, ertapenem (ERT) $(10 \mu \mathrm{g})$, amoxicillin/clavulanic acid (AMC) $(30 \mu \mathrm{g})$, tetracycline (TET) $(30 \mu \mathrm{g})$, impenem (IPM) $(10 \mu \mathrm{g})$, ceftriaxone (CRO) $(30 \mu \mathrm{g})$, and ciprofloxacin (CIP) $(5 \mu \mathrm{g})$

Figure 3.6: Example of Kirby Bauer disk diffusion method; growth of bacterial lawn and zones of inhibition

Figure 3.7: Example of bench scale device for conducting UV experiments, described by Bolton and Linden et al 46

Figure 4.1: Approximate prevalence of antibiotic resistance among 97 E. coli isolates 
Figure 4.2: Distribution of antibiotic resistance for $97 \mathrm{E}$. coli isolates tested with

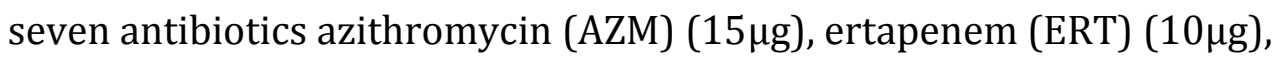

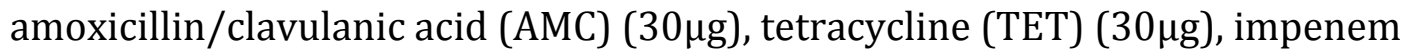

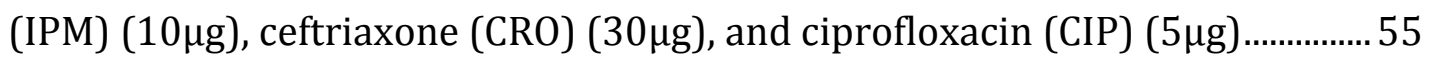

Figure 4.3: E. coli Control Pre-Disinfection Kirby Bauer Antibiotic Resistance Profile

Figure 4.4: E. coli test isolate A Pre-Disinfection Kirby Bauer Antibiotic Resistance Profile

Figure 4.5: E. coli test isolate B Pre-Disinfection Kirby Bauer Antibiotic Resistance Profile

Figure 4.6: E. coli test isolate C Pre-Disinfection Kirby Bauer Antibiotic Resistance Profile 60

Figure 4.7: E. coli test isolate D Pre-Disinfection Kirby Bauer Antibiotic Resistance Profile 60

Figure 4.8: $\log _{10}$ CFU recovery of E. coli per $100 \mathrm{~mL}$ after treatment with $0.1 \mathrm{mg} / \mathrm{L}$ free chlorine with a contact time of 30 seconds

Figure 4.9: $\log _{10}$ CFU recovery of E. coli per $100 \mathrm{~mL}$ after treatment with $1 \mathrm{mg} / \mathrm{L}$ PAA for 10 minutes 63

Figure 4.10: $\log _{10}$ CFU Recovery of E. coli per $100 \mathrm{~mL}$ after $20 \mathrm{~mJ} / \mathrm{cm}^{2}$ irradiation with low-pressure UV 65

Figure 4.11: Recovery of Log10 CFU E. coli per $100 \mathrm{~mL}$ of control and test isolates A, B, C, and D after exposure to FC, PAA and Low-pressure UV. 67 
Figure 4.12: Percentage of changes in E. coli antibiotic susceptibility after disinfection treatment by free chlorine, PAA and low-pressure UV with $95 \%$ confidence $(\mathrm{P}<0.05)$ 70

Figure 4.13: Percentage of changes in E. coli antibiotic susceptibility with respect to each test isolates after exposure to any disinfection treatment with $95 \%$ confidence $(\mathrm{P}<0.05)$ 71

Figure 4.14: Percentage of changes in E. coli antibiotic susceptibility with respect to

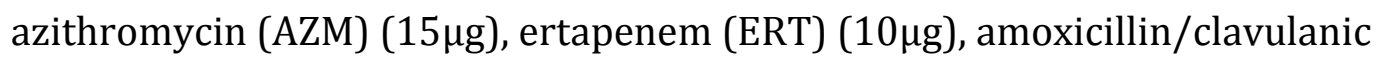

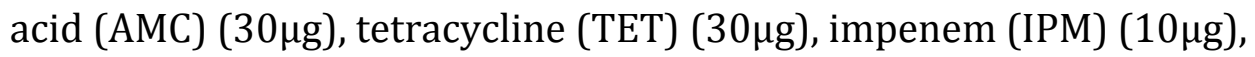

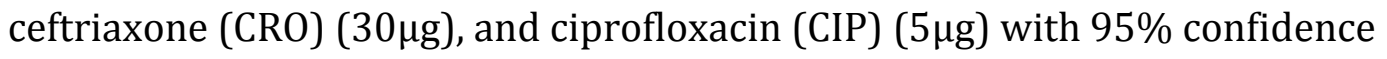
$(\mathrm{P}<0.05)$

Figure 4.15: Changes in zones of inhibition from pre to post disinfection causing reclassification of resistance 


\section{List of Tables}

Table 3.1: Susceptible, intermediate and resistant zone of inhibition ranges for $E$. coli for ertapenem (ERT), imipenem (IPM), amoxicillin/clavulanic (AMC), ceftriaxone (CRO), tetracycline (TET), azithromycin (AZM) and ciprofloxacin (CIP)

Table 3.2: Types of T tests and when they are appropriately applied. 50

Table 4.1: Zones of inhibition for the control and E. coli test isolates for azithromycin (AZM) $(15 \mu \mathrm{g})$, ertapenem (ERT) $(10 \mu \mathrm{g})$, amoxicillin/clavulanic acid (AMC)

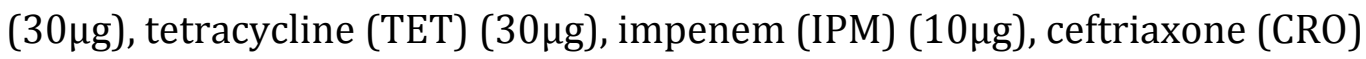
$(30 \mu \mathrm{g})$, and ciprofloxacin (CIP) $(5 \mu \mathrm{g})$ used in disinfection experiments 56

Table 4.2: Qualitative ranking of catalase reaction for each E. coli 64

Table 4.3: Changes in antibiotic resistance classifications, from Susceptible to Intermediate (S to I), Intermediate to Resistant (I to R), or Susceptible to Resistant (S to R) 76

Table 7.1: Control strain zones of inhibition before and after disinfection treatment in millimeters

Table 7.2: Test isolate A Zones of inhibition before and after disinfection treatment in millimeters 113

Table 7.3: Test isolate B Zones of inhibition before and after disinfection treatment in millimeters 114

Table 7.4: Test isolate C Zones of inhibition before and after disinfection treatment in millimeters 114 
Table 7.5: Test isolate D Zones of inhibition before and after disinfection treatment

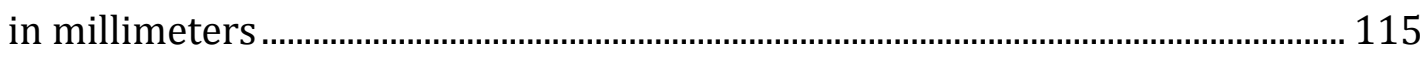

Table 7.6: Zones of inhibition for 97 E. coli isolates against 7 antibiotics................... 115

Table 7.7: Free chlorine disinfection experiment data February 3rd 2018 ............... 118

Table 7.8: Free chlorine disinfection experiment data April 10th 2018...................... 119

Table 7.9: PAA disinfection experiment data February 26th 2018_.............................. 120

Table 7.10: PAA disinfection experiment data March 5th 2018.................................... 121

Table 7.11: Low pressure UV disinfection experiment data March 15th 2018 ........ 122

Table 7.12: Low pressure UV disinfection experiment data March 24th 2018 ........ 123

Table 7.13: Kirby Bauer resistance profiles of control and test isolates pre and post free chlorine disinfection February 3rd 2018 124

Table 7.14: Kirby Bauer resistance profiles of control and test isolates pre and post free chlorine disinfection April 10 2018 125

Table 7.15: Kirby Bauer resistance profiles of control and test isolates pre and post PAA disinfection February $26^{\text {th }} 2018$ 126

Table 7.16: Kirby Bauer resistance profiles of control and test isolates pre and post PAA disinfection March $5^{\text {th }} 2018$ 127

Table 7.17: Kirby Bauer resistance profiles of control and test isolates pre and post low pressure UV disinfection March $15^{\text {th }} 2018$. 128

Table 7.18: Kirby Bauer resistance profiles of control and test isolates pre and post low pressure UV disinfection March 24th 2018 129 
Table 7.19: Secondary wastewater effluent water quality data obtained from the Robert O. Pickard Environmental Center before disinfection (BD) and after

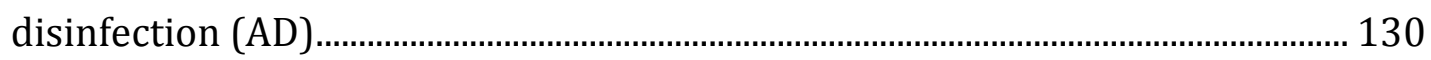




\section{Introduction}

Incidents of infections resistant to antibiotic treatments have been occurring more frequently all around the world, especially in less developed countries. A global review of antimicrobial resistance, commissioned by the government of the United Kingdom in 2016 reported that there were approximately 700,000 deaths in 2014 worldwide that were attributable to antibiotic resistance, and that number is projected to grow to $10,000,000$ by 2050 (O'Neill, 2016). Overuse of antibiotics in the human health and animal agriculture industries, poor sanitation practices, inadequate infection control in hospitals and a lack of new antimicrobial development all contribute to the threat of antibiotic resistance (WHO, 2014). Of the 17,200 metric tons of antibiotics consumed in the United States annually, approximately $80 \%$ is in aquaculture and livestock, while the remaining $20 \%$ is by humans. Antibiotics are often used in non-essential ways, such as doctors prescribing antibiotics for viral infections. In livestock, antibiotics are fed to animals to increase digestion efficiency resulting in increased growth (Hollis \& Ahmed, 2013). Antibiotic resistance in bacteria can arise from exposure to sub-inhibitory concentrations of antibiotics that may occur in the gastro intestinal tract of humans and other animals, animal agriculture wastewater, as well as in wastewater treatment plants (Kumar \& Pal, 2018). Addressing this problem is important as it poses a risk to human health. Mitigation of antibiotic resistance is a multifaceted approach that requires awareness and action at the government, industry and public level. Besides limiting and monitoring appropriate antibiotic usage, 
promoting public awareness and education, practicing better infection protocol and developing new antibiotics, it is also important to address the prevalence of antibiotic resistant bacteria in wastewater treatment plants and assess how effectively they are removed (Kumar \& Pal, 2018). Knowing the extent of antibiotic resistance and how well typical treatment processes remove antibiotic resistant bacteria is important because wastewater plants play a key role in mitigating their propagation and release into the environment (Bouki, Venieri, \& Diamadopoulos, 2013).

Antibiotic resistance in E. coli has been highlighted by the CDC and the World Health Organization (WHO) as an urgent threat, specifically pertaining to beta-lactamase, carbapenemase and extended-spectrum-beta-lactamase producing strains (CDC, 2013). It is the most frequent cause of urinary tract, bloodstream and intraabdominal infections, and is one of the leading causative agents of foodborne infections world wide (WHO, 2014). These reasons are why it is important to study E. coli isolated from wastewater, assess their antibiotic resistance, and determine the effects wastewater treatment processes, specifically disinfection, have on their antibiotic resistance (Harris, Morris, Morris, Cormican, \& Cummins, 2014). Three of the most common disinfection technologies employed in wastewater plants around the world are chlorine in the form of sodium hypochlorite, Peracetic acid (PAA) and low-pressure ultraviolet light. After chlorine is dosed it mainly exists as $\mathrm{HOCl}$ and $\mathrm{OCl}-\mathrm{HOCl}$ reacts with superoxide anions to produce $\cdot \mathrm{OH}$ radicals that destroy bacterial cells by oxidation (Sharma, Johnson, Cizmas, McDonald, \& Kim, 2016). PAA is also an oxidizing agent that is based on the production of reactive 
oxygen species that damage bacterial cell structures (Gehr, Wagner, Veerasubramanian, \& Payment, 2003). Finally, irradiating wastewater with lowpressure UV is an alternative disinfection treatment that damages cellular DNA. This disrupts cellular function and causes subsequent inactivation (Gehr et al., 2003). These different mechanisms may be more or less effective against cellular defenses in E. coli, which may be relevant to an E. coli strain's antibiotic resistance.

Although there are many studies showing the presence of different antibiotic resistant genes in wastewater, analysis of phenotypic antibiotic resistance of $E$. coli in wastewater plants is not conducted as often, and the current knowledge should be added to.

Little literature exists regarding the effects of disinfection treatment on antibiotic resistant $E$. coli compared to susceptible $E$. coli. It is important to make this comparison to determine whether defense mechanisms E. coli contain that confer resistance to antibiotics may also aid them in surviving standard disinfection processes, causing selection for them. Also, whether multidrug resistance correlates to greater resilience to disinfection is unclear.

Another gap in the literature is the ability to directly compare the efficacies of chlorine, PAA and low pressure UV on antibiotic resistant bacteria versus susceptible bacteria because there are many variables (such as matrix, disinfection dose, bacteria species, and initial bacterial concentration) that need to be controlled for. There is also a need for more studies investigating the changes in antibiotic resistance bacteria may exhibit after exposure to disinfection. 
The objectives of this study include the following:

1. Contribute to the current literature regarding the prevalence of antibiotic resistant $E$. coli in wastewater treatment plants, specifically in secondary wastewater effluent prior to disinfection, using the Kirby Bauer Disk diffusion method.

2. Compare the inactivation of antibiotic resistant $E$. coli to that of susceptible $E$. coli. Regardless of disinfection treatment, do antibiotic resistant E. coli have a competitive advantage over susceptible E. coli?

3. Compare effectiveness of free chlorine, PAA and low pressure UV against antibiotic resistant bacteria. Is there one disinfection treatment that can inactivate antibiotic resistant bacteria better than the other treatment types?

4. Analyze and compare the antibiotic resistance of E. coli from before and after exposure to disinfection treatments to determine if exposure to disinfection stress incites antimicrobial defense expression or suppression.

5. Relate changes in antibiotic resistance to how antibiotic resistant the E. coli were before disinfection, the disinfection treatments used, and the antibiotics tested.

\subsection{Hypotheses}

The hypotheses for this study are as follows:

1. Phenotypic antibiotic resistance is prevalent in E. coli isolated from secondary wastewater effluent. 
2. The wastewater isolated E. coli are more resilient to all three disinfection treatments than the susceptible control, and the more antibiotic resistant an E. coli isolate is, the more resilient to disinfection treatment.

3. There is no significant difference between the inactivation of E. coli by chlorine, PAA and low pressure UV.

4. The antibiotic resistance in the wastewater isolated E. coli increases after exposure to disinfection, and no change in the antibiotic resistant profile of the control occurs.

This study will summarize the effects of chlorine, PAA and low pressure UV on antibiotic resistant bacteria and their Kirby Bauer resistance profiles. Because of the controls put in place, such as using distilled water as the matrix, using a lab adapted control, ensuring similar reductions of the control are achieved by the doses used for each treatment type, consistent initial E. coli concentrations, and having four test E. coli isolates representing a spectrum of antibiotic resistance, this study will allow for one to compare the inactivation results from each disinfection treatment to one another, and compare any observed changes in antibiotic resistance from before to after disinfection between the $E$. coli isolates.

This thesis will first begin with a review of the current literature on antibiotic resistance worldwide, its promulgation in wastewater treatment plants and how different disinfection processes can impact antibiotic resistant bacteria. The methodology followed in this study will be presented, followed by the results, a discussion of the results, and final conclusions. 


\section{Literature Review}

\subsection{Antibiotic resistance a growing issue worldwide}

The discovery of antibiotics revolutionized the way bacterial infections are prevented and treated in the health care system. Since their first implementation, the use of antibiotics has expanded into other industries such as animal agriculture, veterinary medicine, aquaculture and bee keeping (Gothwal \& Shashidhar, 2015). This extensive use of antibiotics has greatly benefited these industries, preventing and controlling outbreaks of bacterial disease. Unfortunately, their overuse has contributed to growing resistance to antibiotics among bacterial communities, creating a demand for more advanced antimicrobials that are difficult to develop at the same rate as this resistance. Other factors that contribute to growing resistance include over-prescription of antibiotics, patients not finishing prescribed antibiotic courses, poor infection control in health care settings, and poor hygiene and sanitation (WHO, 2014). These factors create a cycle of increasing resistance, where bacteria are exposed to sub-inhibitory concentrations of antibiotics and those that survive have intrinsic or developed resistance, and then pass on that resistance via vertical translation (when they reproduce) or horizontal transfer (donating, accepting or exchanging DNA with other bacteria) (Levy \& Marshall, 2004). These selective pressures for antibiotic resistant bacteria have dire consequences world wide, and have been highlighted by the World Health Organization (WHO), the United States Center for Disease Control and Prevention (CDC), the European Center for Disease Control and Prevention and the United Kingdom (CDC, 2013; European 
Food Safety Authority \& European Centre for Disease Prevention and Control, 2017; O'Neill, 2016; WHO, 2014). Preventing the propagation of antibiotic resistance is a multifaceted approach that includes methods such as health care professional and public education, development of new antimicrobials, reduction of use, and increased awareness of the issue. Preventing discharge of antibiotic resistant bacteria to the environment is also very important. Wastewater treatment plants act as a collection zone for human and animal wastewater, and have been identified as "hot spots" for antibiotic resistance (Kümmerer, 2009). Figure 2.1 demonstrates the movement of antibiotic resistant genes and bacteria in modern society, and how wastewater plants act as a catch basin for them. This is why it is important to assess the effects that wastewater treatment technologies have on antibiotic resistant bacteria before discharge to the environment. 


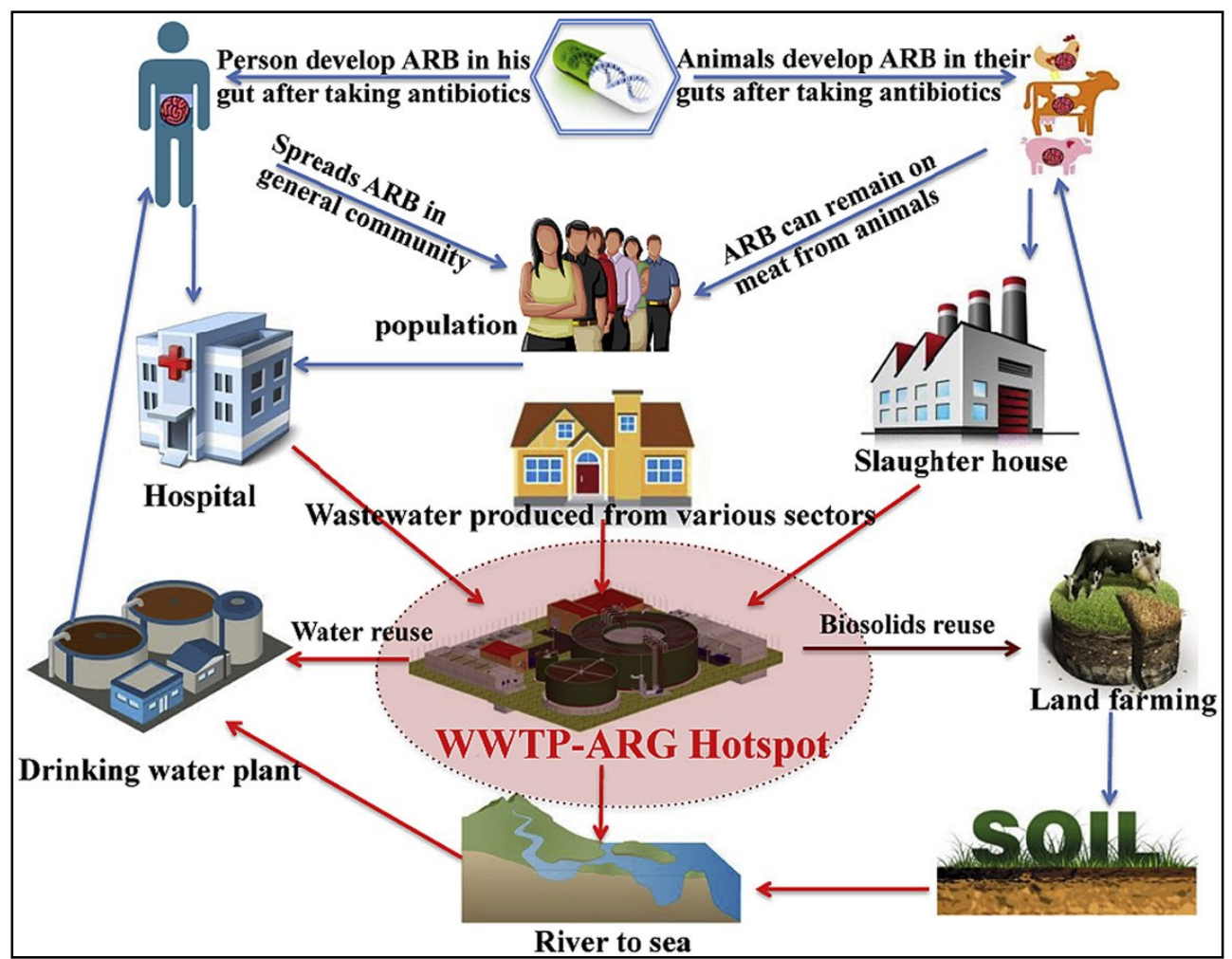

Figure 2.1: Wastewater treatment plants are sewage collection centers and therefore considered "hot spots" for antibiotic resistant bacteria and genes

(J. Guo, Li, Chen, Bond, \& Yuan, 2017)

\subsubsection{History of antibiotics and resistance}

The first antibiotic discovered was penicillin in 1928, and it was first prescribed to treat infections in 1943. Although this discovery was ground breaking, cases of resistance to penicillin via an enzyme in bacteria called penicillinase were discovered in 1940, before the drug was even brought to market (Davies \& Davies, 2010). Sulfonamides were first introduced in 1937, and sulfonamide resistance was subsequently observed in the late 1930's (Davies \& Davies, 2010). Steptomycin, part of the aminoglycoside family, was introduced in 1944 to treat tuberculosis (TB). During antibiotic therapy of patients, strains of Mycobacterium tuberculosis resistant to streptomycin arose, rendering the treatment not as effective. This cycle of 
antibiotic use and subsequent resistance has been occurring since antibiotics were first discovered (CDC, 2013). Figure 2.2 from the CDC gives examples of introduction of antibiotics and discovery of resistance to them. 


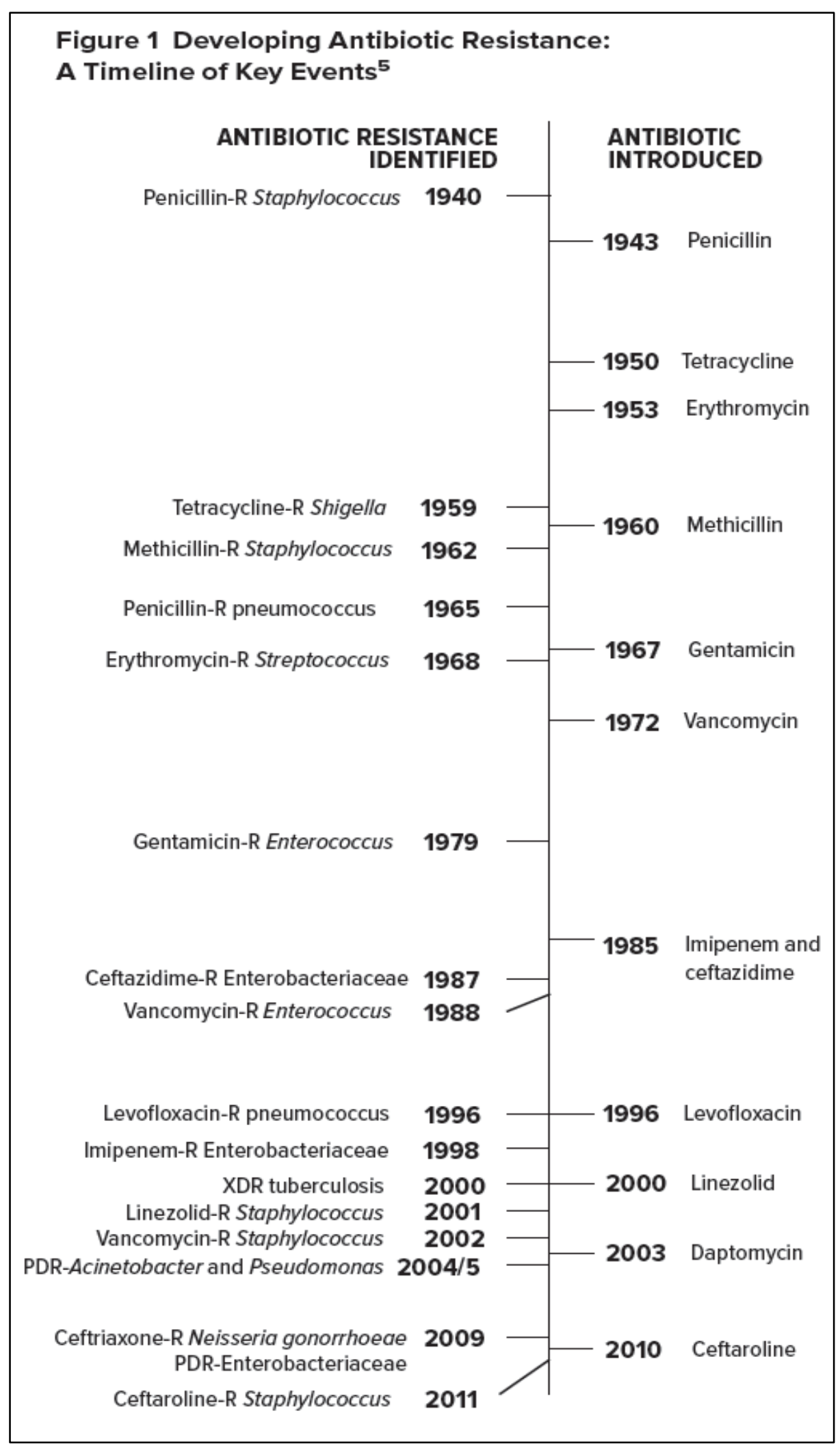

Figure 2.2: Developing antibiotic resistance: A timeline of key events

(Ventola, 2015) 
Bacteria can be intrinsically resistant to an antibiotic or can acquire resistance either by internal chromosomal mutation or receiving DNA encoding resistance from the environment or other bacteria (Munita, Arias, Unit, \& Santiago, 2016). An example of intrinsic resistance could be that a bacteria simply does not contain a certain structure or protein that an antibiotic is designed to attack. Resistance can also be attributed to different defense mechanisms possessed by a bacterial cell when it is exposed to an antibiotic. The modes of resistance can be destruction (hydrolysis) or modification (steric hindrance) of the antibiotic structure by a specific enzyme, efflux pumps within the cell used to remove the antibiotic, regulation of porin proteins preventing the antibiotic from entering the cell, and alteration or protection of the targeted ribosome, enzyme or protein so the antibiotic can not bind and inhibit vital cell function (Blair, Webber, Baylay, Ogbolu, \& Piddock, 2014). The types and number of defenses bacteria can contain varies widely. This allows bacteria to become multi-drug resistant (resistant to three or more antibiotics), because they can be intrinsically resistant and/or acquire resistance to multiple classes of antibiotics.

\subsubsection{Antibiotics and antibiotic resistant bacteria}

Organizations such as the $\mathrm{WHO}$ and the $\mathrm{CDC}$ have highlighted the most important threats to human health with respect to antibiotic resistance based on factors such as clinical impact, economic impact, incidence, future projection of incidence, transmissibility, availability of effective antibiotics and barriers to prevention (CDC, 2013; WHO, 2014). For the purposes of this study, the threats highlighted that relate 
to Gram-negative bacteria and specifically the Enterobacteriaceae family (to which E. coli belongs) will be discussed.

Carbapenem-resistant Enterobacteriaceae (CRE) are the greatest health risk to modern medicine. In the United States in 2013, there were 9,000 infections and 90 deaths due to carbapenem-resistant (CR) E. coli. The two most common types of CRE are Klebsiella pneumonia and E. coli. Carbapenem antibiotics play a critical role in health care settings, as they possess the broadest spectrum of antimicrobial activity and are used as a last line of defense for serious multidrug resistant infections (Papp-Wallace, Endimiani, Taracila, \& Bonomo, 2011). Extended-spectrum-beta-lactamase (ESBL) producing Enterobacteriaceae are considered to be the next greatest threat. Beta lactamase is an enzyme that can break down the structure of beta-lactam antibiotics, rendering them ineffective (Blaak et al., 2014). Approximately 9,000 infections and 600 deaths in 2013 in the United States were attributable to ESBL producing E. coli (CDC, 2013). ESBL producing bacteria are resistant to the penicillin and cephalosporin antibiotic classes, which are heavily relied upon in the health care industry. Other antibiotic resistant Gram-negative bacteria that pose serious health risks include Neisseria gonorrhoeae, multidrug resistant Acinetobacter, and drug resistant Campylobacter, Salmonella and Helicobacter Pylori. These pathogenic Gram-negative bacteria cause a variety of infections, and their resistance to carbapenems, macrolides, fluoroquinolones and cephalosporins has been observed (CDC, 2013). 


\subsubsection{Antibiotics of concern}

The antibiotics used to test for drug susceptibility in this study were selected based on the antibiotics of concern and threats posed by E. coli identified by the recent CDC and the WHO reports on antimicrobial resistance (CDC, 2013; WHO, 2014). They were also chosen so a variety of antibiotic classes and different types within those classes were represented to test for resistance to different inhibitive mechanisms. Four beta-lactam antibiotics (imipenem, ertapenem, amoxicillin/clavulanic acid and ceftriaxone), a macrolide (azithromycin), a fluoroquinolone (ciprofloxacin) and tetracycline were used. The antibiotics were purchased from Oxoid ${ }^{\mathrm{TM}}$, and were provided in standard dosages for the disk diffusion method as described by the CLSI antimicrobial susceptibility testing protocol (Patel, Cockerill, \& Bradford, 2013).

\subsubsection{Beta-Lactams}

Antibiotics in the beta-lactam class interfere with proteins that are essential for synthesis of the bacterial cell wall, and in doing so either inhibit cell growth or kill the bacteria. They do so by binding to penicillin-binding proteins (PBPs) in the cell, which are responsible for cross-linking peptide units during peptidoglycan synthesis. Binding to the PBPs stops peptidoglycan synthesis, causing the cell to lyse and die. Members of this antibiotic class include carbapenems, penicillins, cephalosporins and monobactams (Etebu \& Arikekpar, 2016).

Ertapenem and imipenem were the two carbapenems tested in this study. Carbapenems were discovered out of necessity in 1960, when penicillins were becoming ineffective against bacteria containing the enzyme beta-lactamase. 
Carbapenems are the most effective against Gram-negative and Gram-positive bacteria, with a large spectrum of activity. They are used as a last resort and only administered for severe infections that may harbor antibiotic resistance (Etebu \& Arikekpar, 2016). Unfortunately, resistance to these antibiotics via enzymes called carbapenamases have been discovered and are becoming more common (Cantón et al., 2012). Amoxicillin/clavulanic acid is a penicillin antibiotic (another member of the betalactam class) combined with an ESBL inhibitor (clavulanic acid). Amoxicillin has been developed semi-synthetically with side-chains that confer an ability to evade degradation by some beta-lactamase enzymes and also facilitate the movement of the antibiotic through the outer membrane of bacterial cell walls. Clavulanic acid is a non-antibiotic compound that is able to inhibit penicillinase enzymes to prolong the antibacterial activity of the amoxicillin (Poirel, Brinas, Verlinde, Ide, \& Nordmann, 2005).

Ceftriaxone is a $3^{\text {rd }}$ generation cephalosporin (a member of the beta-lactam class) that was tested in this study. Cephalosporins are similar to penicillins in their structure and mode of action, and are one of the most commonly prescribed antibiotics world wide (WHO, 2014). There are five generations of cephalosporins, with later versions being increasingly more effective against Gram-negative pathogenic bacteria (Etebu \& Arikekpar, 2016). They are equipped with a variety of side chains that allow them to circumvent bacterial defenses, to bind to a greater variety of PBPs, and to resist degradation by penicillinase enzymes (Bush, Jacoby, \& Medeiros, 1995). 
The major resistance mechanisms bacteria have towards beta-lactam antibiotics are hydrolysis, efflux pumps and altering the antibiotic target (Davies \& Davies, 2010).

\subsubsection{Macrolides}

Azithromycin is a macrolide class antibiotic tested in this study. Macrolides bind to ribosomes, preventing the addition of amino acids to polypeptide chains, hindering the process of protein synthesis. Macrolides are prescribed very often in place of penicillin for general infections because they have a wider spectrum of antibiotic activity, or can be used if a patient is allergic to penicillin.

The main resistance mechanisms bacteria have towards these antibiotics are hydrolysis, glycosylation, phosphorylation, efflux pumps, and altering the antibiotic target (Davies \& Davies, 2010).

\subsubsection{Fluoroquinolones}

Ciprofloxacin is part of the fluoroquinolone class of antibiotics, which is derived from the quinolone class. Quinolones are able to interfere with DNA replication and transcription in bacteria, and are based on the basic structure of nalidixic acid. Modifications have been made to the structure of quinolones to improve their bioavailability and increase their spectrum of activity and potency. Ciprofloxacin is used to treat illnesses such as urinary, systemic and respiratory tract infections (Etebu \& Arikekpar, 2016). The main mechanisms of resistance bacteria use against quinolones are acetylation, efflux pumps, and altering the antibiotic target (Davies \& Davies, 2010). 


\subsubsection{Tetracycline}

Tetracycline is part of the first generation of the tetracycline class of antibiotics, which includes tetracycline, chlortetracycline, oxytetracycline and demeclocycline. Tetracycline inhibits bacteria by targeting their ribosomes, and subsequently disrupts the addition of amino acids to polypeptide chains during protein synthesis. Tetracycline at one point was very widely used because it had a vast spectrum of antimicrobial activity, but more recently there have been many cases of resistance to it (Chopra \& Roberts, 2001). The main mechanisms of resistance towards tetracyclines are monooxygenation, efflux pumps, and altering the antibiotic target (Davies \& Davies, 2010).

\subsection{Escherichia coli}

E. coli is a member of the Enterobacteriaceae family and is a Gram-negative rod shaped bacterium. Its only natural habitat is the large intestine of warm-blooded animals. It generally does not survive well anywhere else, so its presence in waster and wastewater effluent usually indicates pour sanitation practices. Its detection does not confirm the presence of pathogenic organisms, but it does mean there is an increased risk of exposure to faecal-borne harmful bacteria and viruses (Odonkor \& Ampofo, 2013) . This is why E. coli is widely used as an indicator organism in water and wastewater treatment. There is a significant amount of literature describing the inactivation of $E$. coli by disinfection treatment. The antibiotic resistance of $E$. coli does not completely representative the entire bacterial community in secondary wastewater effluent, but an analysis of it does shed light on what antibiotic resistant genes are present. Most of the pathogenic bacteria that pose the greatest risks to 
human health are Gram negative (CDC, 2013), so the ability of antibiotics to inhibit E.coli would reflect their ability to inhibit more dangerous bacteria.

\subsection{Wastewater treatment plants act as reservoirs for antibiotic resistance}

Wastewater treatment plants act as a collection zone for human and animal wastewater, and have been identified as "hot spots" for antibiotic resistance (Kümmerer, 2009). This is important because wastewater plants act as a mixing pot for antibiotic resistant bacteria and facilitate the acquisition and sharing of antibiotic resistant genes (Michael et al., 2013). Bacterial populations can be intrinsically resistant to an antibiotic, but they can also acquire it if given access to genes that may encode for defensive mechanisms such as enzymes, increased porin regulation, increased efflux pump regulation and others (Arber, 2014). Bacteria can obtain genes encoding for resistant mechanisms via horizontal gene transfer. Horizontal gene transfer plays an important role in bacterial evolution, and therefore an important role in increasing antibiotic resistance (Forsberg et al., 2012). There are three main methods of DNA transfer between bacteria; transformation, transduction and conjugation. Transformation occurs when a bacterial cell lyses and its DNA is released into the environment and subsequently taken up by another organism and incorporated into its genome. Transduction is facilitated by bacteriophages taking up DNA from one cell and transferring it to another cell. Conjugation occurs by direct contact between bacteria. A "bridge" is formed by plasmids from each cell, resulting in the exchange of genetic information 
(Furuya \& Lowy, 2006). Figure 2.3 depicts the three types of horizontal gene transfer.

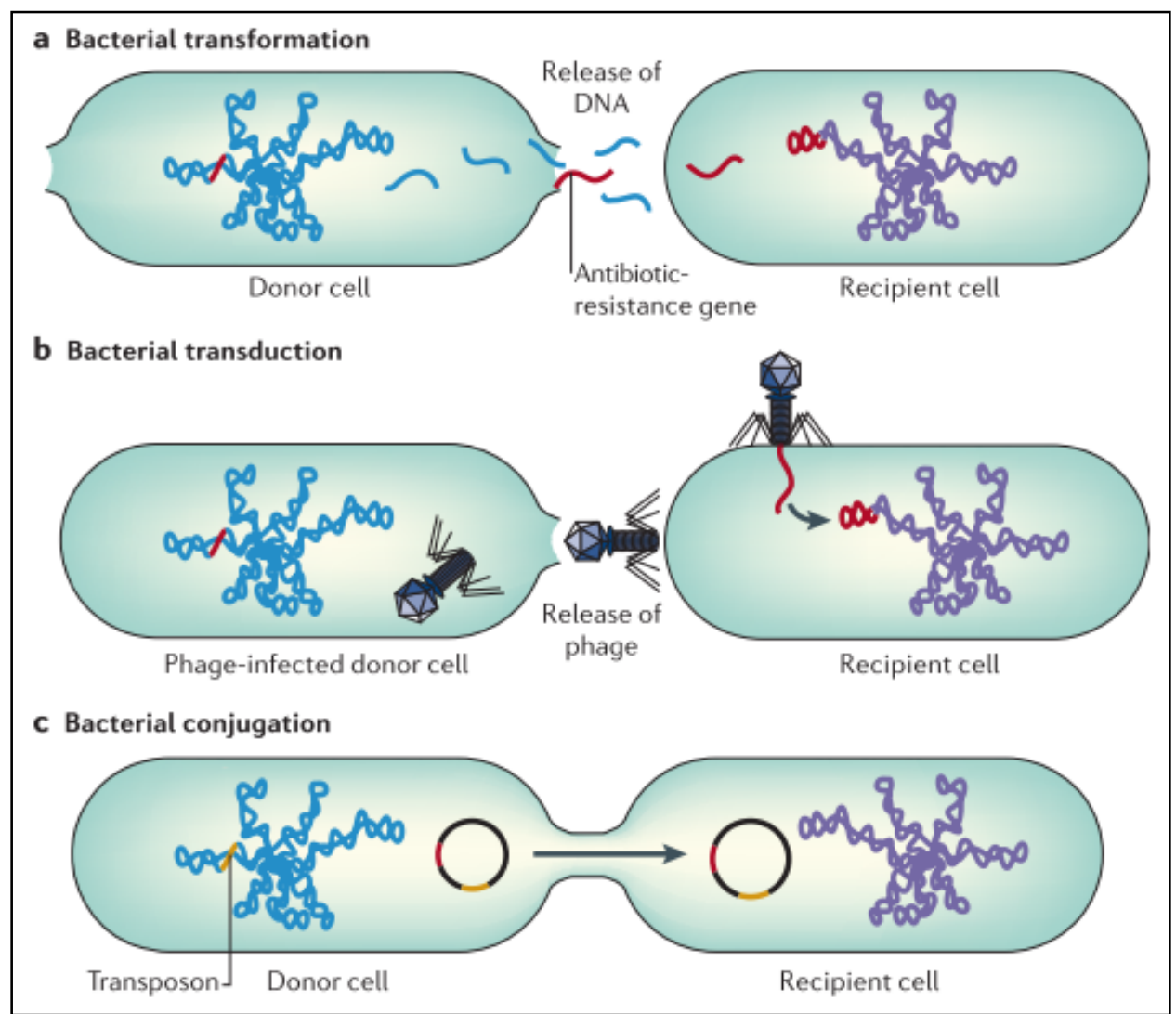

\section{Figure 2.3: Three main methods of horizontal gene transfer: transformation, transduction and conjugation}

(Furuya \& Lowy, 2006)

These mechanisms allow for the exchange of genetic information between all types of bacterial species. This creates opportunities for antibiotic resistant bacteria to share genes responsible for antibiotic defense mechanisms with antibiotic susceptible bacteria. Wastewater treatment plants provide a prime environment for this to occur, and that is why treatment of antibiotic resistant bacteria needs to be studied (Michael et al., 2013). 


\subsection{Disinfection treatment technologies for water and wastewater}

Disinfection of drinking water and wastewater is extremely important to human health, as it is responsible for removing pathogenic bacteria and viruses before distribution to the public or discharge to the environment. The most widely used treatment technologies include chemical and physical inactivation processes. Chemical processes include chlorine, chlorine dioxide, ozone and PAA, while ultraviolet radiation is an example of physical disinfection (Collivignarelli, Abba, Benigna, Sorlini, \& Toretta, 2018). Advanced oxidation processes are also used, and involve combinations of chemical and physical technologies to facilitate the production of hydroxyl radicals.

Inactivation of bacteria is achieved by changing or destroying cell structure, which in turn inhibits vital cell functions. Several wastewater parameters can affect disinfection efficacy, such as $\mathrm{pH}$, ionic strength, temperature, organic loading and suspended solids (Metcalf \& Eddy, 2014). Models of disinfection usually describe the effects of dose and contact time on bacterial survival. A survivor curve is a plot of $\log \left(\mathrm{N} / \mathrm{N}_{0}\right)$ versus time or dose, where $\mathrm{N}$ is number or concentration of bacteria at specific times or doses and $\mathrm{N}_{0}$ is the initial number or concentration of bacteria. In practice, the three most frequently observed types of survivor curves are linear, shouldering and tailing, as shown in Figure 2.4. Linear is what is expected and predicted by the Chick-Watson model. Shouldering occurs when the disinfecting agent preferentially reacts with interfering constituents before inactivating the targeted bacteria. Tailing occurs when bacteria are inactivated quickly at first, and 
then the rate of inactivation slows at higher contact times due to less inactivation sites (Jensen, 2010).

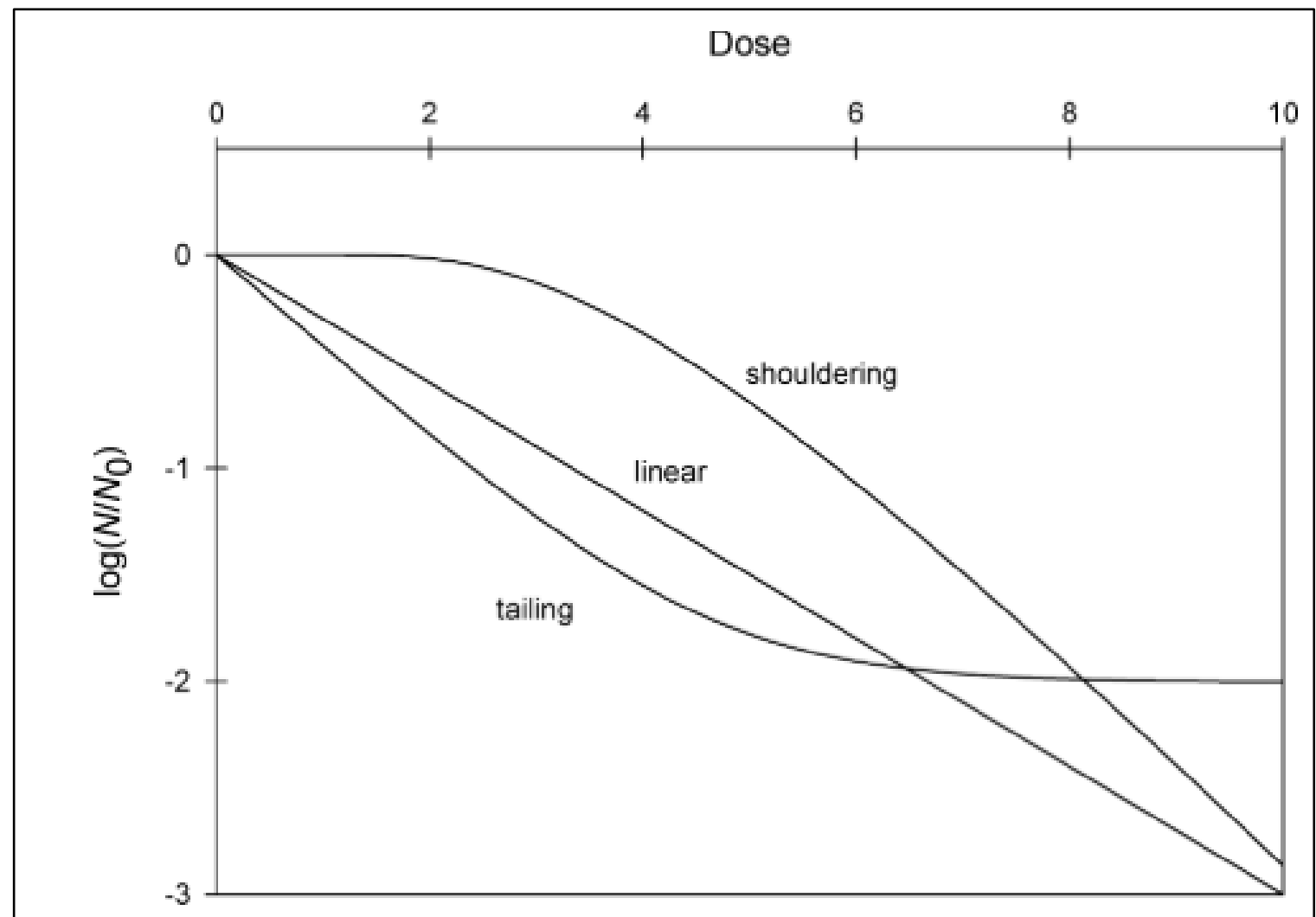

Figure 2.4: Frequently observed survival curves, linear, tailing and shouldering

(Jensen, 2010)

Chlorine, PAA and low-pressure UV treatments were selected for investigation because they are the most common disinfection treatments used around the world, and knowing their effect on antibiotic resistant bacteria links to issues the water and wastewater industry currently deals with (Metcalf \& Eddy, 2014). The action mechanisms, advantages and disadvantages of each technology will be briefly discussed. 


\subsubsection{Chlorine}

Chlorine is the most widely used disinfectant in water and wastewater and is most commonly dosed in the form of sodium hypochlorite. Factors to be considered when dosing chlorine are temperature, $\mathrm{pH}$ and organic content of the water. When sodium hypochlorite is added to water, it undergoes the following reaction forming hypochlorous acid:

$$
\mathrm{NaOCl}+\mathrm{H}_{2} \mathrm{O} \rightarrow \mathrm{HOCl}+\mathrm{NaOH}
$$

Once hypochlorous acid is produced in water, it is then ionized to hypochlorite ions in the following reaction:

$$
\mathrm{HOCl} \leftrightarrow \mathrm{H}^{+}+\mathrm{OCl}^{-}
$$

The total quantity of hypochlorous acid and hypochlorite in water is called the free chlorine. They are both strong oxidants ( $\mathrm{HOCl}$ is stronger) that are available to react with and oxidize bacteria and other organic matter in the wastewater matrix (Hua \& Reckhow, 2007). When determining a dosage, it is the free chlorine that is measured and managed accordingly. Chlorine kills bacteria by direct oxidation of the cell wall, modification of the cell wall permeability, alteration of the cell protoplasm, inhibition of enzyme activity, and damage to the cell DNA or RNA (Metcalf \& Eddy, 2014).

Chlorine is used so ubiquitously because it has a number of advantages. It is an established technology that is very effective against pathogens, it can be easily monitored and maintained, and it is relatively inexpensive. However, there are a number of disadvantages to the technology. Chlorine is not as effective against some viruses, spores and cysts at low dosages, residual concentrations can be toxic to the 
environment and therefore dechlorination is required before discharging wastewater final effluent, it is not effective against Cryptosporidium, and can be inefficient because it is easily consumed by any constituents in the water or wastewater stream (Metcalf \& Eddy, 2014). Chlorine can also produce harmful disinfection by-products that include trihalomethane and acetoacetic when in the presence of organic compounds such as humic and fulvic acid (Rebhun, Hellergrossman, \& Manka, 1993).

\subsubsection{PAA}

PAA is a disinfectant that is bactericidal, virucidal, fungicidal and sporicidal. Its effectiveness in other industries has created a demand for its use in wastewater treatment. PAA is a strong oxidant, and is commercially available in a quaternary equilibrium mixture of hydrogen peroxide, acetic acid, PAA and water as shown by the following equation:

$$
\mathrm{CH}_{3} \mathrm{CO}_{2} \mathrm{H}+\mathrm{H}_{2} \mathrm{O}_{2} \leftrightarrow \mathrm{CH}_{3} \mathrm{CO}_{\mathrm{S}} \mathrm{H}+\mathrm{H}_{2} \mathrm{O}
$$

Where $\mathrm{CH}_{3} \mathrm{CO}_{2} \mathrm{H}$ is acetic acid, $\mathrm{H}_{2} \mathrm{O}_{2}$ is hydrogen peroxide and $\mathrm{CH}_{3} \mathrm{CO}_{s} \mathrm{H}$ is PAA (Kitis, 2004). The PAA is considered to be the biocidal form in the equilibrium mixture, but the hydrogen peroxide does also contribute to the disinfecting process (Metcalf \& Eddy, 2014). That being said, Wagner et al. determined that hydrogen peroxide required much higher doses than PAA to achieve similar levels of disinfection, implying PAA was the more influential oxidant (Wagner, Brumelis, \& Gehr, 2002). The findings for the effectiveness of PAA against bacteria in wastewater have been mixed, and it seems the wastewater characteristics can impact its potency (Kitis, 2004). The disinfecting mechanism of PAA is caused by the 
release of active oxygen or the production of hydroxyl radicals. These two constituents attack bacterial cell walls and membranes, and also destroy vital enzymes and DNA/RNA (Kitis, 2004). The advantages to PAA are that it does not create harmful disinfection by-products, it is not effected by $\mathrm{pH}$ and it can be a highly effective bactericide and virucide (Metcalf \& Eddy, 2014). PAA does cause an increase in biological oxygen demand and chemical oxygen demand in the final effluent from the formation of acetic acid, but it does not produce any known toxic by-products (Mezzanotte, Citterio, Antonelli, \& Nurizzo, 2007). This is the greatest argument for PAA to be considered as a substitute for chlorine.

\subsubsection{Low pressure ultra violet light}

Ultraviolet radiation has proven to be able to disinfect bacteria, protozoa and viruses in both filtered and unfiltered wastewater (Metcalf \& Eddy, 2014). UV radiation occurs in the $100 \mathrm{~nm}$ to $400 \mathrm{~nm}$ electromagnetic spectrum. It is further characterized according to wavelength as long-wave (UV-A), middle-wave (UV-B) and short-wave (UV-C). UV wavelengths between 255 and $265 \mathrm{~nm}$ are the most effective at microbial inactivation, which is in the UV-C range (Metcalf \& Eddy, 2014). Low pressure UV treatment involves the generation of monochromatic radiation within the UV-C range with a large peak at a wavelength of $253.7 \mathrm{~nm}$ and a smaller peak at a wavelength of $184.9 \mathrm{~nm}$ (Hijnen, Beerendonk, \& Medema, 2006). Low pressure UV radiation is different from chlorine and PAA because it is a physical disinfecting agent as opposed to a chemical disinfecting agent. UV penetrates the cell wall of a microorganism and is subsequently absorbed by nucleic acids in DNA and RNA. This absorption damages the DNA and RNA, which interferes 
with normal cell processes such as cell synthesis and cell division (Mezzanotte et al., 2007). Bacteria do have some defense mechanisms against UV light. For example, Mofidi et al. found that when cell DNA is not actively dividing bacteria may be more resistant, implying that the growth phase the bacteria are in can impact its sensitivity to UV (Mofidi et al., 2002). Some organisms are also able to maintain some metabolic activities after being exposed to UV, and may have mechanisms able to repair any damage caused from exposure, such as photoreactivation or dark repair (Metcalf \& Eddy, 2014).

The main advantages of low pressure UV are that it is effective, it does not require hazardous chemicals, has no residual toxicity, is very effective against viruses, spores and cysts, and it does not form any toxic disinfection by products. Some disadvantages to low pressure UV are that there is no immediate measure that can tell if disinfection was successful, it is energy intensive, can be ineffective if the wastewater has high turbidity, and has a high capital cost (G. Tchobanoglous, Burton, \& Stensel, 2003).

\subsection{Antimicrobial susceptibility testing}

Antibiotic susceptibility testing is conducted in clinical settings to determine appropriate drug therapies for patients with bacterial infections. The most widely used testing methods are broth dilution, disk diffusion and gradient diffusion. All three methods provide a qualitative evaluation of susceptibility, while only some provide quantitative results (such as a minimum inhibitory concentration or MIC). All three methods discussed provide accurate detection of antibiotic resistance (Patel et al., 2013). 


\subsubsection{Broth dilution tests}

The broth dilution procedure involves preparing two-fold dilutions of antibiotics (for example, 2, 4, $8 \mu \mathrm{g} / \mathrm{mL}$ ) in liquid growth medium such as tryptic soy broth. The tubes are then inoculated with standard bacterial suspensions of approximately 5$\log _{10} \mathrm{CFU} / \mathrm{mL}$. The suspensions are incubated overnight at $35^{\circ} \mathrm{C}$, and then examined for turbidity, an indicator of bacterial growth. The lowest antibiotic concentration that permits growth is the MIC. The precision for this method is not very high and is considered to be plus or minus 1 two-fold concentration when determining the MIC. Other disadvantages of this method include the tedious preparation of the antibiotic solutions for each test, the high chance of errors in preparing the antibiotic solutions, and large number of reagents required (Jenks et al., 1998). The advantage is that this method does provide a quantitative result in the MIC, but it is harder to observe subtle changes in antibiotic resistance profiles using this method.

\subsubsection{Antimicrobial gradient method}

This method uses the establishment of an antimicrobial concentration in an agar medium as a means to determine antibiotic susceptibility. Thin plastic strips with dried antibiotic concentration gradient on the bottom of them are placed on a 100x15mm agar plate that has been inoculated with a standardized bacterial suspension (such as E. coli in tryptic soy broth). The antibiotic strips are marked with a concentration scale. The agar plates with the antibiotic strips are incubated overnight at $35^{\circ} \mathrm{C}$, and the antibiotic strips are read from the top of the agar plate. The MIC is determined where the test strip and the lower part of the ellipse shaped zone of inhibition intersect (Jorgensen \& Ferraro, 2009). This method provides a 
quantitative result and is very flexible because up to 6 antibiotics of your choice can be tested at once. However, the strips are expensive and are best suited for testing only 1 to 2 antibiotics. There have also been some issues with correlating the MICs derived from this method to the MICs determined from the broth dilution method.

\subsubsection{Disk diffusion method}

This method is simple, practical and is widely used, leading to thorough standardization of methodology and interpretation of results. The test is performed by first applying an approximate $9-\log _{10} \mathrm{CFU} / \mathrm{mL}$ bacterial suspension to a 100x15mm Mueller-Hinton agar plate, then applying up to 12 fixed concentration paper antibiotic disks to the agar surface. The agar plate is then incubated overnight for 16-18 hours, and the zones of inhibition around each antibiotic are measured (A.W. Bauer, W. M. Kirby, J. C. Sherris, 1966). The zone diameters are interpreted using standardized criteria from the Clinical and Laboratory Standards Institute (Patel et al., 2013). They are measured from one edge of the zone to the other through the center of the antibiotic disk. The results from this test are considered "qualitative" because the bacteria are classified as resistant, intermediate or susceptible based on the size of zone of inhibition. This method provides flexibility, very low cost, simple execution, easy interpretation of results, and allows for observation of subtle changes in antibiotic resistance through changes in zone of inhibition diameter (Jorgensen \& Ferraro, 2009). 


\subsection{Antibiotic resistant $E$. coli in water and wastewater}

There have been multiple studies showing the presence of antibiotic resistant genes (ARGs) and bacteria (ARB) in wastewater (L. Rizzo et al., 2013). ARGs in wastewater are a concern, but their mere presence does not necessarily mean they are being expressed by bacteria (Baharoglu \& Mazel, 2014).

There have been a number of studies conducted analyzing the antibiotic resistance profiles of $E$. coli isolated from different locations in wastewater treatment plants, drinking water plants and in the aquatic environment. For example, Aslan et al. isolated 96 E. coli from the influent, secondary wastewater effluent, UV effluent and UV plus chlorine effluent in a wastewater treatment plant. They tested their E. coli isolates for antibiotic resistance to ampicillin (beta-lactam penicillin), ciprofloxacin (fluoroquinolone), sulfamethoxazole (folic acid synthesis inhibitor) and tetracycline using CLSI standards (Patel et al., 2013). Of the 96 isolates, 95\% were resistant to ampicillin, 30\% were resistant to ciprofloxacin, and 30\% were resistant to tetracycline (Aslan, Cole, Bhattacharya, \& Oyibo, 2018). Approximately $21 \%$ of the isolates were resistant to three or more antibiotics, which means they were considered to be multi-drug resistant.

Igwaran et al. conducted a study of $E$. coli antimicrobial resistance in wastewater treatment plant effluents in South Africa. They isolated 111 E. coli over three months and performed antibiotic susceptibility testing with 12 antibiotics. They found very high percentages of resistant E. coli. For example, $100 \%$ of the isolates were either intermediate or resistant to erythromycin (similar to azithromycin used in this study). Of the E. coli isolates, $94.5 \%, 60.3 \%$ and $48.6 \%$ were intermediate or 
resistant to amoxicillin, ciprofloxacin and meropenem, respectively (Igwaran, Iweriebor, \& Okoh, 2018).

Pillay and Olaniran, Harris et al., Zanotto et al., Bergeron et al., Blaak et al., Sabate et al., Luczkiewicz et. al., and Odonkor \& Addo have also studied and reported on the antibiotic resistance profiles of $E$. coli isolated from a variety of sources, including human and animal wastewater, treated drinking water, drinking source water and the aquatic environment (Bergeron, Boopathy, Nathaniel, Corbin, \& LaFleur, 2015; Blaak et al., 2014; Harris et al., 2014; Łuczkiewicz, Jankowska, Fudala-Ksiazek, \& Olańczuk-Neyman, 2010; Odonkor \& Addo, 2018; Pillay \& Olaniran, 2016; Sabaté et al., 2008; Zanotto et al., 2016).

These studies show the abundance of antibiotic resistant $E$. coli and reinforce the need to mitigate the propagation of antibiotic resistance. As disinfection is the last treatment step before discharging to the environment or distribution to the public, it is important to understand the effects current technologies have on antibiotic resistant bacteria compared to susceptible bacteria.

\subsection{Reduction of antibiotic resistant $E$. coli by disinfection treatments}

There have been a few studies investigating the effects of disinfection treatments on antibiotic resistant bacteria with regards to their antibiotic resistance profiles and inactivation.

Sullivan et al. looked at the effects of chlorine and ultraviolet light on environmental tetracycline resistant bacteria. They observed greater than $5 \log _{10} \mathrm{CFU}$ reduction of E. coli by $0.5 \mathrm{mg} / \mathrm{L}$ and $1 \mathrm{mg} / \mathrm{L}$. Furthermore, a low-pressure UV dose of $69.8 \mathrm{~mJ} / \mathrm{cm}^{2}$ 
achieved greater than $4 \log _{10}$ CFU reduction (Sullivan, Vance, Gentry, \& Karthikeyan, 2017).

Zhang et al. tested the effects of low-pressure UV disinfection on a control (ATCC 25922) and several multi-drug resistant E. coli. Their initial E. coli concentration was $10^{9} \mathrm{CFU} / 100 \mathrm{~mL}$, and they tested low-pressure UV doses of $4 \mathrm{~mJ} / \mathrm{cm}^{2}$ to $400 \mathrm{~mJ} / \mathrm{cm}^{2}$ in a phosphate buffer solution (PBS) matrix. They found that the multidrug resistant $E$. coli survived low-pressure UV better than the antibiotic susceptible $E$. coli. The susceptible $E$. coli entered the tailing phase at a dose of $8 \mathrm{~mJ} / \mathrm{cm}^{2}$ while the resistant $E$ coli entered the tailing phase at $20 \mathrm{~mJ} / \mathrm{cm}^{2}$. After both types entered the tailing phase there was no difference in inactivation at higher doses of UV (Zhang, Xu, Wang, Zhuang, \& Liu, 2017).

Other studies on disinfection of antibiotic resistant E. coli using technologies such as PAA (Huang, Xi, Hu, Tang, \& Pang, 2013) solar simulated N-doped $\mathrm{TiO}_{2}$ photocatalysis (L. Rizzo et al., 2014), solar and UV-C driven advanced oxidation with PAA (Luigi Rizzo et al., 2019), UV radiation/chlorine (Luigi Rizzo, Fiorentino, \& Anselmo, 2013), and advanced oxidation processes such as ultraviolet $/ \mathrm{H}_{2} \mathrm{O}_{2}$ and ultraviolet/PAA (Luigi Rizzo et al., 2018) have also been conducted.

\subsection{Changes in antibiotic resistance in bacteria after exposure to disinfection}

There have been some reported results of disinfection processes impacting the antibiotic susceptibility of isolated bacteria.

Zhang et al. reported that $E$. coli susceptible to 9 antibiotics exposed to $80 \mathrm{mj} / \mathrm{cm}^{2}$ low-pressure UV became less susceptible to 6 of the 9 antibiotics used in the study 
because their zones of inhibition diameters decreased slightly $(\mathrm{P}<0.017)$. The

multidrug resistant $E$. coli used in this study was subjected to the same low-pressure UV treatment, but its post disinfection zones of inhibition remained fairly stable. They found that the multidrug resistant $E$. coli strain's resistance profile was more difficult to alter (Zhang et al., 2017).

Rizzo et al. looked at the impact solar simulated $\mathrm{N}$-doped $\mathrm{TiO}_{2}$ catalysis had on the antibiotic resistance of isolated E. coli. The isolates used were resistant to vancomycin, tetracycline and ciprofloxacin, and were susceptible to cefuroxime. The antibiotic resistance profiles of the E. coli were evaluated after $0,10,30$, and 45 minutes. They found that susceptibility to tetracycline and vancomycin remained stable throughout the experiment. They observed a consistent slight increase in susceptibility to cefuroxime and ciprofloxacin at each time interval (L. Rizzo et al., 2014).

Fiorentino et al. in 2015, Ferro et al. in 2015, Rizzo et al. in 2013 and Venieri et al. in 2017 also investigated the changes in antibiotic resistance after exposure to disinfection technologies such as chlorination, UV radiation and solar photocatalysis (Ferro et al., 2015; Fiorentino et al., 2015; Luigi Rizzo et al., 2013; Venieri et al., 2017). All found increases and decreases in antibiotic susceptibility after exposure to disinfection.

\subsection{Conclusions}

The aim of this study is to investigate the effects of common water and wastewater disinfection treatments on antibiotic resistant $E$. coli with respect to their inactivation and changes in their antibiotic resistant profiles. The literature review 
above defined the serious health threats posed by antibiotic resistance and the opportunity to mitigate its propagation by sufficient treatment in drinking water and wastewater plants. It also outlined the current knowledge of the effects different types of disinfection processes have on antibiotic resistant bacteria. Although there have been results reported on the survival of antibiotic resistant $E$. coli after exposure to disinfection as well as an evaluation of changes in their antibiotic resistance, it is difficult to evaluate and compare the results of these studies to one another because of the many variables involved, such as the matrix, initial bacterial suspension, disinfection treatment, antibiotics, susceptibility testing method and microorganism used. One gap in the literature is that there is no easy way to directly compare the effects common disinfection technologies such as chlorine, PAA and low pressure UV have on antibiotic resistance in E. coli. Another gap in the literature is a thorough examination of whether or not an increase in antibiotic resistance in bacteria correlates to an increase in resilience towards chemical and/or physical disinfection treatment. Finally, another question that requires more investigation is whether exposure to disinfection may trigger the expression of genes that confer resistance to antibiotics that may have otherwise been dormant. 


\section{Methodology}

This study was conducted in two phases. The first phase involved the isolation of $E$. coli from secondary wastewater effluent at the Robert 0. Pickard Environment Center, the Ottawa wastewater treatment plant, and analysis of their Kirby Bauer antibiotic resistance profiles. Four of the isolated E. coli were selected as "test isolates" for the disinfection experiments. In the second phase, dosages of free chlorine, PAA and low-pressure ultra violet light (UV) were selected to achieve similar inactivation of the control strain so that the efficacy of each treatment on the test isolates could be compared. The doses were then applied to the control E. coli and 4 test isolates. Survival of each test isolate and changes in antibiotic resistance profiles were observed and recorded.

\subsection{Assessing Prevalence of antibiotic resistant $E$. coli in secondary wastewater effluent}

The following describes the methodology executed in this study to assess the

prevalence of antibiotic resistance in secondary wastewater effluent at the Ottawa wastewater treatment plant. The steps included sampling wastewater, E. coli isolation, resistance profile determination, and selection and storage of E. coli test isolates.

\subsubsection{Sampling of secondary wastewater effluent}

Wastewater was sampled from the weir of the secondary clarifier at the wastewater treatment plant, before disinfection. It was collected in a clean 5-liter plastic jug. $E$. coli isolation was conducted over an 8-week period, with a fresh samples typically 
obtained on Monday mornings between 9:00am and 12:00pm. Approximately 15-20

E. coli were isolated each week. The wastewater characteristics could have an impact on the antibiotic resistance of the $E$. coli isolated. Water quality parameters for the days sampled on can be found in Table 7.19 of the Appendix.

\subsubsection{Spread plating concentrated secondary wastewater effluent and identifying $E$. coli colonies}

Once the secondary wastewater effluent sample was obtained, E. coli were isolated from it. To do so, a number of strategies were implemented to yield the greatest number of distinct, identifiable colonies. The 5-liter jug was shaken to ensure a homogenous mixture. $175 \mathrm{~mL}$ of sample were placed in two $200 \mathrm{~mL}$ centrifuge bottles each (for a total of $350 \mathrm{~mL}$ of sample). The bottles were then centrifuged at 8,000xg for 30 minutes. After centrifugation, the samples were decanted, with approximately $1-2 \mathrm{~mL}$ of bacterial pellet remaining at the bottom of the bottles. The bacterial pellets were rinsed with $1 \mathrm{~mL}$ autoclaved phosphate buffered solution (PBS), which consisted of $1.25 \mathrm{~mL} / \mathrm{L}$ phosphate buffer and $5 \mathrm{~mL} / \mathrm{L}$ magnesium chloride. $1 \mathrm{~mL}$ of the bacterial pellet solution was collected and placed into a $2 \mathrm{~mL}$ tube. The solution was then serial diluted using autoclaved PBS to $10^{-1}$ and $10^{-2}$ concentrations. $100 \mu \mathrm{l}$ of each dilution was placed on $100 \times 15 \mathrm{~mm}$ " 4 Methylumbelliferyl betaD-Glucuronide" (MUG) nutrient agar in triplicates (3 plates each with $100 \mu l$ of solution for both dilutions, $10^{-1}$ and $10^{-2}, 6$ plates total). The $100 \mu l$ was spread plated on to the MUG nutrient agar plate. This involves using a sterile plastic Simport ${ }^{\mathrm{TM}}$ cell spreader to distribute the solution evenly across the MUG agar plate, while spinning the plate on a rotating platform. After applying the 
bacterial sample, the plates were covered, inverted and incubated for $20 \pm 2$ hours at $37 \pm 2{ }^{\circ} \mathrm{C}$. Figure 3.1 describes the process of the spread plating a bacterial sample.

\begin{tabular}{|l|l|}
\hline $\begin{array}{l}\text { Sample }(0.1 \mathrm{~mL}) \text { poured } \\
\text { onto solid medium }\end{array}$ & $\begin{array}{l}\text { Spread sample evenly } \\
\text { over the surface }\end{array}$
\end{tabular}

Figure 3.1: Spread plate technique for applying wastewater sample to 100x15mm MUG nutrient agar plates

(Rijal, 2018)

The MUG nutrient agar was used because it allows the detection of $E$. coli colonies. $E$. coli contain the enzyme b-glucuronidase, which is capable of cleaving the fluorogenic substrate MUG. Therefore, fluorescence observed from a bacterial colony on a MUG nutrient agar plate confirmed it to be E. coli (Feng \& Hartman, 1982).

\subsubsection{Picking E. coli colonies and streaking to isolate pure cultures}

After the MUG nutrient agar plates were incubated, E. coli were identified by observation in darkness under a black light. Bacteria fluorescing light blue were confirmed E. coli colonies. 


\subsubsection{Selecting streaked $E$. coli colonies and growing them to optimal concentration}

Confirmed E. coli colonies were "picked" using a Thomas ${ }^{\circledR}$ sterile disposable inoculating needle and streaked on to MUG nutrient agar plates. Streaking was performed to ensure pure cultures of E. coli, because it would be possible for multiple bacteria to be growing within the same colony on the spread plate. The following procedure was used for streaking E. coli colonies: The first quadrant was streaked with the colony by going back and forth approximately 10 times with the disposable loop gently touching the agar. The plate was then rotated, and the second quadrant was streaked, entering the first quadrant twice. The third quadrant was streaked, starting midway through the second quadrant. The fourth quadrant was streaked without entering the third quadrant. Figure 3.2 shows the pattern for each quadrant. 


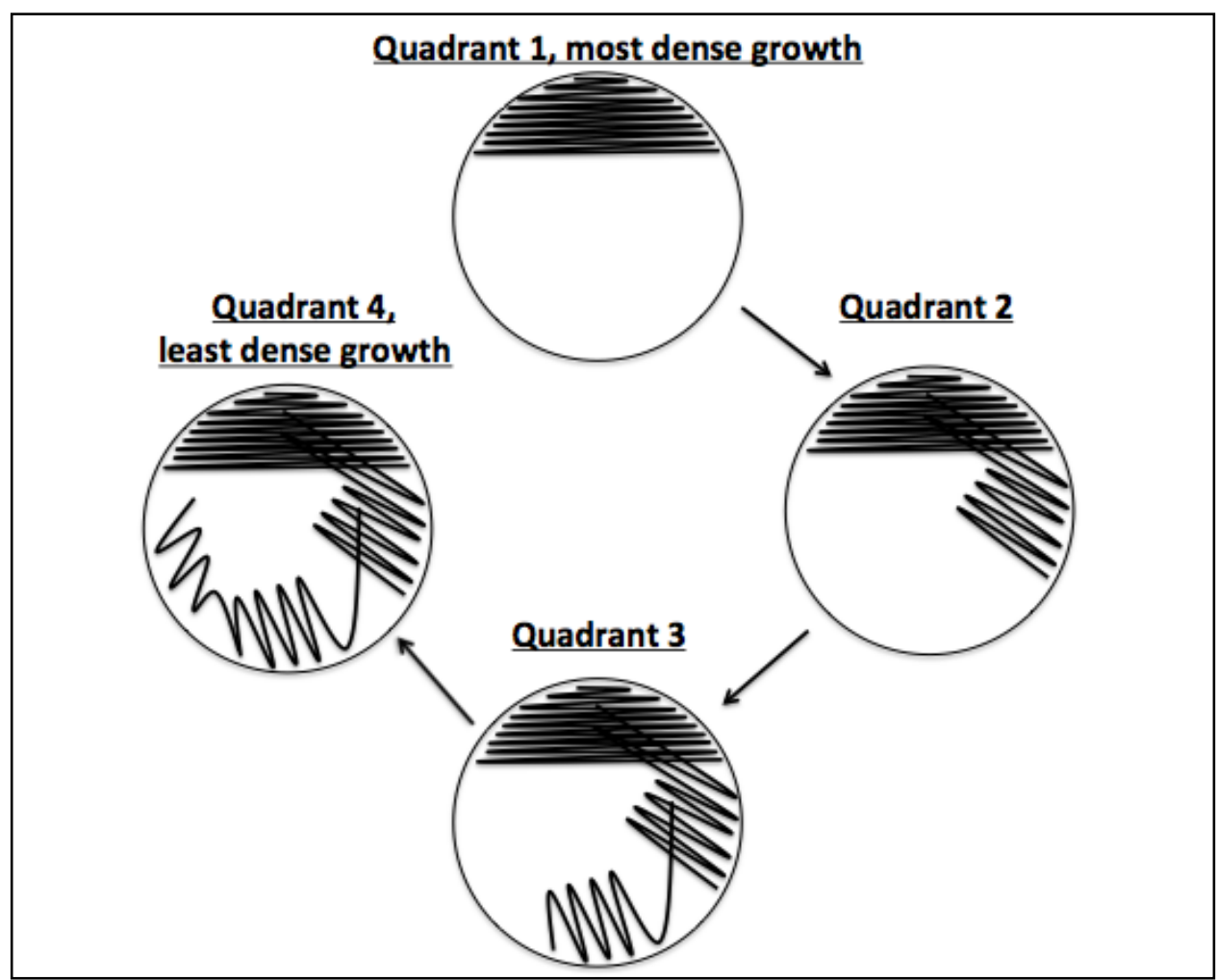

Figure 3.2: Streak plate method for isolating pure E. coli cultures

After picking E. coli colonies and streaking them, the plates were incubated at $37 \pm 2$ ${ }^{0} \mathrm{C}$ for $20 \pm 2$ hours for growth. Figure 3.3 shows an example of a plate that was streaked with a picked E. coli colony. The streaked MUG nutrient agar plates were observed in darkness under a black light to reconfirm that the picked bacterial colony was E. coli. 


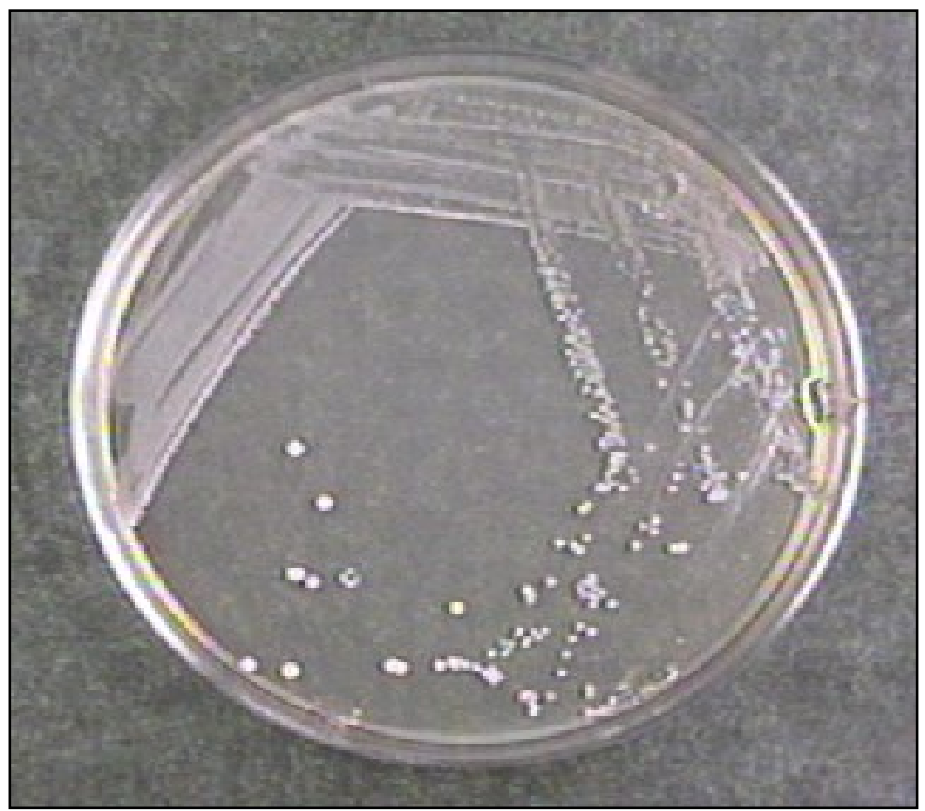

Figure 3.3: Example of E. coli streaked on to 100x15mm MUG nutrient agar plate

Once confirmed to be E. coli, one colony was picked from each using a Thomas ${ }^{\circledR}$ sterile disposable inoculating needle and was inserted in to $10 \mathrm{~mL}$ of Bacto ${ }^{\mathrm{TM}}$ trypticase soy broth (TSB), prepared according to the manufacturers instructions, in a $10 \mathrm{~mL}$ conical tube. The isolated $E$. coli in their respective conical tubes were incubated at $37 \pm 2{ }^{\circ} \mathrm{C}$ for $20 \pm 2$ hours to grow to a concentration of approximately $10^{9} \mathrm{CFU} / \mathrm{mL}$ resulting in a McFarland turbidity standard of 0.5 , which is the required concentration for the Kirby-Bauer disk diffusion method used to determine antibiotic resistance profiles (Patel et al., 2013). At this point, the control E. coli ATCC 25922 purchased from Cedarlane labs (Burlington, Ontario) was rehydrated and cultured in TSB according to provided instructions, to obtain a culture of $10^{9}$ $\mathrm{CFU} / \mathrm{mL}$ and a 0.5 McFarland standard. 


\subsubsection{Swabbing E. coli cultures and placing antibiotic disks on to Mueller-Hinton agar plates for resistance profile determination}

Once the isolated E. coli cultures achieved a 0.5 McFarland standard and approximate concentration of $10^{9} \mathrm{CFU} / \mathrm{mL}$, the cultures were swabbed on to 100x15mm Thermo Scientific ${ }^{\mathrm{TM}}$ Mueller-Hinton Agar (MHA) plates, made according to the provider's instructions. This was done for each isolated E. coli using autoclaved Puritan ${ }^{\mathrm{TM}}$ cotton-tipped non-sterile applicators. The applicator was placed in the culture solution for 5 seconds, and then swirled around the side of the conical tube 10 times. The MHA plate was then swabbed by quadrant in a crosshatch pattern, followed by a swab of the interior perimeter of the plate, shown in Figure 3.4. This was performed for the control as well.

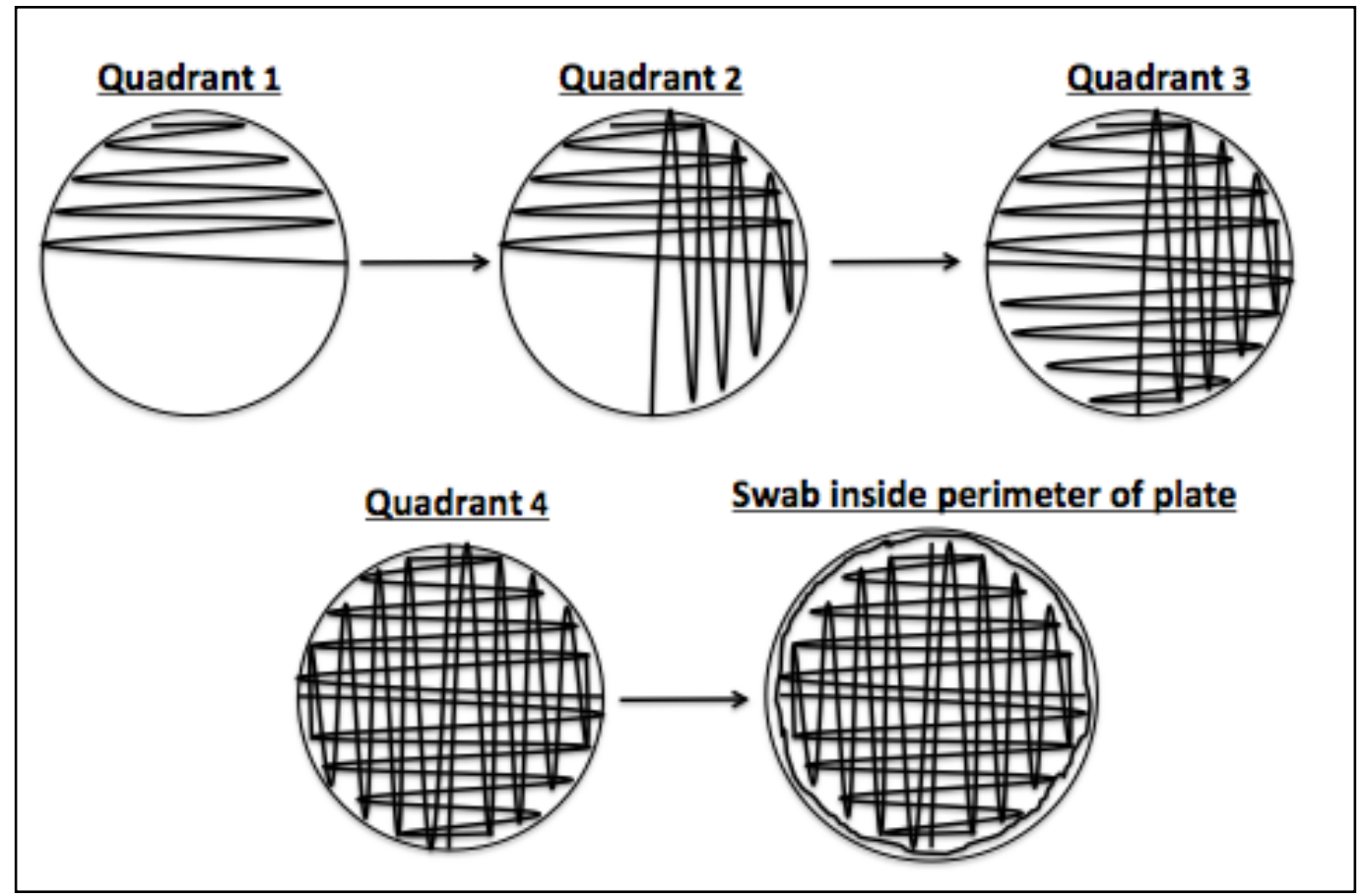

Figure 3.4: Swabbing method for Kirby Bauer antibiotic resistance profile determination 
Once the MHA plates were swabbed with the $E$. coli cultures, Oxoid ${ }^{\mathrm{TM}}$ antibiotic disks from Thermo Scientific ${ }^{\mathrm{TM}}$ were immediately placed in the pattern shown in Figure 3.5. The antibiotics disks used were azithromycin (AZM) (15 $\mu \mathrm{g})$, ertapenem (ERT) $(10 \mu \mathrm{g})$, amoxicillin/clavulanic acid (AMC) (30 $\mu \mathrm{g})$, tetracycline (TET) $(30 \mu \mathrm{g})$,

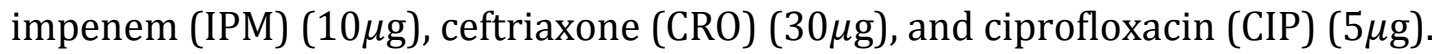
The disks were placed with a minimum $24 \mathrm{~mm}$ of space between them according to the CLSI for susceptibility testing (Patel et al., 2013).

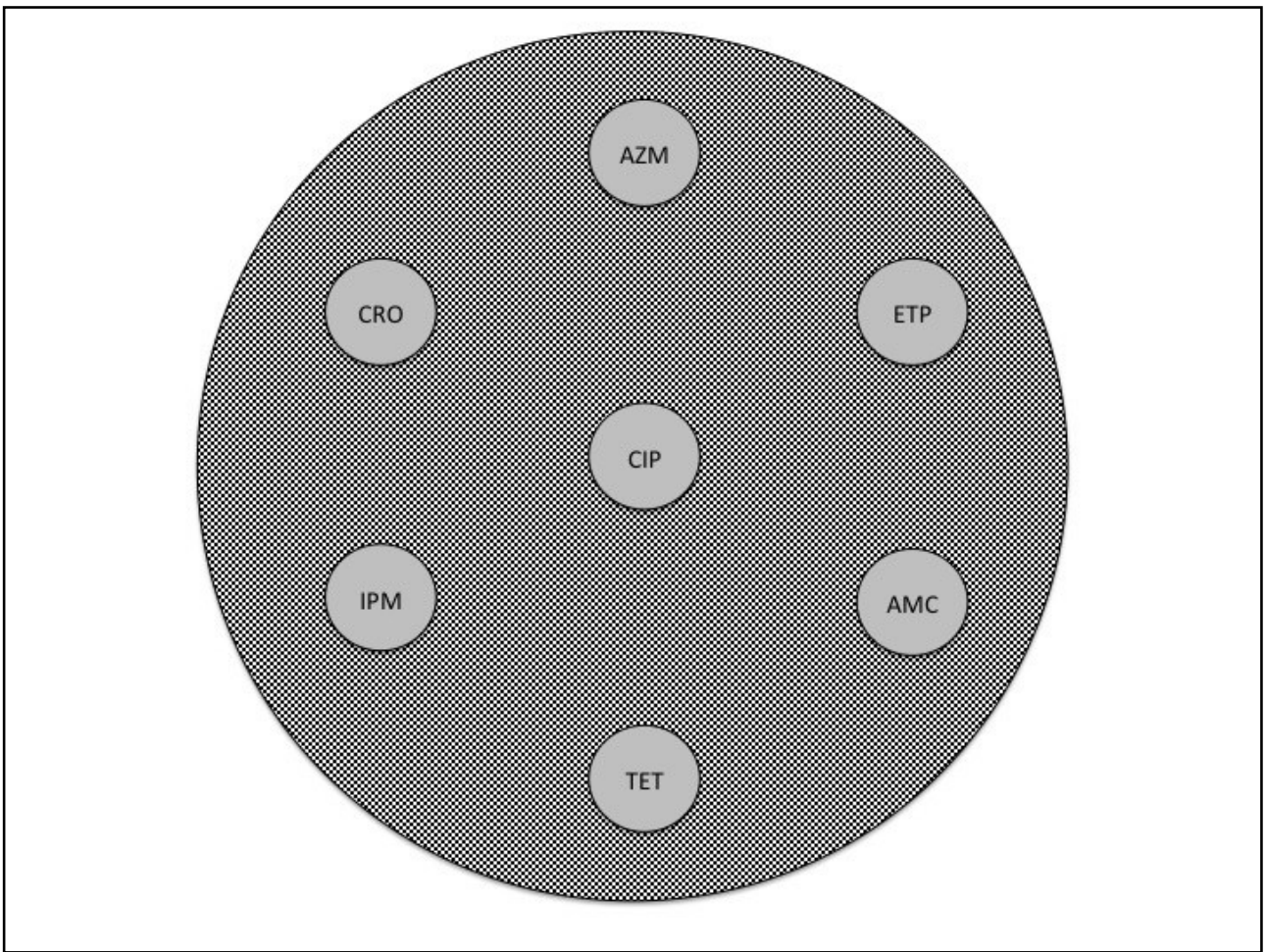

Figure 3.5: Antibiotic disk placement for Kirby Bauer disk diffusion method, with azithromycin (AZM) $(15 \mu \mathrm{g})$, ertapenem (ERT) $(10 \mu \mathrm{g})$, amoxicillin/clavulanic acid (AMC) (30 $\mu \mathrm{g})$, tetracycline (TET) $(30 \mu \mathrm{g})$, impenem (IPM) $(10 \mu \mathrm{g})$, ceftriaxone (CRO) (30 $\mu \mathrm{g})$, and ciprofloxacin (CIP) $(5 \mu \mathrm{g})$

The disks were placed using sterilized metal forceps. Sterilization was conducted with 95\% ethanol and a small flame consistently throughout the application process. This ensured no cross contamination and reliable evaluation of KirbyBauer resistance profiles for the control and isolated E. coli. After application of 
antibiotic disks, the MHA plates were covered, inverted and incubated at $35 \pm 2{ }^{\circ} \mathrm{C}$ for 16-18 hours as per the Kirby-Bauer protocol (Patel et al., 2013). The 10mL conical tubes containing the $E$. coli cultures were capped tightly and placed in a $-4^{\circ} \mathrm{C}$ fridge for potential long-term preservation and storage after evaluation of resistance profiles.

\subsubsection{Kirby Bauer resistance profile determination and selection of $E$. coli isolates for disinfection treatments}

After 16-18 hours incubation, the MHA plates were removed and the zones of inhibition around each antibiotic for all E. coli isolates were measured and recorded. The measurement was performed with a clear ruler to the nearest millimeter, including the diameter of the antibiotic disk. The plate was held a few inches above a black background. The zone of inhibition was considered to be the area around the disk showing no obvious, visible growth detectable by the unaided eye. Faint growth of tiny colonies detectable with a magnifying glass was ignored. The zone of inhibition diameter is measured through the center of the antibiotic disk and includes the diameter of the disk. If the bacterial lawn grew up against the antibiotic disk, the zone of inhibition was considered to be $0 \mathrm{~mm}$ (Patel et al., 2013). For reference, the antibiotic disks are $7 \mathrm{~mm}$ in diameter. Figure 3.6 shows an example of a MHA plate with antibiotic disks that has been swabbed and incubated. 


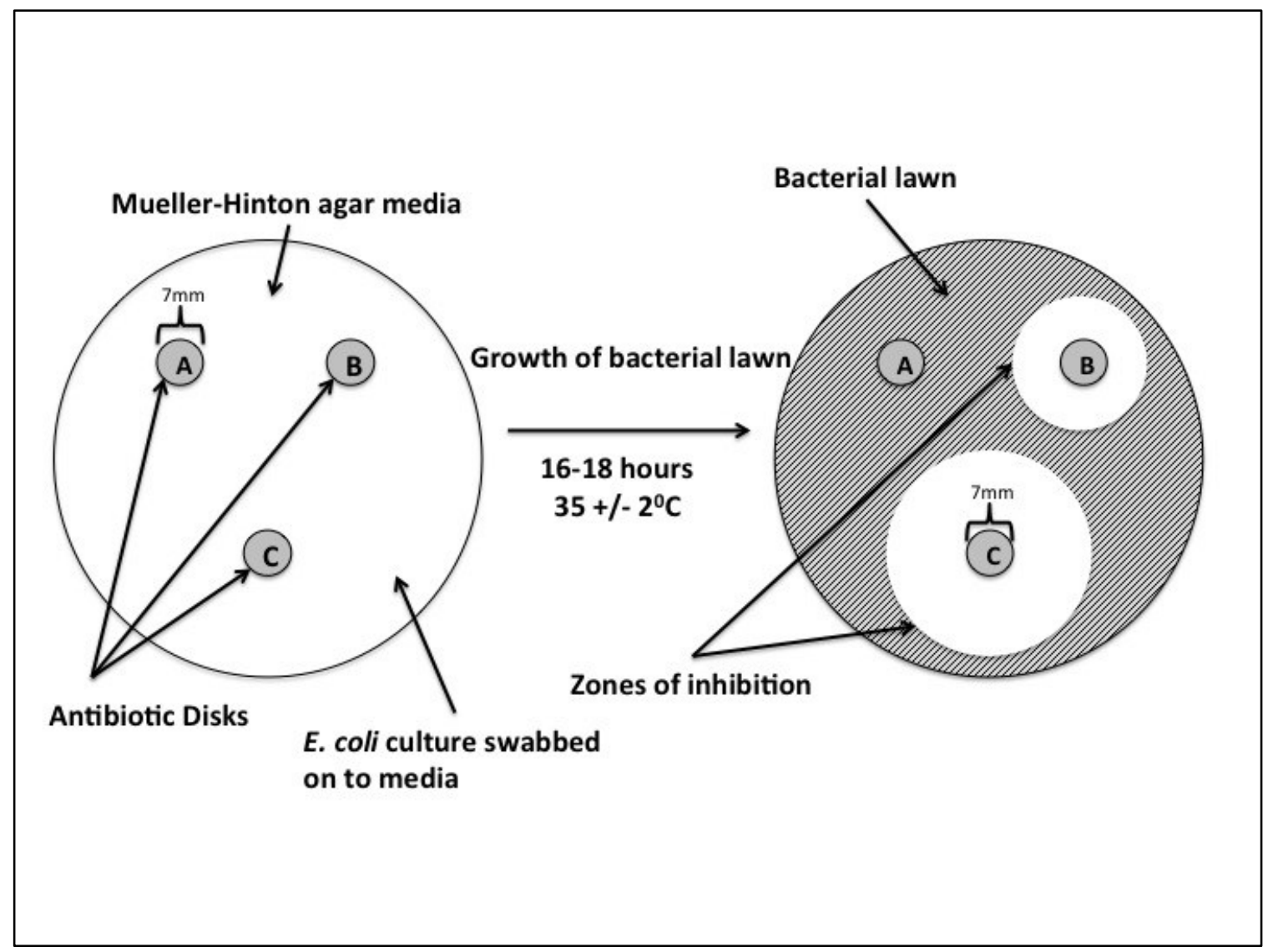

Figure 3.6: Example of Kirby Bauer disk diffusion method; growth of bacterial lawn and zones of inhibition

The zones of inhibition around antibiotics C and B can be observed and measured, meaning the bacteria is more susceptible to those antibiotics. The bacterial lawn grows right up to antibiotic $\mathrm{A}$, corresponding to a zone of inhibition of $0 \mathrm{~mm}$, which means the $E$. coli is not susceptible to the antibiotic.

For the antibiotics used in this study, the zone of inhibition criteria shown inTable 4.1 was used to determine if an E. coli was susceptible, intermediate or resistant to the antibiotics tested. These criteria have been set by the CLSI for E. coli (Patel et al., 2013). 
Table 3.1: Susceptible, intermediate and resistant zone of inhibition ranges for E. coli for ertapenem (ERT), imipenem (IPM), amoxicillin/clavulanic (AMC), ceftriaxone (CRO), tetracycline (TET), azithromycin (AZM) and ciprofloxacin (CIP)

\begin{tabular}{|c|c|c|c|c|c|}
\hline Antibiotic & \multirow{2}{*}{ Class } & Mechanism & \multicolumn{3}{|c|}{ Diameter of Zone of Inhibition } \\
\cline { 4 - 6 } & Beta Lactam & $\begin{array}{c}\text { Cell wall } \\
\text { synthesis }\end{array}$ & $\geq 22 \mathrm{~mm}$ & $19-21 \mathrm{~mm}$ & $\leq 18 \mathrm{~mm}$ \\
\hline Ertapenem & Beta Lactam & $\begin{array}{c}\text { Cell wall } \\
\text { synthesis }\end{array}$ & $\geq 23 \mathrm{~mm}$ & $20-22 \mathrm{~mm}$ & $\leq 19 \mathrm{~mm}$ \\
\hline Iminipenem & Beta Lactam & $\begin{array}{c}\text { Cell wall } \\
\text { synthesis }\end{array}$ & $\geq 18 \mathrm{~mm}$ & $14-17 \mathrm{~mm}$ & $\leq 13 \mathrm{~mm}$ \\
\hline Amoxicillin & Beta Lactam & $\begin{array}{c}\text { Cell wall } \\
\text { synthesis }\end{array}$ & $\geq 23 \mathrm{~mm}$ & $20-22 \mathrm{~mm}$ & $\leq 19 \mathrm{~mm}$ \\
\hline Ceftriaxone & Tetracycline & $\begin{array}{c}\text { Protein } \\
\text { Synthesis } \\
\text { Inhibitor }\end{array}$ & $\geq 15 \mathrm{~mm}$ & $12-14 \mathrm{~mm}$ & $\leq 11 \mathrm{~mm}$ \\
\hline Azithromycin & Macrolide & $\begin{array}{c}\text { Protein } \\
\text { Synthesis } \\
\text { Inhibitor }\end{array}$ & $\geq 13 \mathrm{~mm}$ & - & $\leq 12 \mathrm{~mm}$ \\
\hline Ciprofloxacin & Fluoroquinolone & $\begin{array}{c}\text { DNA Synthesis } \\
\text { Inhibitor }\end{array}$ & $\geq 21 \mathrm{~mm}$ & $16-20 \mathrm{~mm}$ & $\leq 15 \mathrm{~mm}$ \\
\hline
\end{tabular}

(Patel et al., 2013)

\subsubsection{Selecting for carbapenem resistant $E$. coli test isolates to add to study}

After isolating and evaluating the resistance profiles of $97 \mathrm{E}$. coli, none were found to show resistance (some showed intermediate resistance) to the carbapenem antibiotics used in this study (imipenem and ertapenem). For the purposes of this study an E. coli isolate that showed resistance to a carbapenem was desired to compare to the susceptible isolates. The following procedure was developed in the lab to isolate a carbapenem resistant E. coli.

$5 \mathrm{~mL}$ of autoclaved TSB were added to 4 separate $10 \mathrm{~mL}$ conical tubes. $10 \mu \mathrm{g}, 7.5 \mu \mathrm{g}$,

$5 \mu \mathrm{g}$, and $2.5 \mu \mathrm{g}$ of imipenem were added to each tube. $1 \mathrm{~mL}$ of secondary wastewater effluent was added to each tube. The tubes were incubated for $20 \pm 2$ hours at 37 $\pm 2^{\circ} \mathrm{C}$. After incubation, $10 \mu \mathrm{l}$ of bacterial solution from each tube were spread plated 
onto separate MUG plates, following the same methodology as previously described. The spread plates were covered and incubated for $20 \pm 2$ hours at $37 \pm 2^{\circ} \mathrm{C}$. The plates were observed in darkness under a black light, and identified E. coli colonies were picked and placed in separate $10 \mathrm{~mL}$ conical tubes with $10 \mathrm{~mL}$ of TSB. The conical tubes were incubated for $20 \pm 2$ hours at $37 \pm 2^{\circ} \mathrm{C}$ to grow to a $0.5 \mathrm{McF}$ arland standard, approximately $10^{9} \mathrm{CFU} / \mathrm{mL}$. The Kirby-Bauer procedure described previously (section 3.1.3-3.1.6) was followed, and multiple E. coli cultures were identified to be multidrug resistant and showed intermediate resistance to imipenem.

\subsubsection{Preserving $E$. coli isolates and long term storage}

Once the resistance profiles of each isolated $E$. coli were determined, potential isolates selected for disinfection experiments were preserved and stored for longterm use. Approximately $1-2 \mathrm{~mL}$ of $100 \%$ glycerol was added to each $10 \mathrm{~mL}$ conical tube that was stored in a $-4^{\circ} \mathrm{C}$ fridge. The tubes were placed in the incubator for $1-2$ hours at $37 \pm 2^{\circ} \mathrm{C}$ to invigorate the E. coli. The culture/glycerol mixtures were then pipetted in $2 \mathrm{~mL}$ aliquots into $2 \mathrm{~mL}$ tubes. The tubes were labeled and stored in a $-20^{\circ} \mathrm{C}$ freezer for later use.

\subsection{Disinfection experiments and resistance profile analysis with control and $E$. coli test isolates}

Disinfection experiments with chlorine, low-pressure UV and PAA were conducted on the control and four E. coli test isolates (A, B, C and D). $\log _{10}$ CFU recovery and change in antibiotic resistance profiles were determined and analyzed. 


\subsubsection{E. coli test isolates and experimental matrix}

As stated previously, the control used in this experiment was ATCC 25922

(Cedarlane labs, Burlington Ontario). The frozen stocks $\left(10^{9} \mathrm{CFU} / \mathrm{mL}\right)$ of the control and test isolates $\mathrm{A}, \mathrm{B}, \mathrm{C}$, and $\mathrm{D}$ were retrieved and thawed in $37 \pm 2^{\circ} \mathrm{C}$. The cultures were incubated for $20 \pm 2$ hours at $37 \pm 2^{\circ} \mathrm{C}$ in TSB at a ratio of $1: 100$. After incubation, the cultures were washed with autoclaved PBS two times, centrifuging for 5 minutes at 8,000xg between each wash. The supernatant was discarded after each round of centrifuging, and the E. coli were re-suspended in PBS. The matrix used in this experiment was distilled water. Experimental suspensions were created by adding $1 \mathrm{~mL}$ of the PBS suspended $E$. coli to $100 \mathrm{~mL}$ of distilled water, resulting in an initial titer of $10^{9} \mathrm{CFU} / 100 \mathrm{~mL}$. Distilled water was used as the experimental matrix to control for other factors impacting the results of the inactivation experiments. Matrices such as secondary wastewater effluent contain parameters (such as organic matter, total dissolved solids, $\mathrm{pH}$, etc.) that can vary and influence experimental results.

\subsubsection{Chemical disinfection treatment by chlorine and PAA}

The chemical disinfection treatments were performed using a $150 \mathrm{~mL}$ glass dish on a stir plate, with a magnetic stir bar mixing at approximately $120 \mathrm{rpm}$. The glass dish and stir plate were placed in a dark box for the duration of the experiment to avoid light interference. 


\subsubsection{Chlorine disinfection}

Chlorine dosing was performed using $10.3 \%$ by weight commercially available sodium hypochlorite. Free chlorine was measured with N,N Diethyl1,4 Phenylenediamine Sulfate (DPD) reagent pillows using Hach method 8021 for low range free chlorine $(0-2.00 \mathrm{mg} / \mathrm{L})$, with Hach spectrophotometer DR2800 (program 80). Quenching of the chlorine immediately after the contact time concluded was done with $2 \%$ by weight sodium thiosulfate $\left(\mathrm{Na}_{2} \mathrm{~S}_{2} \mathrm{O}_{3}\right)$ solution. Quenching by sodium thiosulfate addition was confirmed by observing a $0 \mathrm{mg} / \mathrm{L}$ free chlorine reading.

\subsubsection{PAA Disinfection}

Chemical dosing was performed using Peraclean $15^{\mathrm{TM}}$ solution (Evonik Industries). Peraclean $15^{\mathrm{TM}}$ is composed of $15 \%$ (wt/vol) PAA, 25\% (wt/vol) hydrogen peroxide and 17\% (wt/vol) acetic acid. PAA was measured with DPD chlorine pillows using Hach method 10290 for medium range PAA (0.1-10.00 mg/L), with Hach spectrophotometer DR2800. Quenching was performed in the same manner as chlorine, with $2 \%(\mathrm{wt} / \mathrm{vol})$ sodium thiosulfate solution.

\subsubsection{Low-pressure ultra violet disinfection}

Low-pressure UV experiments were conducted with a bench-top UV collimated beam apparatus. A schematic of the apparatus used is shown in Figure 3.7. The matrix was placed in a $150 \mathrm{~mL}$ dish on a magnetic stir plate with a stir bar mixing at approximately 120rpm. The set up allowed for the UV lights to be turned on once the matrix was in total darkness. 


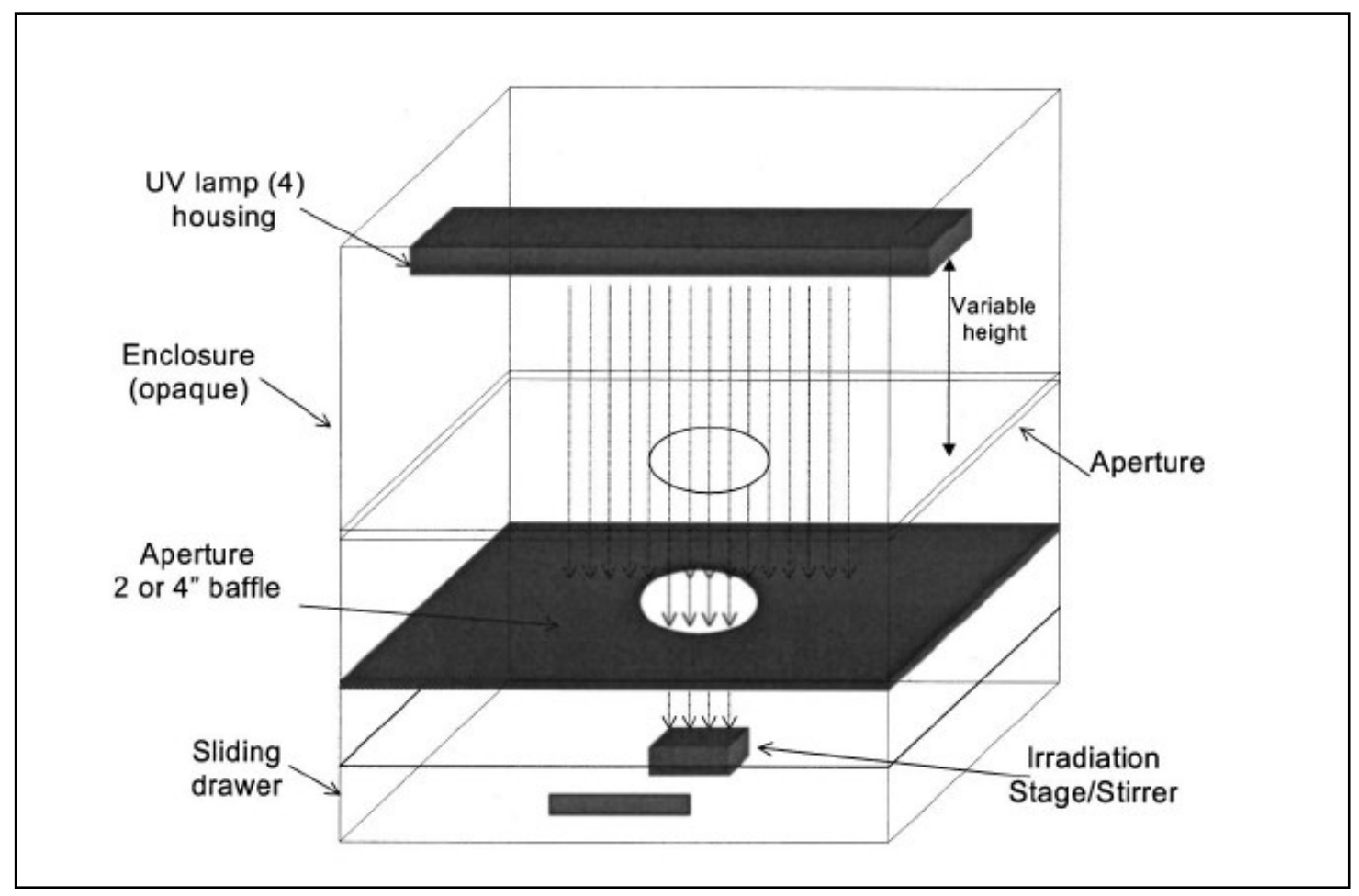

Figure 3.7: Example of bench scale device for conducting UV experiments, described by Bolton and Linden et al.

(Bolton, Linden, \& Asce, 2003)

The UV lights were turned on for an exact amount of time to achieve the desired UV dose or fluence. The fluence delivered to a sample is given by the following equation from Bolton and Linden et al.

$$
\text { Fluence }=E_{\text {avg }}^{\prime} \times t
$$

\section{Equation 1: Calculation of UV dose/fluence in Watts}

Where $E_{\text {avg }}^{\prime}$ is the average fluence rate in $\mathrm{W} / \mathrm{m}^{2}$ and $t$ is the time for which the fluence rate is the exposure time (Bolton et al., 2003). To determine the average fluence rate, the UV light's radiant power in $\mathrm{W} / \mathrm{m}^{2}$ was measured using an International Light NIS Traceable Radiometer/Photometer (Model IL 1399A), 
placed at the same height as where the surface of the matrix would be. After measuring this value, four unit-less factors had to be taken into account to estimate the total fluence actually reaching the water matrix. These factors are the Petri Factor (PF), Water Factor (WF), the Divergence Factor (DF), and the Reflection Factor (RF) (Bolton, Beck, Linden, Cres, \& Tr, 2016). The average fluence ( $\left.E_{\text {avg }}^{\prime}\right)$ delivered to the matrix is given by the following equation from Bolton and Linden et al.

$$
E_{\text {avg }}^{\prime}=E_{0} \times P F \times W F \times D F \times R F
$$

\section{Equation 2: Calculation of average fluence rate in $\mathrm{W} / \mathrm{m} 2$}

Where $E_{0}$ is the fluence or radiant power from the UV light measured by the photometer.

The petri factor accounts for the surface area of the petri dish used in the experiment, and was set to a value of 1 due to the small size of the dish used. The water factor accounts for the absorbance of the matrix at a wavelength of 254nm (for low-pressure UV) used in this experiment. The water factor is defined by the following equation.

$$
\text { Water Factor }=\frac{1-10^{-a l}}{a l \times \ln (10)}
$$

\section{Equation 3: Calculation of water UV absorbance factor}

Where $a$ is the absorbance $\left(\mathrm{cm}^{-1}\right)$ for a $1 \mathrm{~cm}$ path length of the matrix used, and $l$ is the vertical path length $(\mathrm{cm})$ or depth of the matrix in the dish. The matrix depth was measured and kept consistent throughout the experiments. The absorbance 
factor for the matrix was measured before every experiment with a UV-Visible spectrophotometer (Varian Model Cary 100BIO) using a 1-cm quartz cuvette.

In this study, the matrix was distilled water with an initial E. coli concentration of approximately $10^{9} \mathrm{CFU} / 100 \mathrm{~mL}$.

The divergence factor accounts for the distance between the UV lamp and the surface of the sample being irradiated. If there is any significant distance between the lamp and the surface of the matrix, the beam is not completely collimated and diverges significantly. The divergence factor is calculated using the following equation from Bolton and Linden et al.

$$
\text { Divergence Factor }=\frac{L}{L+l}
$$

\section{Equation 4: Calculation of divergence factor accounting for distance between matrix surface and UV light}

Where $L$ is the distance between the UV lamp and the surface of the matrix and $l$ is the path length (depth) of the matrix.

The path length and the distance between the lamp and the matrix were maintained as constants throughout the experiments.

Finally, the reflection factor accounts for how much UV light is reflected off the interface between air and water. For water, the average refractive index in the 200$300 \mathrm{~nm}$ region is 1.372, which corresponds to a fraction reflected of $R=0.025$ according to the Frensel Law (Bolton et al., 2003). This corresponds to a reflection factor of $(1-R)$, resulting in an $\mathrm{RF}$ of 0.975 for water. Measuring the irradiant power from the UV light used in the experiment and applying the four discussed factors allowed for the calculation of the average fluence 
rate. Then, a desired UV fluence (or dose) was selected, and an appropriate exposure time was calculated.

\subsubsection{Filtration and enumeration of initial and disinfection-treated $E$. coli colonies}

The initial and disinfection-treated E. coli colonies were enumerated following the membrane filtration method outlined in protocol 9222 B of Standard Methods for the Examination of Water and Wastewater (Standard Methods, 1999). Glass filtration units with $0.45 \mu \mathrm{m}$ membrane filters by Millipore were used. The agar plates were made from $30 \mathrm{~g} / \mathrm{L}$ Bacto ${ }^{\mathrm{TM}}$ tryptic soy broth Soybean-Casein digest combined with $15 \mathrm{~g} / \mathrm{L}$ agar to create tryptic soy agar (TSA). The TSB and agar were combined according to the manufacturers instructions. Two replicates of each disinfection experiment were conducted, with each dilution tested in each experiment performed with three replicates.

\subsubsection{Kirby Bauer resistance profile comparison from pre to post disinfection}

Before each disinfection experiment, a Kirby-Bauer resistance profile of the control and each test isolate was conducted to ensure pre-disinfection zones of inhibition were consistent throughout the study. After exposure to disinfection and subsequent incubation at $37 \pm 2^{\circ} \mathrm{C}$ for $20 \pm 2$ hours, 5 surviving $E$. coli colonies of the control and each test isolate were picked and placed in $10 \mathrm{~mL}$ of TSB in $10 \mathrm{~mL}$ conical tubes. The same Kirby-Bauer protocol as described previously was followed to determine the post-disinfection antibiotic resistance profiles of the control and test isolates. 


\subsection{Statistical analysis}

T-tests were used in this study to compare: 1 . changes in zones of inhibition from before and after disinfection exposure and $2 . \log _{10} \mathrm{CFU}$ inactivation by disinfection between the E. coli control and test isolates. There are three types of T tests, shown in Table 3.2.

Table 3.2: Types of $T$ tests and when they are appropriately applied

\begin{tabular}{|c|l|c|}
\hline Type Number & Type Name & Used when \\
\hline 1 & Paired (Dependent) T test & $\begin{array}{c}\text { Two sample sets are the } \\
\text { same/related }\end{array}$ \\
\hline 2 & $\begin{array}{c}\text { Equal Variance } \\
\text { (Independent) T test }\end{array}$ & $\begin{array}{c}\text { The two sample sets are } \\
\text { not the same/related and: } \\
\text { are the same size or the } \\
\text { two sample sets have } \\
\text { equal variances }\end{array}$ \\
\hline 3 & $\begin{array}{c}\text { Unequal Variance } \\
\text { (Independent) T test }\end{array}$ & $\begin{array}{c}\text { The two sample sets are } \\
\text { not the same/related and: } \\
\text { the two sample sets have } \\
\text { unequal variances }\end{array}$ \\
\hline
\end{tabular}

(Kenton, 2019)

A two-tailed t-test was used to compare pre and post disinfection average results and determine if they were significantly different. A two-tailed test, as opposed to a one-tailed test, does not assume that the difference between means of two data sets will be in one direction or the other (McDonald, 2014).

The two sample sets being compared in this investigation were not related, were not the same size, and were assumed to have unequal variances. It was not known whether the zones of inhibition would increase or decrease after exposure to disinfection, so it was important for the statistical methods used to be able to capture either scenario. Based on these criteria, a type 3 two-tailed t-test was 
deemed to be most appropriate for analyzing the data in this study. The statistical analysis was conducted in Microsoft Excel using the T-test function provided.

A type 3, two-tailed T-test was used to compare $\log _{10} \mathrm{CFU}$ recovery of the control and 4 test isolates by free chlorine, PAA and low-pressure UV to determined if there were any significant differences. A confidence level of $95 \%$ was chosen $(\mathrm{P}<0.05)$ because it is commonly used to compare groups and determine if there is a statistically significant difference. A type 3, two-tailed T-test was used to compare antibiotic zones of inhibition from before and after disinfection treatment for the control and each test isolate, to determine if disinfection treatment had any influence on their respective antibiotic resistance profiles. A confidence level of $95 \%$ was used $(\mathrm{P}<0.05)$. 


\section{Results}

The results of this investigation are presented in four parts. Part one covers the findings from the isolated E. coli. This includes an analysis of the prevalence of antibiotic resistance of $E$. coli isolated from secondary wastewater effluent. The seven antibiotics used in this study were ertapenem (ERT), imipenem (IPM), tetracycline (TET), amoxicillin/clavulanic acid (AMC), azithromycin (AZM), ceftriaxone (CRO) and ciprofloxacin (CIP). The antibiotics were selected because of their importance to human healthcare, and because they represent a range of antibiotic classes used against gram-negative bacteria. Kirby Bauer disk diffusion antibiotic resistance profiles of each E. coli isolate were determined and trends in the data were examined. The final selection of test isolates used in subsequent disinfection experiments will be discussed.

In part two, the results from the disinfection experiments are analyzed. Four test isolates and one control (ATCC 25922) were exposed to free chlorine ( $\mathrm{NaClO}$ ), PAA and low-pressure UV treatments. The $\log _{10} \mathrm{CFU}$ colony forming units (CFU) recovery of the test isolates were compared to that of the control. In part three, the changes in Kirby Bauer antibiotic resistance profiles of predisinfection and post-disinfection are discussed. During the experiments, significant changes in antibiotic resistance profiles were recorded. A significant change is considered to have occurred if the average post-disinfection zone of inhibition increased or decreased from the average pre-disinfection zone of inhibition with $90 \%$ confidence $(\mathrm{P}<0.05)$. The number of significant changes was related to the type 
of antibiotic, disinfection treatment type and $E$. coli isolate to see if there were any trends directly linked to any of those three variables.

Finally, in part 4, the cases of Kirby Bauer resistance classification changes from pre to post-disinfection are discussed. A classification change occurs when a zone of inhibition changes enough so that the post-disinfection diameter falls within a new resistance classification range dictated by Kirby Bauer standard methods.

\subsection{Part 1: Prevalence of antibiotic resistant $E$. coli in secondary wastewater effluent}

97 E. coli were isolated from secondary wastewater. Antibiotic resistance profiles of each isolated E. coli were determined using standard Kirby Bauer methodology. An E. coli isolate was considered to be susceptible, intermediate or resistant to an antibiotic depending on the diameter of the zone of inhibition around the antibiotic disk. The diameter ranges for each category are given in the clinical standards for Kirby Bauer testing and are provided in Table 4.1 in the Methodology section (Patel et al., 2013).

The Approximate prevalence of antibiotic resistance can be seen in Figure 4.1. If an E. coli isolate was classified as resistant or intermediate to an antibiotic, it was considered to exhibit resistance to that specific antibiotic. 


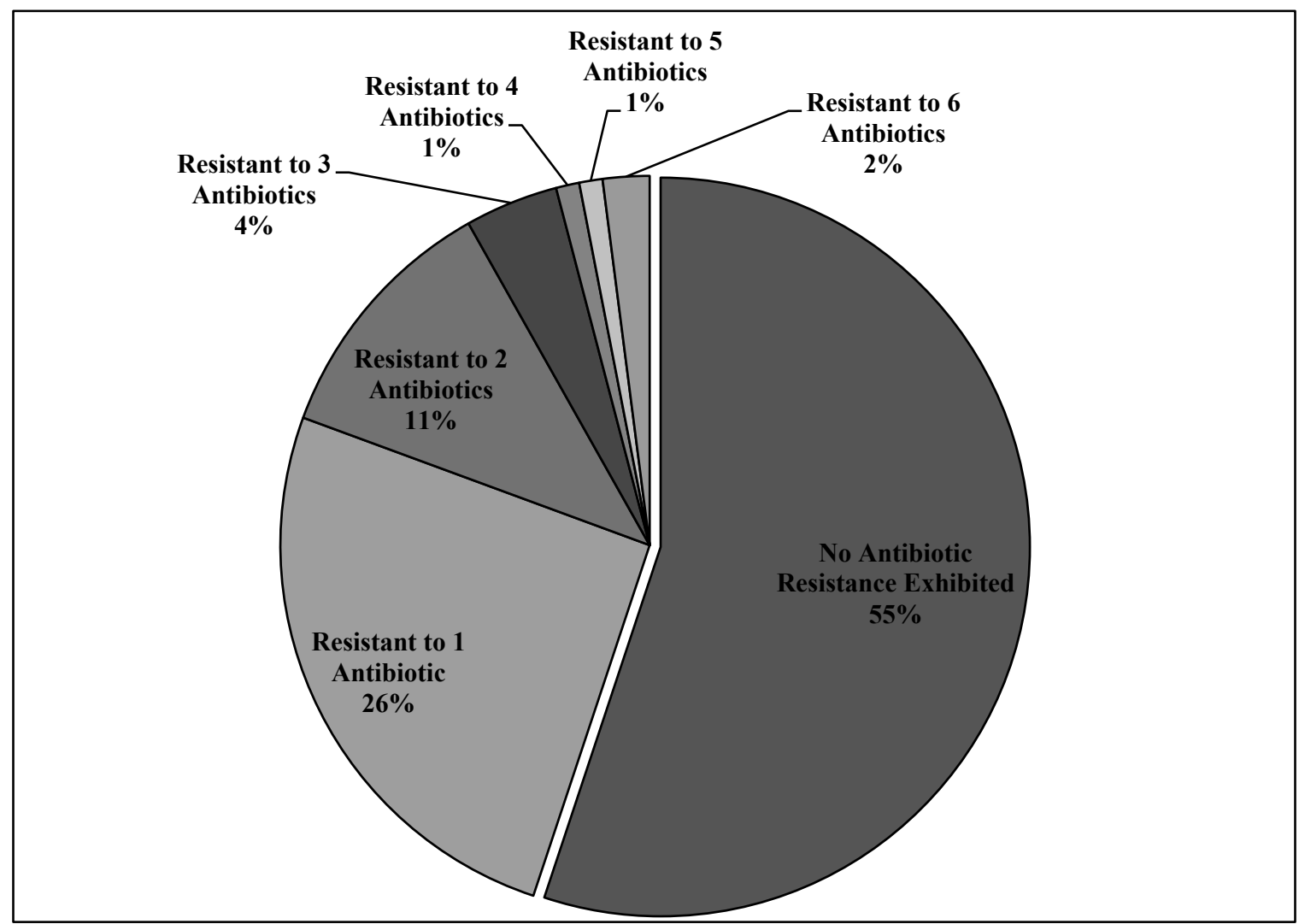

Figure 4.1: Approximate prevalence of antibiotic resistance among $97 \mathrm{E}$. coli isolates

Among the 97 E. coli isolates, 55\% showed no form of resistance to any of the seven antibiotics tested. However, the other $45 \%$ showed some form of resistance to at least 1 antibiotic. Of all the $E$. coli isolated, 26\% showed resistance to only one antibiotic, $11 \%$ showed resistance to two, $4 \%$ showed resistance to three, $1 \%$ showed resistance to four, $1 \%$ showed resistance to 5 and $2 \%$ showed resistance to 6 antibiotics. The majority of $E$. coli isolates exhibited resistance to 1 to 2 antibiotics. $8 \%$ of the isolates were resistant to 3 or more antibiotics, and therefore are considered "multi-drug resistant".

The distribution of resistance among the 97 E. coli was examined based on each individual antibiotic. This was performed to see if there were any antibiotics that 
were much less effective against the E. coli than others. For the purposes of this figure, an isolate was deemed to be "showing resistance" if it was either intermediate or resistant to the antibiotic, otherwise it was considered to be "showing susceptibility". The results from this are shown in Figure 4.2.

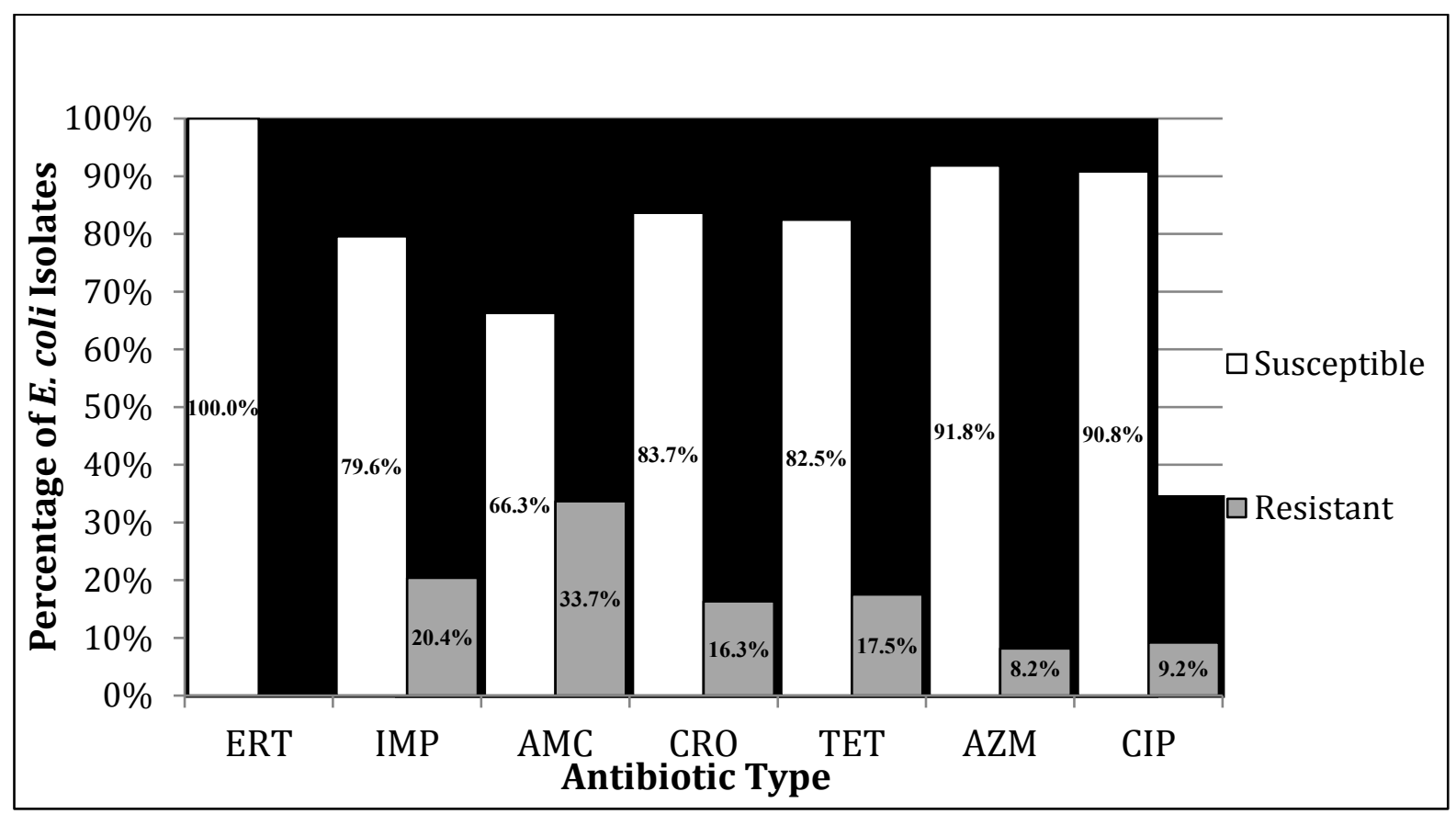

Figure 4.2: Distribution of antibiotic resistance for $97 \mathrm{E}$. coli isolates tested with seven antibiotics azithromycin (AZM) $(15 \mu \mathrm{g})$, ertapenem (ERT) $(10 \mu \mathrm{g})$,

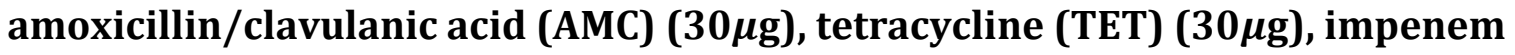
(IPM) $(10 \mu \mathrm{g})$, ceftriaxone (CRO) (30 $\mu \mathrm{g})$, and ciprofloxacin (CIP) $(5 \mu \mathrm{g})$

Of the seven antibiotics tested in this study, the most effective at inhibiting bacterial growth was ertapenem, to which $100 \%$ of the isolates were susceptible. Azithromycin was the second most effective antibiotic, inhibiting $91.8 \%$ of the isolates. Ciprofloxacin, ceftriaxone, tetracycline, and imipenem inhibited 90.8\%, $83.7 \%, 82.5 \%$ and $79.6 \%$ of the isolates, respectively. The least effective antibiotic was shown to be amoxicillin, to which $33.7 \%$ of the isolates showed at least some resistance. 
From the 97 E. coli, four were selected as test isolates for exposure to free chlorine, PAA and low-pressure UV disinfection. The test isolates were chosen to represent a range in antibiotic resistance. Table 4.1 shows resistance profiles of the control and the four E. coli. Test isolates. The zones of inhibition for each antibiotic were recorded in millimeters. Green highlighted areas indicate a test isolate is "susceptible" to that antibiotic. Yellow corresponds to "intermediate" and red indicates the test isolate is "resistant".

Table 4.1: Zones of inhibition for the control and $E$. coli test isolates for azithromycin (AZM) (15 $\mu \mathrm{g})$, ertapenem (ERT) $(10 \mu \mathrm{g})$, amoxicillin/clavulanic

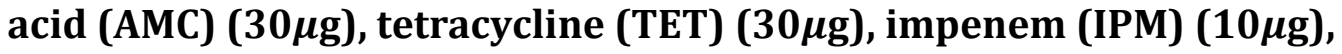
ceftriaxone (CRO) $(30 \mu \mathrm{g})$, and ciprofloxacin (CIP) $(5 \mu \mathrm{g})$ used in disinfection experiments

\begin{tabular}{|l|l|l|l|l|l|l|l|}
\hline \multirow{2}{*}{\begin{tabular}{l}
\multirow{2}{*}{$\begin{array}{l}\text { E. coli } \\
\text { Isolate }\end{array}$} \\
\cline { 2 - 9 }
\end{tabular}} & ERT & IMP & AMC & CRO & TET & AZM & CIP \\
\hline Control & 28 & 23 & 19 & 26 & 22 & 22 & 27 \\
\hline A & 27 & 23 & 18 & 24 & 18 & 22 & 27 \\
\hline B & 28 & 25 & 21 & 27 & 21 & 7 & 13 \\
\hline C & 26 & 24 & 18 & 6 & 7 & 11 & 0 \\
\hline D & 23 & 21 & 0 & 0 & 0 & 0 & 0 \\
\hline
\end{tabular}

The control was susceptible to all antibiotics. Test isolate A, a wastewater isolated $E$. coli, was also susceptible to all antibiotics and thus acted as an environmental control. Test isolate A would have been exposed to the same wastewater treatment stresses as test isolates B, C and D, so if there were any differences in inactivation rates between test isolate $A$ and the rest, it would imply degree of antibiotic resistance could be a factor. Test isolates $\mathrm{B}, \mathrm{C}$ and $\mathrm{D}$ were progressively more 
antibiotic-resistant. This was done purposefully to see if there was any correlation between multi-drug resistance profiles and $\log _{10} \mathrm{CFU}$ inactivation by free chlorine, PAA or low-pressure UV. Figure 4.3, Figure 4.4, Figure 4.5, Figure 4.6, and Figure 4.7 show examples of the antibiotic resistance profiles for the control and test isolates $\mathrm{A}, \mathrm{B}, \mathrm{C}$ and $\mathrm{D}$, respectively. The beige colour is the bacterial lawn that has grown on the agar plate. The white disks are the antibiotics that were placed and left to diffuse into the agar. The clear circles around the disks are the zones of inhibition, where no E. coli has grown because of the antibiotic. The larger the zone of inhibition, the more susceptible the E. coli test isolate was to the antibiotic.

As stated previously, the control was an ATCC lab adapted strain of E. coli that was susceptible to all 7 antibiotics, shown in Figure 4.3. The zones of inhibition around each antibiotic can clearly be seen and measured.

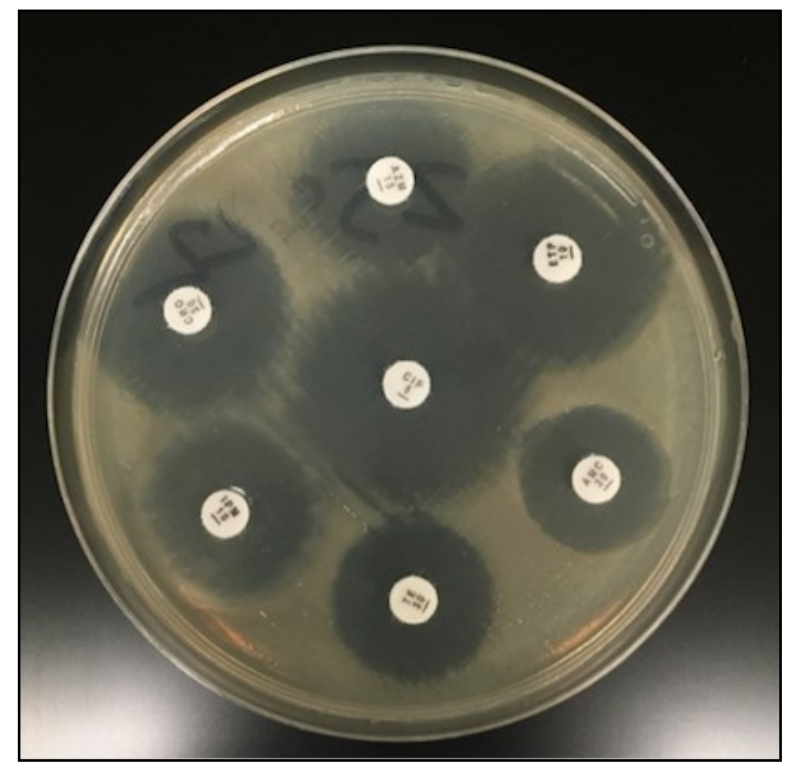

Figure 4.3: E. coli Control Pre-Disinfection Kirby Bauer Antibiotic Resistance Profile 
Test isolate A was a wastewater isolated E. coli that was susceptible to all 7 antibiotics as shown in Figure 4.4. the zones of inhibition around each antibiotic can clearly be seen and measured.

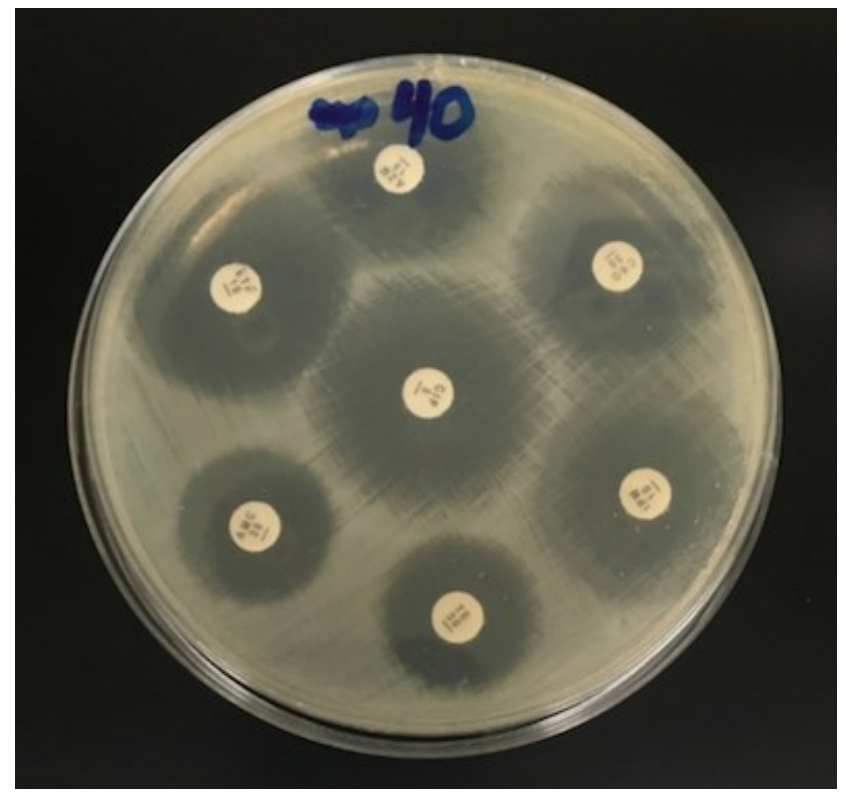

Figure 4.4: E. coli test isolate A Pre-Disinfection Kirby Bauer Antibiotic Resistance Profile

Test isolate B was susceptible to ertapenem, imipenem, amoxicillin, ceftriaxone and tetracycline, and was resistant to ciprofloxacin and azithromycin as shown in Figure 4.5. The zones of inhibition around each antibiotic can clearly be seen and measured. The zones of inhibition around ciprofloxacin (middle of plate) and azithromycin (top and middle of plate) are noticeably smaller due to the test isolate's resistance to those antibiotics. 


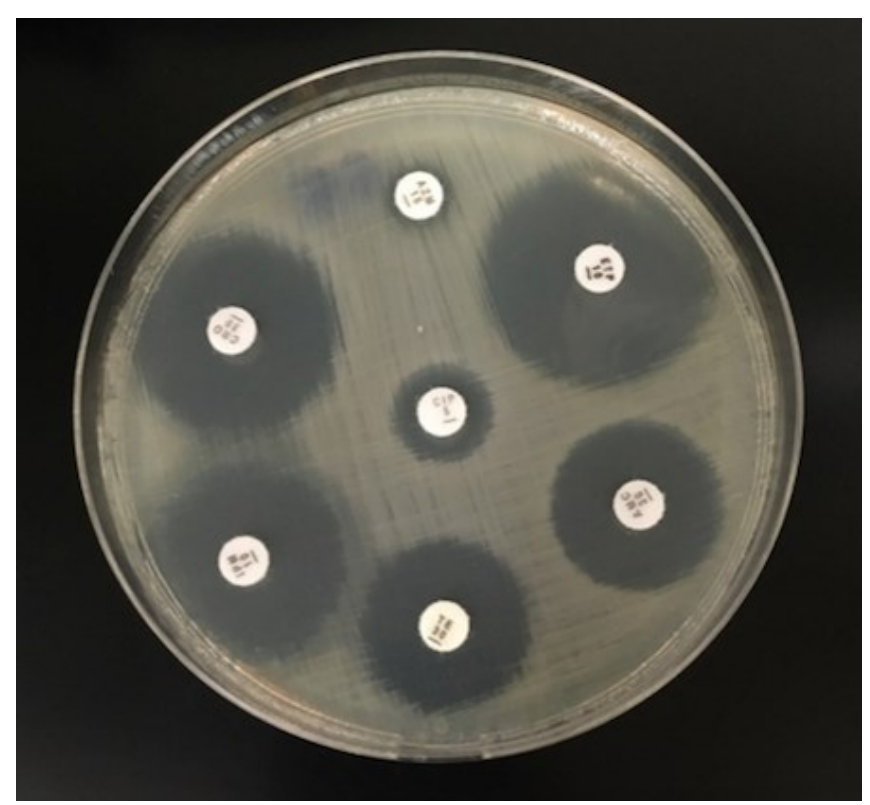

Figure 4.5: E. coli test isolate B Pre-Disinfection Kirby Bauer Antibiotic Resistance Profile

Test isolate $\mathrm{C}$ was susceptible to ertapenem, imipenem, and amoxicillin, and was resistant to ceftriaxone, tetracycline, ciprofloxacin and azithromycin as shown in Figure 4.6. It can be seen that the bacterial lawn grows close to the antibiotic disks that the E. coli is resistant to. This test isolate is considered to be "multi-drug resistant" because it is resistant to three or more antibiotics. 


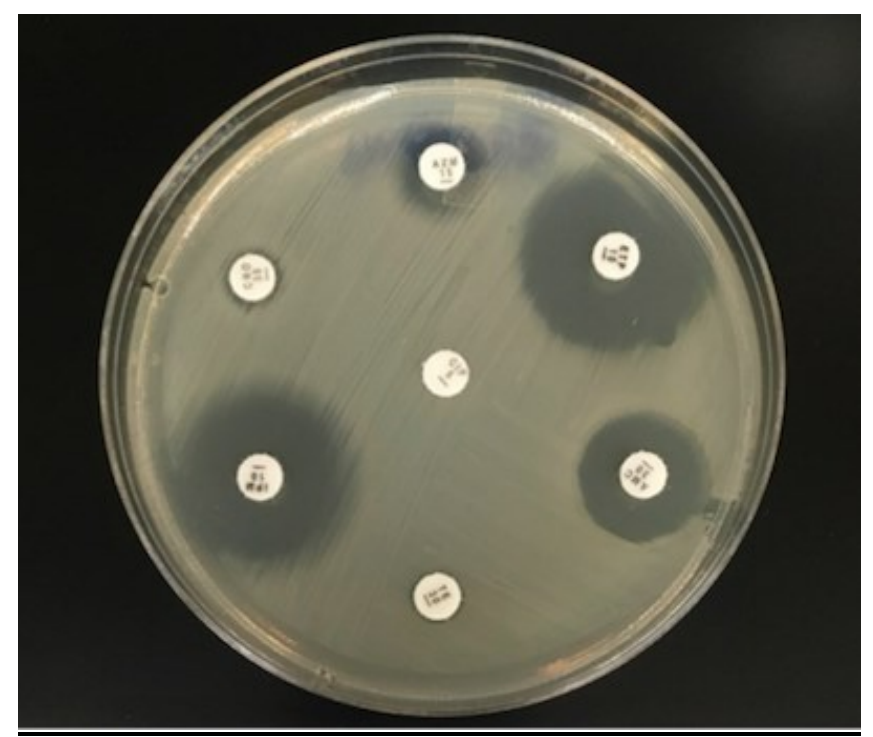

Figure 4.6: E. coli test isolate C Pre-Disinfection Kirby Bauer Antibiotic Resistance Profile

Test isolate D was susceptible to ertapenem, showed intermediate resistance to imipenem, and was resistant to amoxicillin, ceftriaxone, tetracycline, ciprofloxacin and azithromycin as shown in Figure 4.7.

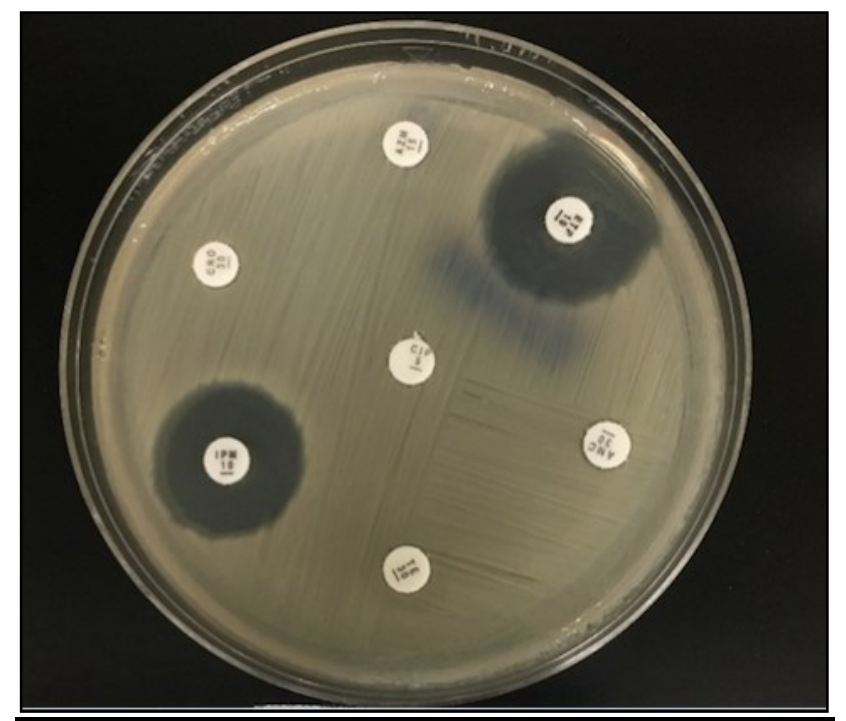

Figure 4.7: E. coli test isolate D Pre-Disinfection Kirby Bauer Antibiotic Resistance Profile

This test isolate is considered to be "multi-drug resistant" because it is resistant to three or more antibiotics. It is especially important because it is showing 
intermediate resistance to imipenem, which is one of the strongest antibiotics used in modern healthcare.

\subsection{Part 2: $\log _{10}$ CFU recovery of $E$. coli test isolates}

Each selected E. coli test isolate was exposed to free chlorine, PAA and low-pressure UV. Doses and contact times for each type of treatment were chosen so that there would be at least $10^{2}-10^{3} \mathrm{CFU} / 100 \mathrm{~mL}$ recovered on the TSA plates. This was desired for the following reasons:

1. To allow for $10^{2}-10^{3} \mathrm{CFU} / 100 \mathrm{~mL}$ survival of each $E$. coli test isolate after disinfection to assess and compare $\log _{10} \mathrm{CFU}$ reductions

2. To determine if changes in antibiotic resistance profiles could be caused by exposure to disinfection (i.e. causing antibiotic resistance genes to be expressed), it was required that the test isolates were sufficiently stressed so defense-related gene expression might occur

3. To ensure an adequate number of survivors to do colony picks for postdisinfection Kirby Bauer antibiotic resistance profiles.

\subsubsection{Free chlorine}

Figure 4.8 shows the results of the free chlorine disinfection experiment. The mean initial titers for the control and test isolates A, B, C and D were 8.98 $\pm 0.04,8.98$ $\pm 0.08,8.56 \pm 0.04,8.97 \pm 0.15$ and $8.93 \pm 0.24 \log _{10} \mathrm{CFU} / 100 \mathrm{~mL}$, respectively. The average $\log _{10} \mathrm{CFU}$ initial titer for the five isolates was $8.88 \pm 0.20$. 


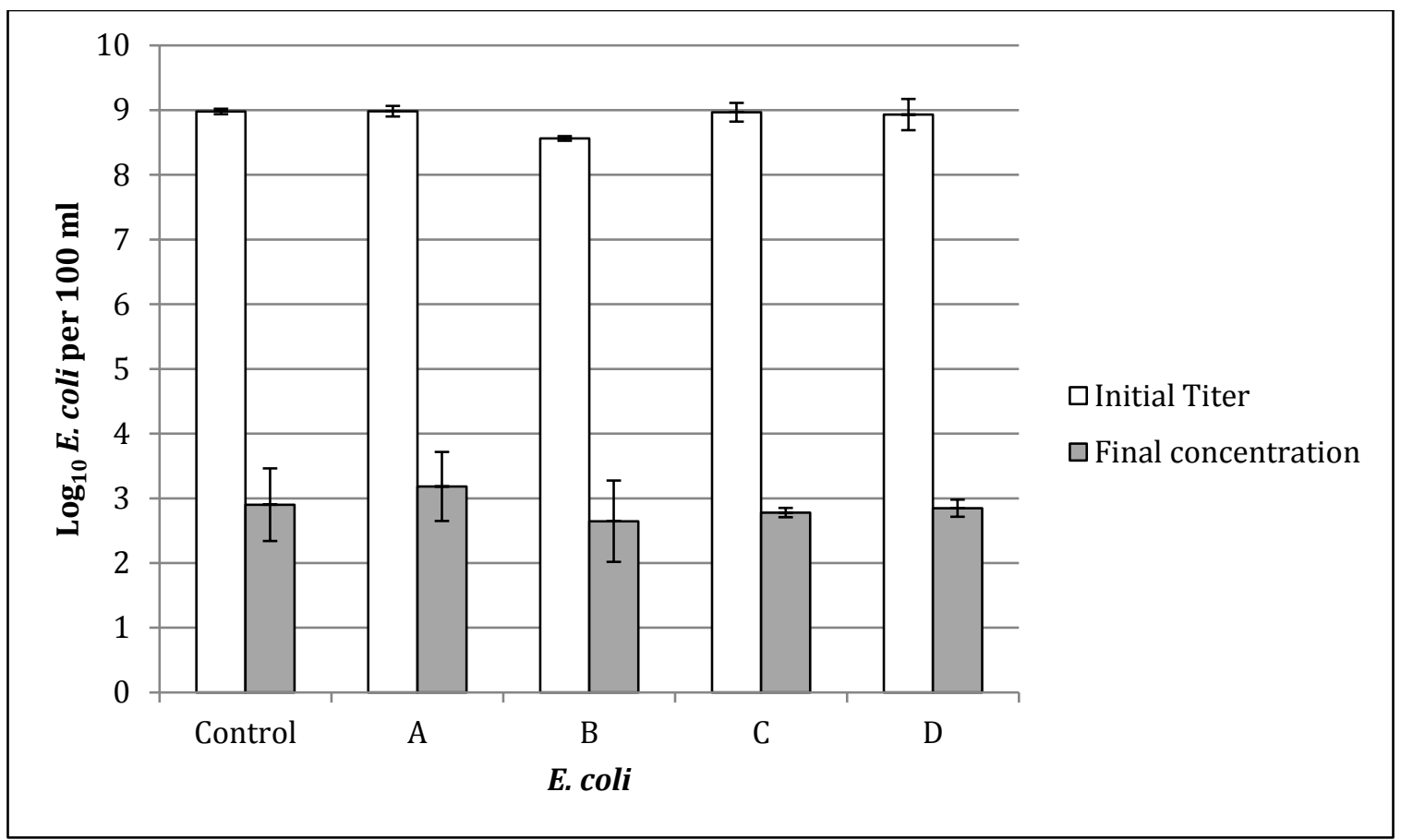

Figure 4.8: $\log _{10}$ CFU recovery of $E$. coli per $100 \mathrm{~mL}$ after treatment with 0.1 $\mathrm{mg} / \mathrm{L}$ free chlorine with a contact time of 30 seconds

As can be seen in Figure 4.8, after disinfection with free chlorine, the $\log _{10}$

CFU/100mL recovery of the control and test isolates $A, B, C$, and D were $2.90 \pm 0.56$,

$3.18 \pm 0.53,2.65 \pm 0.0 .63,2.78 \pm 0.07$, and $2.85 \pm 0.13$, respectively. This

corresponds to a $\log _{10}$ CFU reduction of $6.08 \pm 0.26,5.80 \pm 0.23,5.92 \pm 0.03,6.19$

\pm 0.11 , and $6.08 \pm 0.05$ for the control and test isolates $A, B, C$ and $D$ respectively.

From these results, it was determined using a two-tailed type 3 T-test with 95\%

confidence $(\mathrm{P}<0.05)$ that there was no statistically significant difference between

the $\log _{10}$ CFU inactivation of the control and the E. coli test isolates.

\subsubsection{PAA}

Figure 4.9 shows the results of the PAA disinfection experiment. The light grey bars show the initial E. coli $\log _{10} \mathrm{CFU} / 100 \mathrm{~mL}$ concentrations for each test isolate The initial titers for the control and test isolates A, B, C and D were 8.93 $\pm 0.04,9.026$ 
$\pm 0.01,8.50 \pm 0.01,8.85 \pm 0.01$ and $8.40 \pm 0.64 \log _{10} \mathrm{CFU} / 100 \mathrm{~mL}$, respectively.

The average $\log _{10} \mathrm{CFU}$ initial titer for the five $E$. coli tested was $8.74 \pm 0.34$.

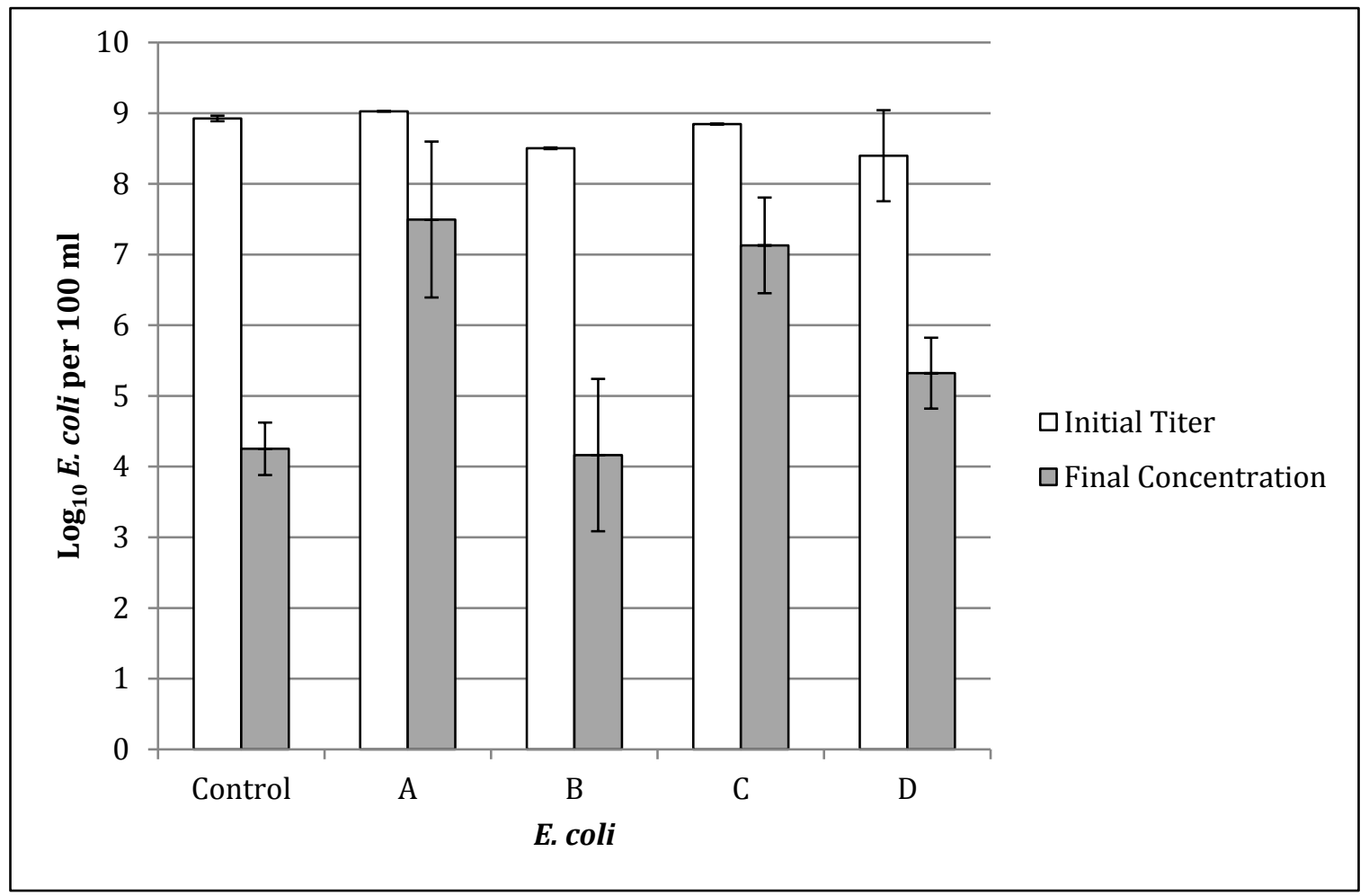

Figure 4.9: $\log _{10}$ CFU recovery of $E$. coli per $100 \mathrm{~mL}$ after treatment with 1 $\mathrm{mg} / \mathrm{L}$ PAA for 10 minutes

As can be seen in Figure 4.9, after disinfection by PAA the final $\log _{10} \mathrm{CFU}$

concentrations of the control and test isolates A, B, C and D were $4.25 \pm 0.37,7.50$

$\pm 1.10,4.16 \pm 1.08,7.13 \pm 0.68$, and $5.32 \pm 0.50$. This corresponds to a $\log _{10} \mathrm{CFU}$

reduction of $4.67 \pm 0.41,1.53 \pm 1.11,4.34 \pm 1.11,1.72 \pm 0.67$, and $3.08 \pm 0.14$ for

the control and test isolates A, B, C and D respectively. There was a distinct

difference between the inactivation of the control and test isolates $\mathrm{A}, \mathrm{C}$ and $\mathrm{D}$, with

the test isolates surviving PAA disinfection better. Test isolate B survived PAA

similarly to the control. It was suspected that this was due to the wastewater E. coli

containing the enzyme catalase. Catalase is an enzyme that can be present in E. coli 
that catalyzes the decomposition of hydrogen peroxide to water and oxygen, which is one of the main disinfecting agents in PAA. A catalase test was conducted on surviving colonies of each E. coli isolate, and the strengths of the observed reactions were ranked qualitatively on scale of 0 to 4 . The strength of the reaction was based on the amount of bubbles created after the addition of hydrogen peroxide, which indicated the amount of oxygen being produced. The results of this test can be seen in Table 4.2 below.

Table 4.2: Qualitative ranking of catalase reaction for each $E$. coli

\begin{tabular}{|c|c|c|}
\hline E. coli & Strength of Reaction (0-4) & Presence of Catalase $(+/-)$ \\
\hline Control & 0 & - \\
\hline A & 4 & + \\
\hline B & 2 & + \\
\hline C & 4 & + \\
\hline D & 3 & + \\
\hline
\end{tabular}

The results of the catalase test corroborate the $\log _{10} \mathrm{CFU}$ reductions. For example, test isolates $\mathrm{A}$ and $\mathrm{C}$ were the most resistant (1.5 and 1.7- $\log _{10} \mathrm{CFU}$ reductions) to PAA and scored the highest on the catalase test. The control was the least resistant to PAA (4.6- $\log _{10} \mathrm{CFU}$ reduction) and scored a 0 on the catalase test, meaning it was unable to decompose the hydrogen peroxide to water and oxygen, indicating the absence of catalase in the control. 


\subsubsection{Low-pressure UV}

The results of the low-pressure UV disinfection experiment are presented in Figure 4.10. The light grey bars show the initial $\log _{10} \mathrm{CFU} / 100 \mathrm{~mL}$ E. coli concentrations for each E. coli. The initial titers of the control and test isolates A, B, C and D were $9.07 \pm 0.13,9.13 \pm 0.02,8.61 \pm 0.05,8.96 \pm 0.02$ and $8.88 \pm 0.01 \log _{10} \mathrm{CFU} / 100 \mathrm{~mL}$ respectively. The average $\log _{10} \mathrm{CFU}$ initial titer for the five E. coli tested was 8.93 \pm 0.19 .

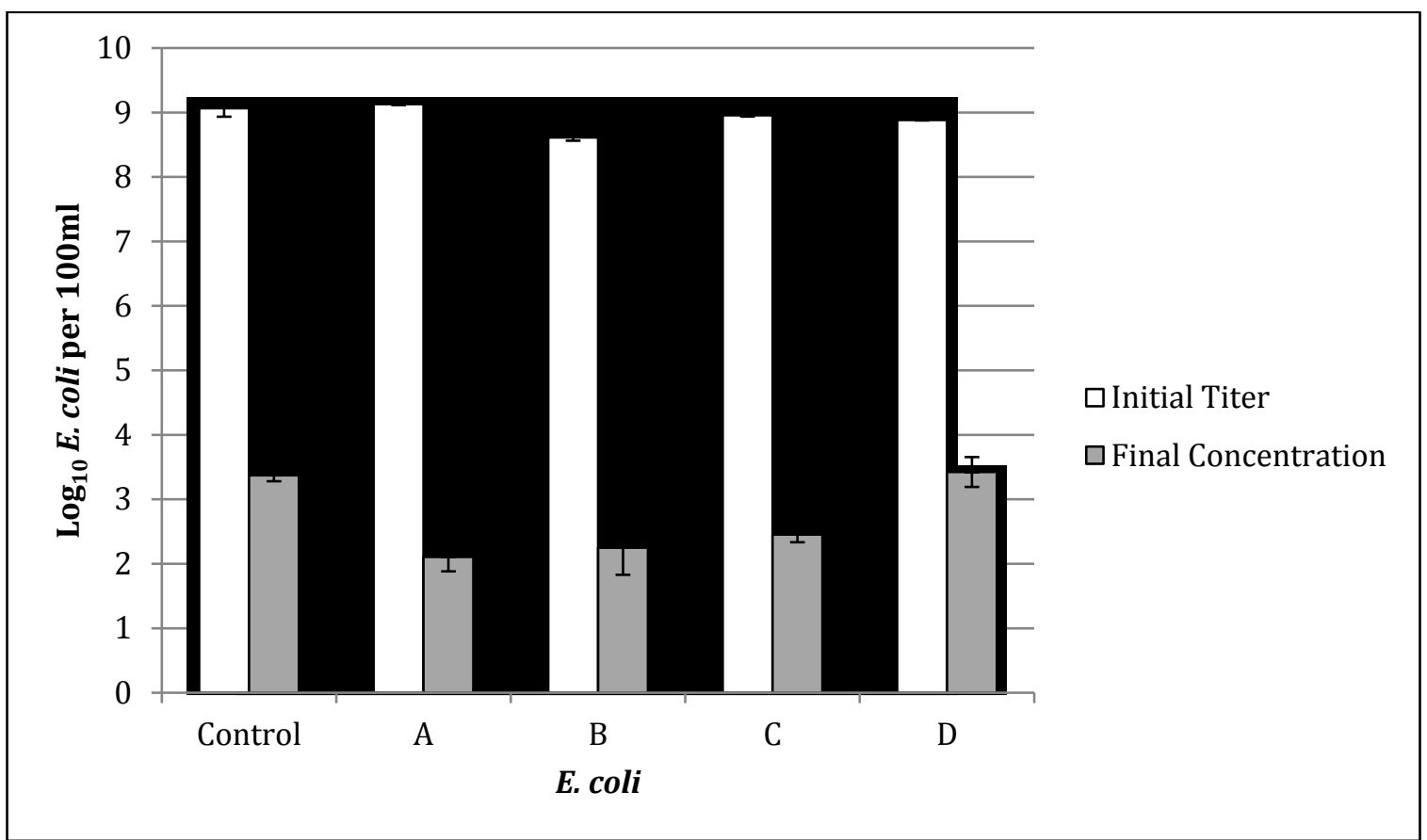

Figure 4.10: $\log _{10}$ CFU Recovery of $E$. coli per $100 \mathrm{~mL}$ after $20 \mathrm{~mJ} / \mathrm{cm}^{2}$ irradiation with low-pressure UV

The dark grey bars in Figure 4.10 show the $\log _{10} \mathrm{CFU}$ concentration of E. coli after disinfection. The $\log _{10}$ CFU per $100 \mathrm{~mL}$ recovery of the control and test isolates $\mathrm{A}, \mathrm{B}$, $\mathrm{C}$ and D were $3.37 \pm 0.09,2.11 \pm 0.23,2.25 \pm 0.42,2.45 \pm 0.12$, and $3.42 \pm 0.23$ respectively. This corresponds to a $\log _{10} \mathrm{CFU}$ reduction of $5.67 \pm 0.23,7.02 \pm 0.21$, $6.37 \pm 0.37,6.50 \pm 0.14$, and $5.46 \pm 0.23$ for the control and test isolates A, B, C and 
D respectively. These results show that the lab-adapted control survived the lowpressure UV better than test isolates A, B and C. The control also survived about as well as test isolate D. After further statistical analysis using a two-tailed type $3 \mathrm{~T}$ test, it was found that the differences in $\log _{10} \mathrm{CFU}$ removal between the control and test isolates $\mathrm{B}, \mathrm{C}$ and $\mathrm{D}$ were insignificant with $95 \%$ confidence $(\mathrm{P}>0.05)$. This implies that the difference in $\log _{10} \mathrm{CFU}$ reduction is negligible because of the sample sizes and standard deviations within each data set. The difference in $\log _{10}$ CFU reduction between the control and test isolate A was significant with $95 \%$ confidence $(\mathrm{P}<0.05)$. Test isolate A had a $1.35 \log _{10} \mathrm{CFU}$ higher reduction compared to the control. It is unclear why test isolate A was more effected by low pressure UV than the control strain, but a $1.35 \log _{10} \mathrm{CFU}$ difference is relatively inconsequential when reviewing disinfection data.

\subsubsection{Disinfection efficacy comparisons between free chlorine, PAA and low-pressure UV}

Figure 4.11 shows the initial and recovery $\log _{10}$ CFU E. coli $/ 100 \mathrm{~mL}$ concentrations for each test isolate used in the study before and after exposure to chlorine, PAA and low-pressure UV. 


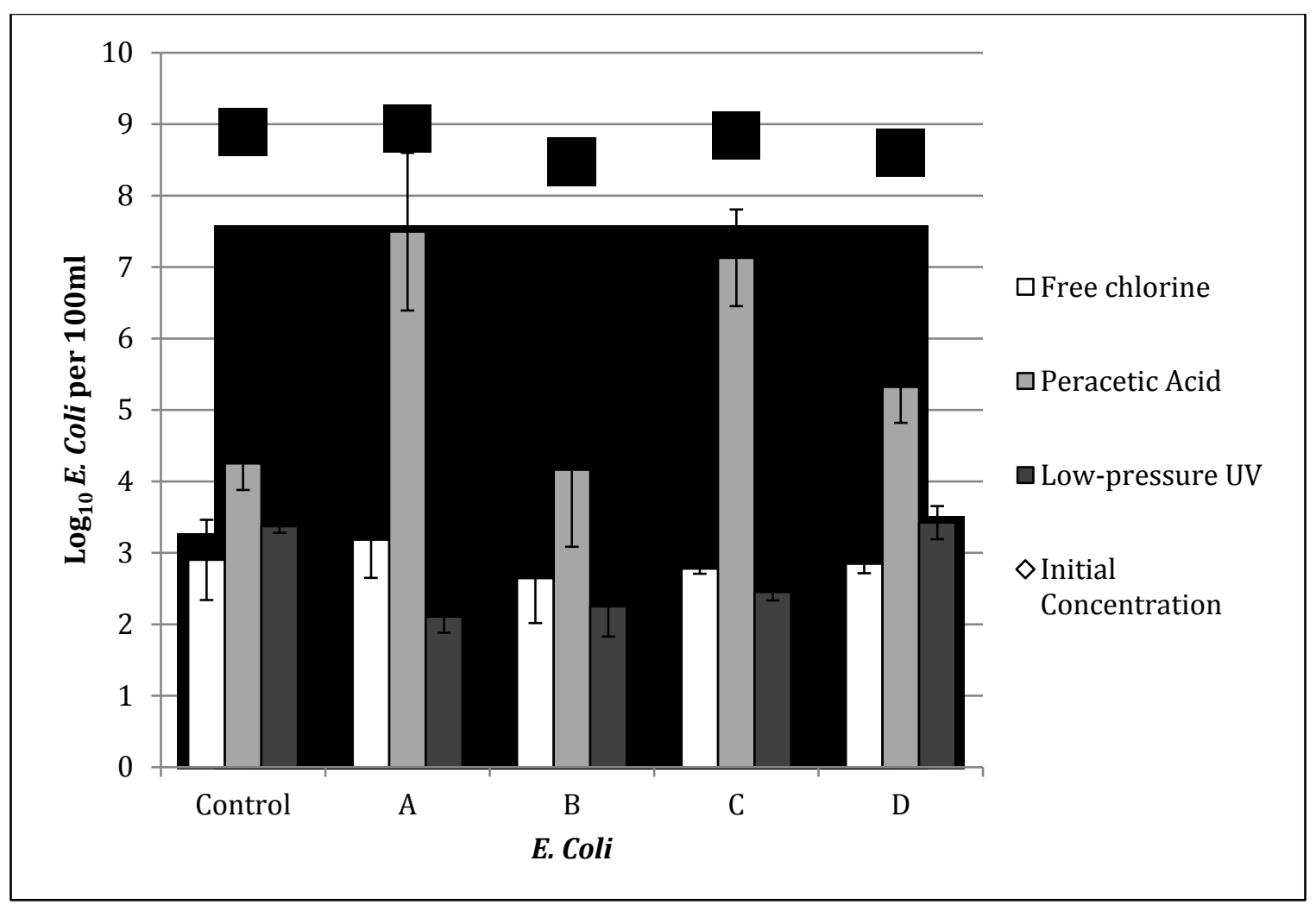

Figure 4.11: Recovery of Log10 CFU E. coli per 100mL of control and test isolates A, B, C, and D after exposure to FC, PAA and Low-pressure UV

As shown in Figure 4.11, similar $\log _{10}$ CFU reduction of the control occurred after exposure to the selected doses of free chlorine and low-pressure UV (6.05 and 5.58, respectively). The $\log _{10}$ CFU reduction of the control after exposure to the selected PAA dose was less then what was achieved by the free chlorine and UV doses $(4.70$ $\log _{10}$ CFU).

In general, the selected doses of chlorine and low-pressure UV for all four test isolates achieved similar $\log _{10}$ CFU reductions compared to the control, ranging from 5.5 to $7 \log _{10} \mathrm{CFU}$ reduction, regardless of exhibited antibiotic resistance. PAA was not as effective against the four test isolates compared to the control, with $\log _{10}$ CFU reductions ranging from 4.37 to as low as $1.51 \log _{10}$ CFU. 


\subsection{Part 3: Susceptibility changes in antibiotic resistance profiles}

For each experiment, Kirby Bauer antibiotic resistance profiles were determined before exposure to disinfection. Surviving colonies were then picked to obtain postdisinfection Kirby Bauer resistance profiles. For each disinfection treatment type, 6 pre-disinfection profiles and 10 post-disinfection profiles were determined for the control and $4 E$. coli test isolates. The zone of inhibition for each antibiotic was measured to the nearest millimeter. The average zones of inhibition for the pre and post-disinfection profiles were determined and then compared to see if there were any significant $(\mathrm{P}<0.05)$ increases or decreases in diameters. An increase in diameter indicates that the E. coli in question became more susceptible to the antibiotic after being exposed to free chlorine, PAA or low-pressure UV. A decrease in diameter indicates that the E. coli became less susceptible.

The data was organized to relate the number of significant changes in zones of inhibition to the three independent variables; disinfection treatment, E. coli isolate, and type of antibiotic.

\subsubsection{Changes in $E$. coli antibiotic susceptibility versus disinfection treatment}

Zones of inhibition from before and after exposure to disinfection were analyzed and compared to determine changes in antibiotic susceptibility. A change in zone of inhibition size was determined to be statistically significant using a type 3, twotailed t-test with a $90 \%$ confidence interval $(\mathrm{P}<0.05)$. The changes in antibiotic susceptibility were recorded, and were correlated to the disinfection treatments used in this study. Figure 4.12 below shows the results of this comparison. For 
example, in the chlorine disinfection experiments $20 \%$ of the post-disinfection zones of inhibition were significantly larger $(\mathrm{P}<0.05)$ than before disinfection, inferring an increase in susceptibility to the antibiotics tested. Of the postdisinfection zones of inhibition, $2.9 \%$ were significantly smaller $(\mathrm{P}<0.05)$ than before disinfection, inferring a decrease in susceptibility to the antibiotics tested. For further context, there were a total of 35 "results" from each disinfection experiment (5 different $E$. coli tested against the 7 antibiotics). Therefore, of the 35 postchlorine disinfection E. coli picks, 7 of them (20\%) were more antibiotic-susceptible than they were pre-disinfection, and $1(2.9 \%)$ was less antibiotic-susceptible than it was pre-disinfection. There was no observed change in antibiotic susceptibility in the other 27 post-disinfection E. coli picks (77.1\%), indicating no change in resistance to the antibiotics. 


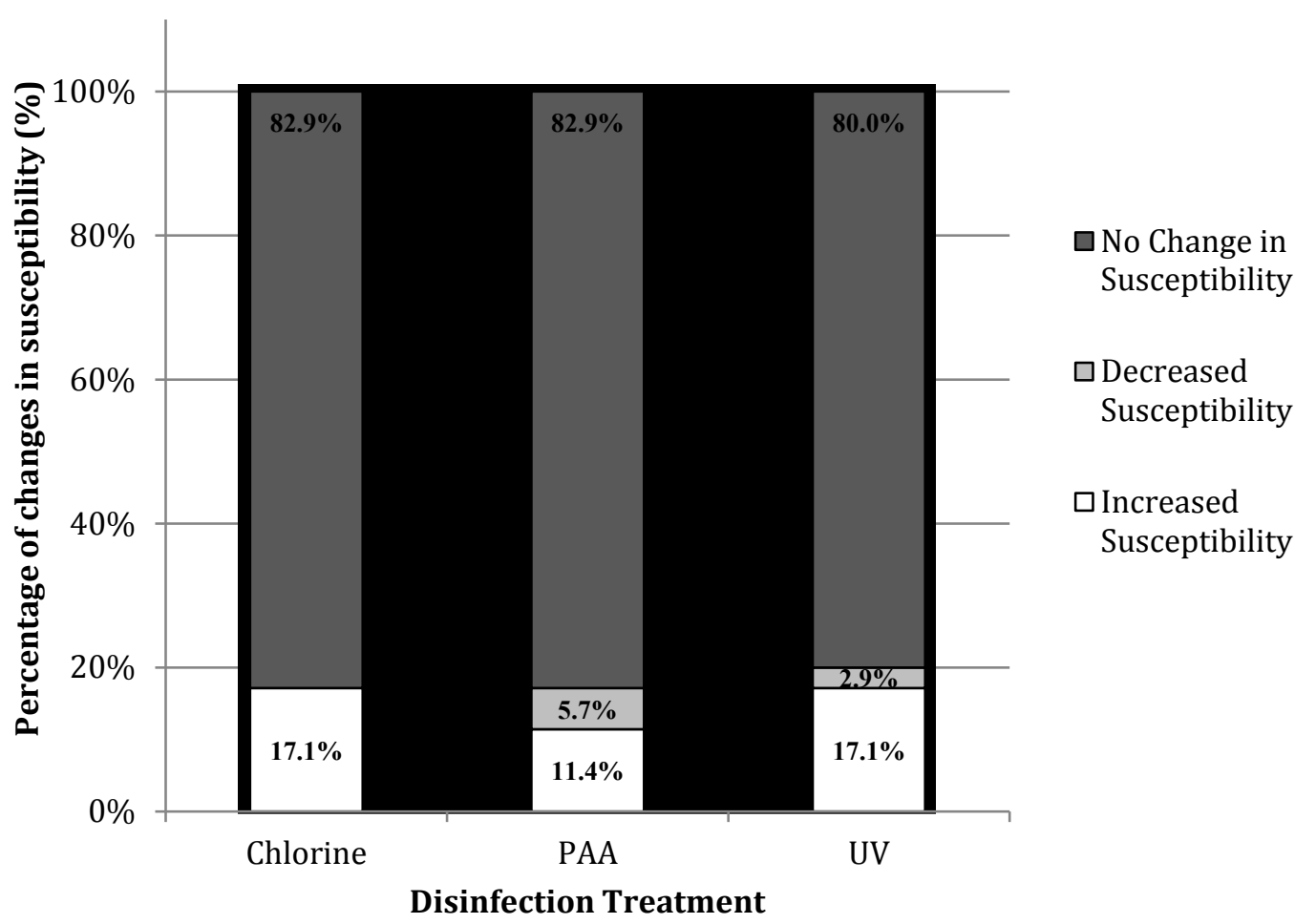

Figure 4.12: Percentage of changes in E. coli antibiotic susceptibility after disinfection treatment by free chlorine, PAA and low-pressure UV with $95 \%$ confidence $(\mathrm{P}<0.05)$

For free chlorine, PAA and low-pressure UV, over $80 \%$ of the post-disinfection zones of inhibition were not significantly different from the pre-disinfection zones of inhibition, indicating no change in antibiotic susceptibility. For free chlorine, PAA and low-pressure UV, $17.1 \%, 11.4 \%$ and $17.1 \%$ of the post-disinfection zones of inhibition were larger than the pre-disinfection zones of inhibition, indicating an increase in susceptibility to the antibiotics tested. Finally, the prevalence of significant decreases in zones of inhibition was $0 \%, 5.7 \%$ and $2.9 \%$ for free chlorine, PAA and low-pressure UV, respectively, which indicated a decrease in susceptibility to the antibiotics tested.

In the following section, the question of which $E$. coli isolate experienced the most changes to their resistance profiles will be answered. 


\subsubsection{Changes in $E$. coli antibiotic susceptibility versus $E$. coli test isolates}

Figure 4.13 below shows the proportion of increased, decreased and no change in antibiotic susceptibility for the control and each E. coli test isolates after exposure to chlorine, PAA and low pressure UV. This comparison was done to determine if there were any E. coli that tended to become more or less susceptible to antibiotics after exposure to any of the disinfection treatments.

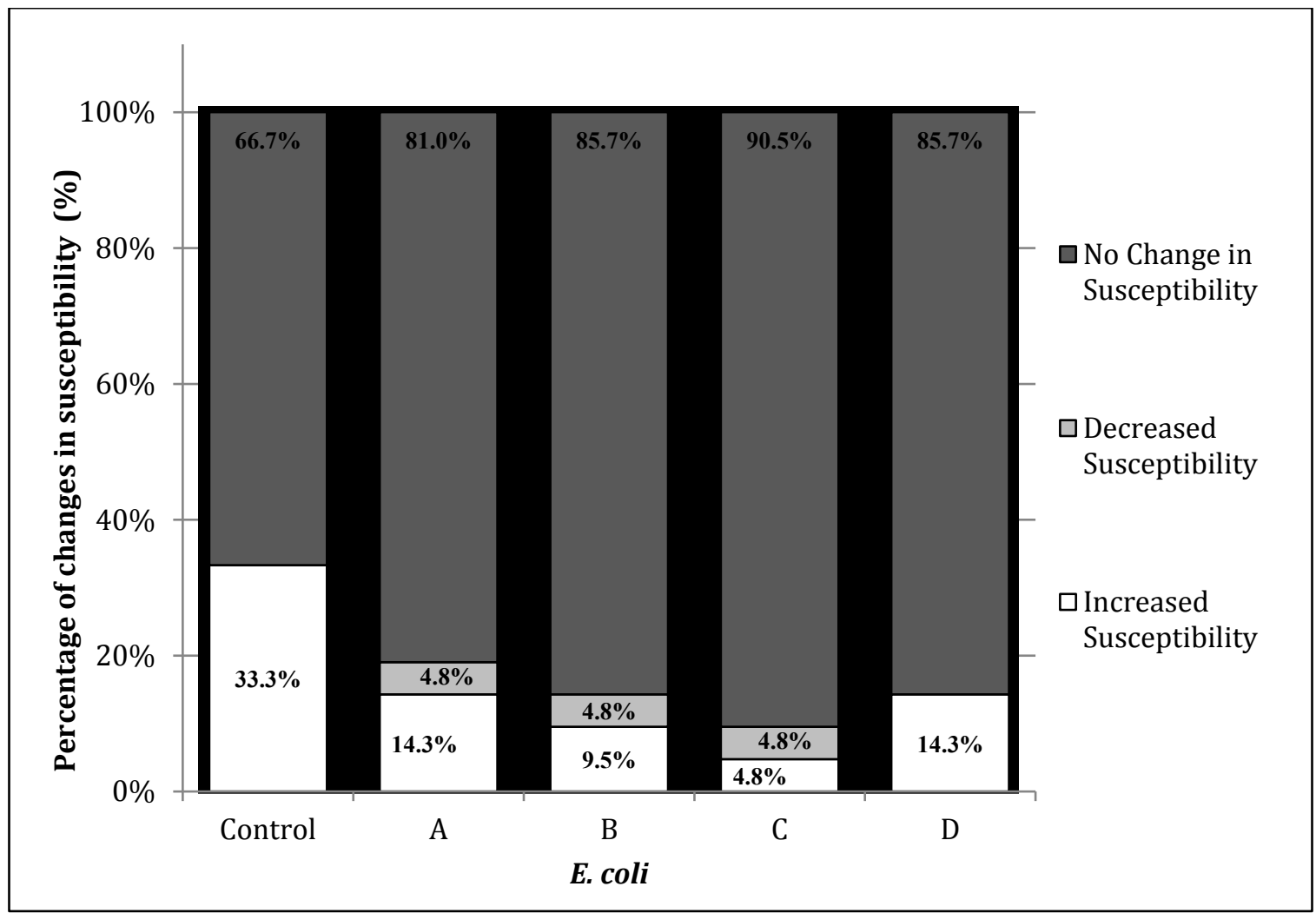

Figure 4.13: Percentage of changes in E. coli antibiotic susceptibility with respect to each test isolates after exposure to any disinfection treatment with 95\% confidence $(\mathrm{P}<0.05)$

For the control, $66.7 \%$ of the post-disinfection zones of inhibition showed no change in antibiotic susceptibility compared to the pre-disinfection zones, and 33.3\% showed an increased susceptibility. There were no observed decreases in 
susceptibility. This shows that the control strain's antibiotic susceptibility either did not change or increased after exposure to disinfection.

For test isolate A, $81.0 \%$ of the post-disinfection E. coli picks showed no change in antibiotic susceptibility. $14.3 \%$ of the post-disinfection E. coli picks showed an increase in antibiotic susceptibility, and $4.8 \%$ showed a decrease in susceptibility. In test isolate B, $85.7 \%$ of the post-disinfection $E$. coli picks showed no change in antibiotic susceptibility. $9.5 \%$ of the post-disinfection E. coli picks showed an increase in antibiotic susceptibility, and $4.8 \%$ showed a decrease in susceptibility. This showed that the resistance profile of test isolate B could be influenced by exposure to disinfection, but not as considerably as test isolate A was. In test isolate C, $90.5 \%$ of the post-disinfection $E$. coli picks showed no change in antibiotic susceptibility. $4.8 \%$ of the post-disinfection E. coli picks showed an increase in antibiotic susceptibility, and $4.8 \%$ showed a decrease in susceptibility. This showed that the resistance profile of test isolate $\mathrm{C}$ could be influenced by exposure to disinfection, but not as significantly as the profiles of test isolates A and B.

In test isolate D, $85.7 \%$ of the post-disinfection zones of inhibition showed no change from the pre-disinfection zones of inhibition. However, $14.3 \%$ of the postdisinfection zones of inhibition showed an increase in diameter, indicating an increase in susceptibility. There were no observed significant decreases in zone of inhibition, indicating no increase in antibiotic resistance. This showed that the resistance profile of test isolate $\mathrm{D}$ could be influenced by exposure to disinfection, 
but not as significantly as the other test isolates. In the following section, an analysis of changes in resistance to each antibiotic after disinfection will be presented.

\subsubsection{Changes in E. coli antibiotic susceptibility versus antibiotics tested}

Figure 4.14 below shows the proportion of increases, decreases and no change in antibiotic susceptibility for each antibiotic tested. This comparison was done to determine if there were any antibiotics that tended to become more or less effective at inhibiting the E. coli control and test isolates after exposure to any of the disinfection treatments.

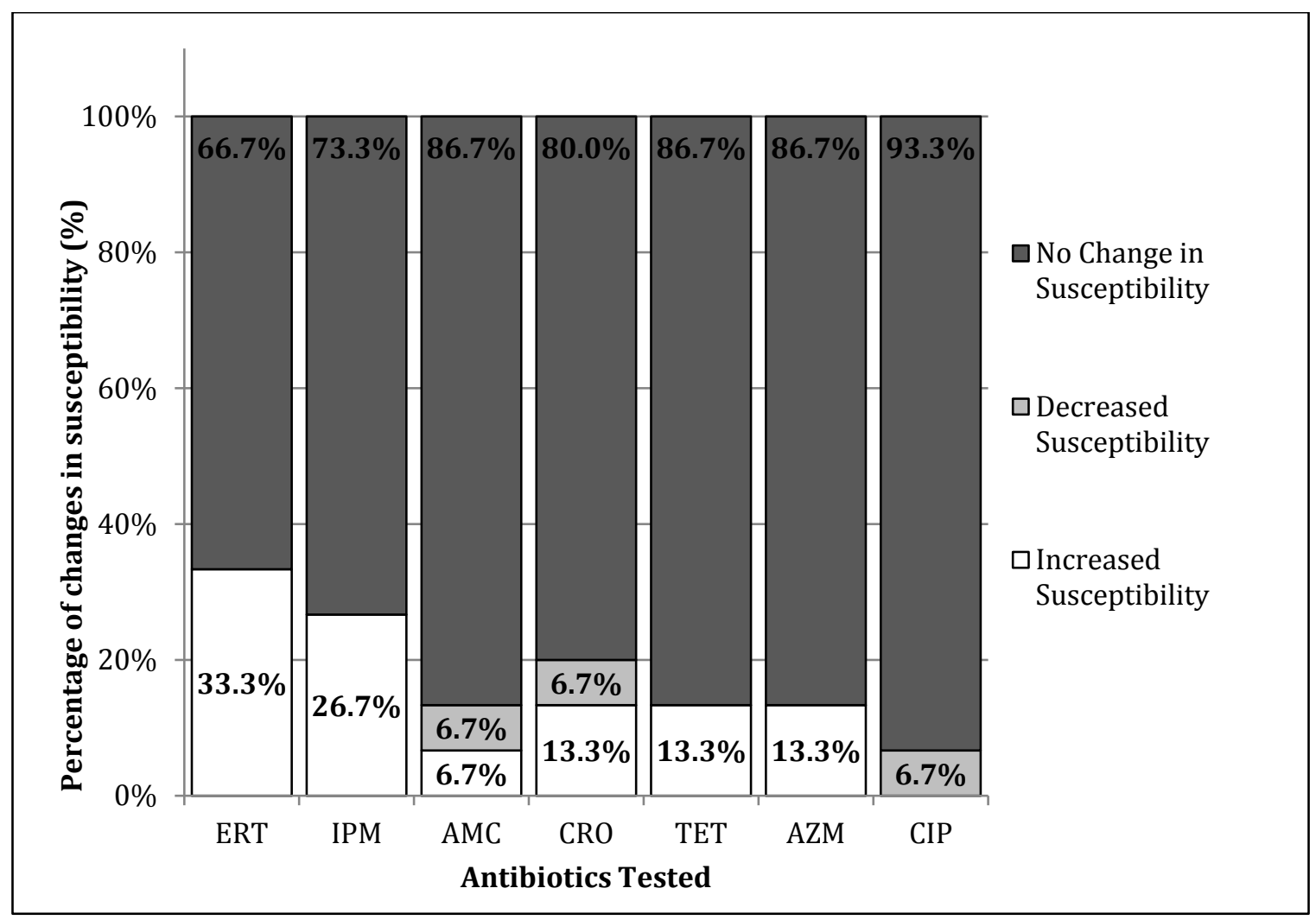

Figure 4.14: Percentage of changes in E. coli antibiotic susceptibility with respect to azithromycin (AZM) $(15 \mu \mathrm{g})$, ertapenem (ERT) $(10 \mu \mathrm{g})$, amoxicillin/clavulanic acid (AMC) (30 $\mu \mathrm{g})$, tetracycline (TET) $(30 \mu \mathrm{g})$, impenem (IPM) $(10 \mu \mathrm{g})$, ceftriaxone (CRO) (30 $\mu \mathrm{g})$, and ciprofloxacin (CIP) $(5 \mu \mathrm{g})$ with 95\% confidence $(\mathrm{P}<0.05)$ 
From the figure it can be seen that the distribution of increases, decreases and no changes in antibiotic susceptibility in the post disinfection E. coli picks was fairly consistent for amoxicillin, ceftriaxone, tetracycline, azithromycin and ciprofloxacin. The percentages of results that showed no change in antibiotic susceptibility were $86.7 \%, 80.0 \%, 86.7 \%, 86.7 \%$, and $93.3 \%$, respectively. For ertapenem and imipenem, only $66.7 \%$ and $73.3 \%$ of the post-disinfection E. coli picks showed no change in antibiotic susceptibility; $33.3 \%$ and $26.7 \%$ showed a significant increase in susceptibility and neither showed a significant decrease in susceptibility. The antibiotics that showed the most decreases in antibiotic susceptibility after disinfection were amoxicillin, ceftriaxone and ciprofloxacin. Overall, there was very little decrease in susceptibility to the antibiotics after exposure to disinfection.

\subsection{Part 4: Reclassification of antibiotic resistance of post- disinfection $E$. coli picks}

The pre and post-disinfection efficacy test zones of inhibition have been compared and analyzed to determine changes in antibiotic susceptibility. It is important to note that although an increase or decrease in diameter indicates a change in susceptibility that a post disinfection E. coli isolate exhibits to a specific antibiotic, it does not necessarily mean that the "resistance classification" of that isolate has changed. As discussed previously and shown in Table 3.1 an E. coli can be classified as susceptible, intermediate or resistant to an antibiotic based on the diameter of the zone of inhibition. There are prescribed ranges to classify each antibiotic, susceptible, intermediate and resistant, and the classification of an isolate is determined based on what range the diameter of its zone of inhibition lies in. 
Throughout this study, 1050 different post-disinfection zones of inhibition were measured and classified ( 5 E. coli $\times 3$ disinfection treatments $\times 7$ antibiotics $\times 10$ picks of post-disinfection surviving E. coli colonies). Of the 1050 post-disinfection zones of inhibition measured, 16 cases of classification change were recorded. A classification change occurs when the zone of inhibition increases or decreases enough after exposure to disinfection to fall within in a different diameter range. This corresponds to $1.5 \%$ of the post disinfection zones of inhibition.

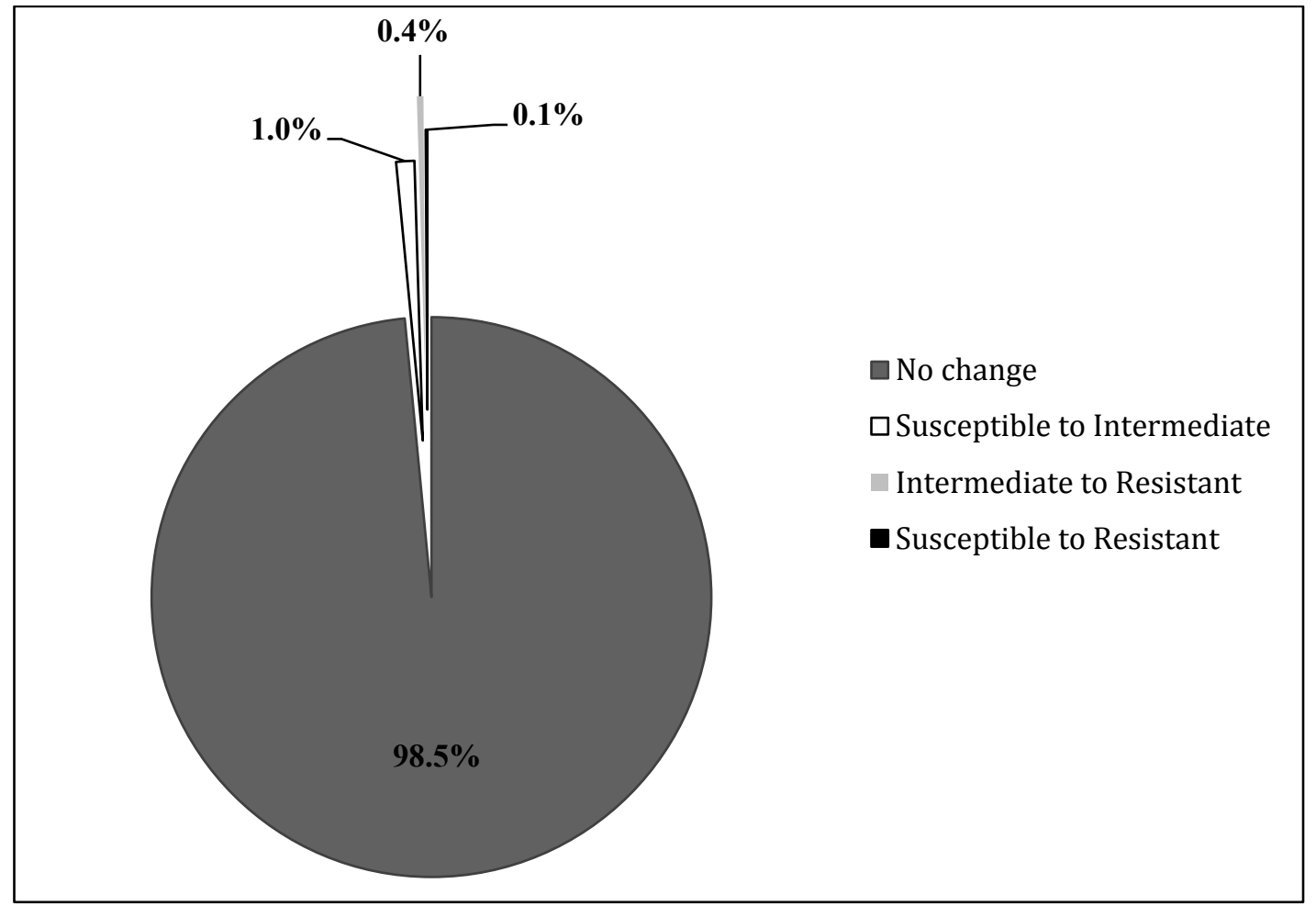

Figure 4.15: Changes in zones of inhibition from pre to post disinfection causing reclassification of resistance

For each case of classification change, the $E$. coli isolate, antibiotic, disinfection treatment, and average pre-disinfection zone diameter are shown in Table 4.3. The post-disinfection zone of inhibition diameter and the description of classification change (susceptible to Intermediate (S to I), Susceptible to Resistant (S to R), or Intermediate to Resistant (I to R)) were also recorded. 
Table 4.3: Changes in antibiotic resistance classifications, from Susceptible to Intermediate (S to I), Intermediate to Resistant (I to R), or Susceptible to Resistant (S to R)

\begin{tabular}{|l|l|l|l|l|l|}
\hline E. coli & Antibiotic & $\begin{array}{l}\text { Disinfection } \\
\text { Treatment }\end{array}$ & $\begin{array}{l}\text { Pre- } \\
\text { disinfection } \\
\text { zone of } \\
\text { inhibition } \\
\text { diameter, } \mathrm{mm} \\
(\mathrm{n}=6)\end{array}$ & $\begin{array}{l}\text { Post- } \\
\text { disinfection } \\
\text { zone of } \\
\text { inhibition } \\
\text { diameter, } \mathrm{mm} \\
(\mathrm{n}=1)\end{array}$ & $\begin{array}{l}\text { Classification } \\
\text { change (S, I, } \\
\text { R) }\end{array}$ \\
\hline Control & CRO & PAA & $28.67 \pm 1.03$ & 22 & S to I \\
\hline A & IPM & Chlorine & $23.33 \pm 0.52$ & 21 & S to I \\
\hline A & CRO & Chlorine & $25.5 \pm 0.84$ & 22 & S to I \\
\hline A & IPM & PAA & $23.33 \pm 0.52$ & 22 & S to I \\
\hline A & IPM & PAA & $23.33 \pm 0.52$ & 21 & S to I \\
\hline A & IPM & PAA & $23.33 \pm 0.52$ & 21 & S to I \\
\hline A & IPM & PAA & $23.33 \pm 0.52$ & 22 & S to I \\
\hline A & AMC & PAA & $19.00 \pm 0.63$ & 17 & S to I \\
\hline A & IPM & UV & $23.33 \pm 0.52$ & 22 & S to I \\
\hline B & IPM & PAA & $25.67 \pm 0.82$ & 22 & S to I \\
\hline C & AMC & Chlorine & $18.83 \pm 0.75$ & 0 & S to R \\
\hline C & AMC & Chlorine & $18.83 \pm 0.75$ & 15 & S to I \\
\hline D & ERT & Chlorine & $23.67 \pm 0.52$ & 18 & S to R \\
\hline D & IPM & Chlorine & $19.92 \pm 0.49$ & 19 & I to R \\
\hline D & IPM & UV & $19.92 \pm 0.49$ & 19 & I to R \\
\hline D & IPM & UV & $19.92 \pm 0.49$ & 19 & I to R \\
\hline
\end{tabular}

Although there were only 16 occurrences of antibiotic resistance classification changes, all of these incidences were a decrease in antibiotic susceptibility, either from susceptible to intermediate, intermediate to resistant, or susceptible to resistant. It is important to note there were no observed classification changes involving an increase in susceptibility.

As shown in Table 4, at least one occurrence of classification change was observed in all five E. coli isolates. Viewing the data from an isolate specific view, there was 1 observed $\mathrm{S}$ to I change in the control, 8 changes in test isolate $\mathrm{A}, 1$ change in test isolate $\mathrm{B}, 2$ changes in test isolate $\mathrm{C}$ and 4 changes in test isolate $\mathrm{D}$. From a 
treatment specific view, of the 16 classification changes, 6 were observed after exposure to chlorine, 7 after exposure to PAA, and 3 after exposure to low-pressure UV. Finally, from an antibiotic specific view, 2 observed changes were in resistance to ceftriaxone, 3 changes were in resistance to amoxicillin, one was in resistance to ertapenem, and 10 changes were to imipenem. 


\section{Discussion}

\subsection{Part 1: Prevalence of antibiotic resistant bacteria in secondary wastewater effluent}

There have been multiple studies showing the presence of antibiotic resistant genes (ARGs) and bacteria (ARB) in wastewater (L. Rizzo et al., 2013). ARGs in wastewater are a concern, but their mere presence does not necessarily mean they are being expressed by bacteria (Baharoglu \& Mazel, 2014). The Kirby Bauer resistance profiles determined for the $97 \mathrm{E}$. coli isolates show an actual antibiotic resistance expression.

Among the E. coli isolates tested in this study, approximately 55\% were susceptible to all seven antibiotics tested. However, the other $45 \%$ showed some resistance to at least one antibiotic, with $8 \%$ of the isolates showing multi-drug resistance (resistant to 3 or more antibiotics). The most antibiotic resistance observed was to amoxicillin/clavulanic acid (33.7\%), which is an indicator of beta-lactamase activity. Beta-lactamases are enzymes produced by bacteria to provide resistance to betalactam antibiotics such as penicillins, cephalosporins and carbapenems (Blaak et al., 2014). If bacteria are resistant to more than one class of beta-lactam antibiotic, this suggests the presence of extended-spectrum-beta-lactamases (ESBLs), which have been highlighted by the WHO as an urgent threat to human health worldwide (WHO, 2014). Although there was no recorded resistance to ertapenem in this study (0\%), $16.3 \%$ and $20.4 \%$ of the $E$. coli showed resistance to ceftriaxone ( $3^{\text {rd }}$ gen cephalosporin) and imipenem, respectively, which indicates the presence of ESBLs in this study. Generally speaking, carbapenems are usually resistant to ESBLs and 
can inhibit bacterial growth despite their presence (Nordmann \& Poirel, 2014), and because of this they are a drug used in extreme situations when all other antibiotics have failed. The resistance to imipenem found in this study implies the presence of metallo-beta-lactamases, which are an emerging threat in the Enterobacteriaceae family that confer resistance to all beta-lactam antibiotics (Van Hoek et al., 2011). Other mechanisms of resistance used by E. coli besides beta-lactamases can be efflux pumps within the cell that actively remove antibiotics, or mutations that effect the structure or function of the cell's porins (channels through which the antibiotic enters the cell) (Papp-Wallace et al., 2011). A bacterial cell having one or more of these defensive mechanisms can confer greater resistance to a broader range of antibiotics.

$17.5 \%$ and $8.2 \%$ of the $E$. coli isolates showed resistance to tetracycline and azithromycin, respectively. Tetracycline is a "broad-spectrum" antibiotic that is relatively safe and has a low cost. It is the second most prescribed antibiotic class after penicillin worldwide. Its main antibacterial mechanism is protein synthesis inhibition. Azithromycin is part of the macrolides class, and is another widely prescribed antibiotic. Like tetracycline, it is also a protein synthesis inhibitor. Both antibiotics are used to treat a variety of common bacterial infections such as pneumonia, whooping cough, urinary tract infections, acne and sexually transmitted infections. The mainstream use of these antibiotics has lead to an increase in resistance to them, which was demonstrated by this study. The main mechanisms of resistance to tetracycline and azithromycin are efflux pumps, rRNA methylases and antibiotic-inactivating enzymes (Van Hoek et al., 2011). 
Finally, $9.2 \%$ of the E. coli isolates showed resistance to ciprofloxacin, a member of the fluoroquinolone antibiotic class. Ciprofloxacin is a DNA synthesis inhibitor, meaning it impedes the action of DNA gyrase and topoisomerase, two enzymes that are essential for bacterial DNA replication (Van Hoek et al., 2011). Without the means to replicate itself, the bacteria dies. Resistance mechanisms to fluoroquinolones have been discovered and are related to porin loss, overexpression of naturally occurring efflux pumps, or mutations of the molecular targets DNA gyrase and topoisomerase (Van Hoek et al., 2011). Ciprofloxacin is a synthetic bactericidal antibiotic with a broad-spectrum of activity. Examples of when it is used include difficult to treat urinary tract infections, hospital-acquired pneumonia and bacterial prostatitis (WHO, 2014).

Although there are not as many studies using phenotypic analysis to characterize the prevalence of $A R B$ in wastewater, the few that have been done have shown similar results to those found in this investigation.

Aslan et al. isolated 96 E. coli from the influent, secondary wastewater effluent, UV effluent and UV plus chlorine effluent in a wastewater treatment plant. They tested their E. coli isolates for antibiotic resistance to ampicillin (beta lactam penicillin), ciprofloxacin (fluoroquinolone), sulfamethoxazole (folic acid synthesis inhibitor) and tetracycline using CLSI standards (Patel et al., 2013). Of the 96 isolates, 95\% were resistant to ampicillin, 30\% were resistant to ciprofloxacin, and 30\% were resistant to tetracycline (Aslan et al., 2018). Approximately 21\% of the isolates were resistant to three or more antibiotics, which means they were considered to be 
multi-drug resistant. The percentages of isolates in this study that were resistant to amoxicillin (similar to ampicillin), ciprofloxacin and tetracycline were 33.7\%, 17.5\% and $9.2 \%$ respectively. $8 \%$ of the E. coli isolates in this study were considered to be multi-drug resistant. The study conducted by Aslan et al. did appear to have more resistant $E$. coli isolates, but their methodology may have selected for more resistant bacteria. They first exposed wastewater samples to antibiotics, isolated surviving bacteria and then determined Kirby Bauer profiles, whereas in this study E. coli was isolated straight from secondary wastewater effluent and their resistance profiles were determined immediately afterwards.

Igwaran et al. conducted a study of E. coli antimicrobial resistance in wastewater treatment plant effluents in South Africa. They isolated 111 E. coli over three months and performed antibiotic susceptibility testing with 12 antibiotics. They found very high percentages of resistant E. coli. For example, 100\% of the isolates were either intermediate or resistant to erythromycin (similar to azithromycin used in this study). Of the $E$. coli isolates, $94.5 \%, 60.3 \%$ and $48.6 \%$ were intermediate or resistant to amoxicillin, ciprofloxacin and meropenem, respectively (Igwaran et al., 2018). The higher percentage of resistance found by Igwaran et al. compared to this study may be due to a number of factors. The influent to the wastewater treatment plants may be more heavily polluted with antibiotics. The treatment may not be as high in quality as the wastewater treatment plant in Ottawa. Also, Igwaran et al. isolated E. coli after chlorine disinfection, so it is possible this treatment step selects for more antibiotic resistant E. coli. 
Pillay and Olaniran determined Kirby Bauer resistance profiles of E. coli that were isolated from two wastewater treatment plants in Germany. They collected samples over 6 months from before chlorination, final effluent, upstream of the final effluent and downstream of the final effluent. 62 E. coli were isolated from before chlorine disinfection (30 from one plant, 32 from the other). Of the E. coli isolated from before chlorine disinfection, $63 \%$ were resistant to tetracycline, $66.5 \%$ were resistant to ampicillin (similar to amoxicillin), 40\% to amoxicillin, $21 \%$ to ciprofloxacin, $8.42 \%$ to gentamycin (similar to azithromycin), $6.5 \%$ to ceftazidime (similar to ceftriaxone) and $0 \%$ to cefazolin (similar to ceftriaxone) (Pillay \& Olaniran, 2016). The percentages of isolates resistant to the mentioned antibiotics are higher than what was found in this study, but in general similar trends were observed.

Luczkiewicz et. al. tested the antimicrobial resistance of $153 \mathrm{E}$. coli isolated from the raw influent, final effluent, aeration chamber and activated sludge in Poland. They tested for resistance to 19 antimicrobials from a range of classes including carbapenems, cephalosporins, fluoroquinolones, beta-lactamase inhibitors, penicillins and tetracyclines. Approximately $48 \%$ of the isolates exhibited resistance to at least one antibiotic. Among the isolates, resistance to ampicillin (34\%), piperacillin (24\%) and tetracycline (23\%) was the most common. $9 \%$ of the E. coli isolates were multi-drug resistant, similar to what was found in this study. Extended spectrum beta-lactamase producing E. coli were detected only once in the study in the aeration chamber. No resistance to imipenem or meropenem was detected (Łuczkiewicz et al., 2010). 
In summary, there was an abundance of antibiotic resistant $E$. coli in the secondary wastewater effluent sampled in this study, which was consistent with many other studies. The relative abundance of antibiotic resistant E. coli detected can differ based on a number of factors, such as location of sampling, influent wastewater characteristics, susceptibility testing methods, etc. Antibiotic resistant E. coli can be easily isolated from wastewater samples at all points in a treatment plant. Despite the different mechanisms of the antibiotics used in this study to inhibit bacteria, 8\% of the isolated E. coli were multi-drug resistant. This demonstrates how one bacterial isolate can possess several defensive mechanisms to inhibit the actions of

antibiotics. This shows the magnitude of a problem that is only going worsen if steps for mitigation are not taken.

Specifically for this study, the E. coli were isolated towards the end of the treatment train, before disinfection, which shows that the preceding treatment steps did not remove all antibiotic resistance bacteria. This leaves final disinfection as the last defense before discharge of antibiotic resistant bacteria into the receiving environment, which is why it is important to observe the effects of disinfection technologies on antibiotic resistant bacteria.

\subsection{Part 2: $\log _{10}$ CFU inactivation of $E$. coli test isolates versus the control by free chlorine, PAA and low-pressure UV}

In this study, the efficacy of free chlorine against the control was no different than against any of the test isolates. It can be hypothesized that because the wastewater isolated E. coli had been exposed to the environment and other WWTP treatment steps, they might be more resistant to chemical disinfection because they would 
have intrinsic defenses that the lab adapted ATCC control would not. The results from this experiment do not support this. Furthermore, at 95\% confidence there was no statistically significant difference between the $\log _{10}$ CFU inactivation of the antibiotic susceptible test isolate $\mathrm{A}$ and any of the other $E$. coli. These results suggest that in this experiment there was no apparent trend between antibiotic resistance profiles and susceptibility to free chlorine. For example, the observed $\log _{10} \mathrm{CFU}$ recovery of multidrug resistant test isolate D was approximately the same as the control and test isolate A, neither of which had any antibiotic resistance. The average $\log _{10} \mathrm{CFU}$ reduction for the control and the test isolate $E$. coli was 6.01 \pm 0.15 .

The efficacy of PAA against the control versus the test isolates differed significantly. Overall, the test isolates survived PAA disinfection better than the control. It was suspected that the reason the $E$. coli test isolates survived better was because they contained an enzyme called catalase. Catalase is an enzyme that is commonly found in bacteria that catalyzes the decomposition of hydrogen peroxide to water and oxygen (Baeza et al., 2013). Hydrogen peroxide is one of the active disinfecting substances in PAA (22\% by weight), which explains why the test isolates were demonstrably less affected compared to the control. PAA itself does have disinfecting properties, however its mode of action is not solidly understood yet (Di Cesare, Fontaneto, Doppelbauer, \& Corno, 2016). To confirm this, a catalase test was conducted on the surviving colonies of each $E$. coli test isolate. A catalase test consists of dropping $3 \%$ hydrogen peroxide on to surviving $E$. coli colonies. If the $E$. coli contained the catalase enzyme, it would break the hydrogen peroxide down into 
water and oxygen. The release of oxygen creates bubbles, and the strength and rate of the reaction was measured qualitatively by observing the amount of bubbles created: the stronger the observed reaction, the greater the presence of catalase. The strength of reaction was ranked on a qualitative scale from 0 to 4 . When comparing the results from the qualitative analysis of catalase reaction strength with the $\log _{10} \mathrm{CFU}$ reduction by PAA for each test isolate, parallels can be seen. For example, for A and C there was a lower reduction than the control by 3.14 and $2.96 \log _{10} \mathrm{CFU} / 100 \mathrm{~mL}$, respectively. This correlates directly with the results from the catalase test, where they both scored a 4 in reaction strength. Test isolate D had the next greatest difference in $\log _{10}$ CFU reduction from the control of 1.6 and scored a 3 in the catalase test. Finally, test isolate B was very similar to the control with a $\log _{10}$ CFU reduction difference of only 0.33 , which corresponds with its reaction strength score of 2 .

The conclusion that can be drawn from these results is that, although the test isolates did survive PAA better than the control, it was not due to their antibiotic resistance profile. The test isolates contained the enzyme catalase, which is likely what the observed resistance to PAA is attributable to. When comparing the proficiencies of free chlorine, PAA and low-pressure UV in inactivating the control versus the four test isolates, it was observed that chlorine and low-pressure UV achieved very similar $\log _{10} \mathrm{CFU}$ reductions of the control and all test isolates studied, while PAA was not as effective against the test isolates as it was against the control. The $\log _{10} \mathrm{CFU}$ reductions of the control achieved by chlorine and low-pressure UV were $6.077 \pm 0.259$ and $5.675 \pm 0.225$. The average 
$\log _{10}$ CFU reductions of the four test isolates by chlorine and low-pressure UV were $5.996 \pm 0.153$ and $6.339 \pm 0.650$. These results show that chlorine and low-pressure UV were similarly effective against the control and the test isolates, regardless of antibiotic resistance. The average $\log _{10} \mathrm{CFU}$ reductions by PAA of the control and four test isolates were $4.674 \pm 0.410$ and $3.067 \pm 1.448$ respectively. This shows that PAA was much less effective against the four test isolates as it was against the control.

In summary, the results of this study showed that chlorine and low-pressure UV were effective in reducing the control and the test isolates, regardless of antibiotic resistance. PAA was successful in reducing the control, but was not able to inactivate the test isolates as well. This was not attributable to antibiotic resistance. No correlation was found between antibiotic resistance and resilience to effects of disinfection treatment.

Other studies have investigated the efficacy of standard disinfection treatments against antibiotic resistant bacteria. It is difficult to directly compare the results of this investigation to these different studies, as the combination of experimental type (bench, pilot or full scale), disinfection treatment (process type, contact time, dose), matrix (wastewater, distilled water, phosphate buffer solution, etc.), bacterial species and antibiotics tested vary greatly (Sharma et al., 2016). Sullivan et al. looked at the effects of chlorine and ultraviolet light on environmental tetracycline resistant bacteria. They observed greater than $5 \log _{10} \mathrm{CFU}$ reduction of E. coli by $0.5 \mathrm{mg} / \mathrm{L}$ and $1 \mathrm{mg} / \mathrm{L}$. Furthermore, a low-pressure UV dose of $69.8 \mathrm{~mJ} / \mathrm{cm}^{2}$ achieved greater than $4 \log _{10}$ CFU reduction (Sullivan et al., 2017). The $\log _{10} \mathrm{CFU}$ 
reduction by low-pressure UV was lower than observed in this study, which could be due to the starting concentration being much higher in the study conducted by Sullivan et al. $\left(10^{9} \mathrm{CFU} / \mathrm{mL}\right.$ versus $10^{7} \mathrm{CFU} / \mathrm{mL}$ in this study). Sullivan et al. took their study a step further and analyzed the regrowth of tetracycline resistant $E$. coli 24 hours after disinfection. While the E. coli exposed to chlorine remained inactivated, those exposed to low-pressure UV experienced significant regrowth, suggesting that chlorine was a more effective treatment in eliminating antibiotic resistant bacteria and mitigating environmental propagation (Sullivan et al., 2017). Zhang et al. tested the effects of low-pressure UV disinfection on a control strain (ATCC 25922) and several multi-drug resistant E. coli. Their initial E. coli concentration was $10^{9} \mathrm{CFU} / 100 \mathrm{~mL}$, and they tested low-pressure UV doses of $4 \mathrm{~mJ} / \mathrm{cm}^{2}$ to $400 \mathrm{~mJ} / \mathrm{cm}^{2}$ with a PBS matrix. They found that the multidrug resistant E. coli survived low-pressure UV better than the antibiotic susceptible E. coli. The susceptible $E$. coli entered the tailing phase at a dose of $8 \mathrm{~mJ} / \mathrm{cm}^{2}$ while the resistant $E$ coli entered the tailing phase at $20 \mathrm{~mJ} / \mathrm{cm}^{2}$. After both types entered the tailing phase there was no difference in inactivation at higher doses of UV. A dose of 20 $\mathrm{mJ} / \mathrm{cm}^{2}$ was used in our study, and similar inactivation rates of the E. coli were observed (Zhang et al., 2017). They attributed the resistance to UV to the production of capsular material by the antimicrobial resistant bacteria. Microbial selfaggregation is caused by the change in surface characteristics and the production of extracellular polymers during UV irradiation, and it is thought to cause the tailing effect observed in UV inactivation experiments (Kollu \& Örmeci, 2015). Production of capsular material slows the self-aggregation process, which could contribute to 
the resistant $E$. coli entering the tailing phase at a higher UV dose (Zhang et al., 2017).

Huang et al. tested the ability of PAA to inactivate bacteria resistant to penicillin, ampicillin, cephalexin, tetracycline, chloramphenicol and rifampicin. They compared the inactivation of the resistant bacteria to susceptible total heterotrophic bacteria (THB) at PAA doses of $0,3,5,8,10$ and $20 \mathrm{mg} / \mathrm{l}$ with a contact time of 10 minutes. The experiment was performed in secondary wastewater effluent. They found that ampicillin, penicillin and cephalexin resistant bacteria were less tolerant to PAA than the THB, while chloramphenicol and rifampicin resistant bacteria showed similar tolerance to PAA as the THB. Tetracycline resistant bacteria were significantly more tolerant to PAA. However, catalase activity was not assayed as in this study, which could potentially cause the tolerance to PAA observed by Huang et al. They also investigated the regrowth of bacteria 22 hours after exposure to PAA, and found that at concentrations less than $8 \mathrm{mg} / \mathrm{L}$ there was significant regrowth of all bacteria tested. Only tetracycline resistant bacteria showed significant regrowth at PAA doses greater than $8 \mathrm{mg} / \mathrm{L}$. (Huang et al., 2013). Other studies on disinfection of antibiotic resistant E. coli using technologies such as solar simulated $\mathrm{N}$-doped $\mathrm{TiO}_{2}$ photocatalysis (L. Rizzo et al., 2014), solar and UV-C driven advanced oxidation with PAA (Luigi Rizzo et al., 2019), UV radiation/chlorine (Luigi Rizzo et al., 2013), and advanced oxidation processes such as ultraviolet $/ \mathrm{H}_{2} \mathrm{O}_{2}$ and ultraviolet/PAA (Luigi Rizzo et al., 2018) have been conducted. Details such as matrix, initial titer, antibiotics, disinfection doses and contact times vary, but overall these studies show that antibiotic resistant $E$. coli can be successfully inactivated 
regardless of antibiotic resistance. No clear link between antibiotic resistance in $E$. coli and tolerance to disinfection treatments has been established. Our study validates these findings, and further reinforces them because of the controls used, such as comparisons to the control and the antibiotic-susceptible test isolate (A), the use of distilled water as a matrix (no interfering substances), the consistent initial titers of all E. coli throughout the study, and the fact that similar $\log _{10} \mathrm{CFU}$ reductions of the control by each treatment type was observed.

\subsection{Part 3: Susceptibility changes in antibiotic resistance profiles versus disinfection treatment, $E$. coli test isolates and antibiotic}

It was determined, based on the changes in antibiotic susceptibility in postdisinfection E. coli picks after the three disinfection processes that all treatment types had similar impacts on the antibiotic resistant profiles of the E. coli test isolates. The proportion of unaffected, increased and decreased antibiotic susceptibility was approximately the same for free chlorine, PAA and low-pressure UV. A change in antibiotic susceptibility (either increased or decreased) was observed in approximately $15 \%$ of the post-disinfection E. coli picks. This shows that exposure to disinfection can cause discernable changes in antibiotic resistance profiles.

From observing the changes in antibiotic susceptibility in post-disinfection E. coli picks for each test isolates, it was determined that the control strain's antibiotic resistance profiles were changed the most, but the changes were all increases in antibiotic susceptibility. Test isolate A was the next most influenced, followed by B, 
$\mathrm{C}$ and $\mathrm{D}$. This trend suggests that the more antibiotic resistant a test isolate is prior to disinfection, the less it's resistance profile will change after exposure to stress. This could be because a test isolate that is displaying multi drug resistance has all of its "defenses" already activated. Test isolate A for example, was a wastewater isolated E. coli that was initially susceptible to all of the tested antibiotics. It is possible that exposure to disinfection may cause the E. coli to express defensive antibiotic resistant genes that it was not otherwise using, causing changes in its resistance profile.

From observing the changes in antibiotic susceptibility in post-disinfection E. coli picks for each tested antibiotic, the majority of zones of inhibition were unchanged from pre to post-disinfection. Ertapenem and imipenem caused the most increases in post-disinfection E. coli pick antibiotic susceptibility. This was expected because they are carbapenem antibiotics that are very effective at inhibiting bacterial growth, and carbapenem resistant genes are rare. Ciprofloxacin, amoxicillin and ceftriaxone showed the most decreases in post disinfection E. coli pick antibiotic susceptibility.

There have been few studies assessing the change in antibiotic resistance profiles of bacteria exposed to disinfection. More commonly there are publications regarding the reduction of antibiotic genes in wastewater, and the change in proportion of those antibiotic resistance genes relative to all other bacterial DNA before and after disinfection (Di Cesare et al., 2016; C. Guo et al., 2017). There have been some reported results of disinfection processes impacting the antibiotic susceptibility of isolated bacteria. 
Zhang et al. reported that $E$. coli susceptible to 9 antibiotics exposed to $80 \mathrm{mj} / \mathrm{cm}^{2}$ low-pressure UV became less susceptible to 6 of the 9 antibiotics used in the study because their zones of inhibition diameters decreased slightly $(\mathrm{P}<0.017)$. The multidrug resistant $E$. coli used in this study was subjected to the same low-pressure UV treatment, but its post disinfection zones of inhibition remained fairly stable. They found that the multidrug resistant $E$. coli strain's resistance profile was more difficult to alter (Zhang et al., 2017). This is similar to the findings from this study, because test isolates $\mathrm{C}$ and $\mathrm{D}$ (multidrug resistant $E$. coli test isolates) did not change their antibiotic susceptibility substantially after exposure to stresses from chlorine, PAA and low-pressure UV. Most changes in susceptibility occurred in the control and $A$, which were the most antibiotic susceptible test isolates. Rizzo et al. looked at the impact solar simulated $\mathrm{N}$-doped $\mathrm{TiO}_{2}$ catalysis had on the antibiotic resistance of isolated $E$. coli. The strains used were resistant to vancomycin, tetracycline and ciprofloxacin, and was susceptible to cefuroxime. $\mathrm{TiO}_{2}$ catalysis achieved a 7- $\log _{10} \mathrm{CFU}$ reduction after 60 minutes of irradiation. The antibiotic resistant profile of the E. coli was evaluated after $0,10,30$, and 45 minutes. They found that susceptibility to tetracycline and vancomycin remained stable throughout the experiment. They observed a consistent slight increase in susceptibility to cefuroxime and ciprofloxacin at each time interval (L. Rizzo et al., 2014). This study showed that susceptibility to some antibiotics could be influenced by exposure to a disinfecting stress, as in our study.

Giovanni et al. determined the impacts that solar disinfection and solar driven advanced oxidation processes had on a multidrug resistant $E$. coli isolated from the 
biological process of an urban wastewater treatment plant. The disinfection processes used were $\mathrm{H}_{2} \mathrm{O}_{2}$ /sunlight, $\mathrm{TiO}_{2}$ /sunlight, $\mathrm{H}_{2} \mathrm{O}_{2} / \mathrm{TiO}_{2}$ /sunlight and natural photo-Fenton. All treatments resulted in a 5 - $\log _{10} \mathrm{CFU}$ reduction. The E. coli was resistant to ampicillin, tetracycline and ciprofloxacin and was susceptible to cefuroxime and nitrofurantoin. They found very little change in the antibiotic resistant profiles of E. coli picks isolated post disinfection. The average diameters of zones of inhibition remained very stable, regardless of whether the E. coli was resistant or susceptible to the antibiotic before disinfection (Ferro et al., 2015). The strain tested was multidrug resistant, and it was difficult to change its antibiotic resistant profile, which was similar to what was observed in our study. Rizzo et al. determined the influences of chlorine and low-pressure UV on the antibiotic resistance profiles of two multidrug resistant E. coli. Both disinfection treatments tested achieved complete inactivation of the two E. coli strains. After low-pressure UV irradiation, they observed an increase in susceptibility to ciprofloxacin, with the minimum inhibiting concentration dropping 33\% and 50\% after 60 minutes and 120 minutes or irradiation, respectively. This implied that the longer the E. coli were subjected to the UV, the more susceptible they became to ciprofloxacin. However, no change in resistance to amoxicillin and sulfamethoxazole was observed. Exposure to free chlorine yielded no change in antibiotic susceptibility for either E. coli strain (Luigi Rizzo et al., 2013). There were no observations of decreased susceptibility to any of the antibiotics in this study, and overall there was very little change in antibiotic susceptibility. 
Venieri et al. investigated the effects of solar photocatalysis on an antibiotic resistant Klebsiella pneumonia in sewage. Klebsiella pneumonia is a Gram-negative bacteria in the same family as E. coli, so it is relevant to compare the results of this study to ours. The disinfection treatments tested were metal-doped $\mathrm{TiO}_{2}$ under artificial and natural sunlight, chlorination and UV-C irradiation, and were conducted in real wastewater. With an initial titer of $10^{7} \mathrm{CFU} / \mathrm{mL}$, they achieved 2-6 $\log _{10} \mathrm{CFU}$ reductions of the isolated bacteria. The antibiotics tested were ampicillin, cefaclor, sulfamethoxazole and tetracycline. Considerable changes in the minimum inhibitory concentration (MIC) levels for cefaclor and tetracycline were observed after exposure to most of the disinfection treatments. For ampicillin, the majority of the treatment processes (including UV and chlorine) lead to an increased MIC from 128 to $256 \mu \mathrm{g} / \mathrm{mL}$, which shows a decrease in susceptibility. However, for cefaclor, a reduction in MIC from 512 to $256 \mu \mathrm{g} / \mathrm{mL}$ was observed after chlorine and UV treatment, showing an increase in susceptibility. There was no observed change in susceptibility to sulfamethoxazole after chlorine and UV treatment. Finally, the susceptibility to tetracycline decreased from 32 to 4 and $2 \mu \mathrm{g} / \mathrm{mL}$ for chlorine and UV, respectively (Venieri et al., 2017). The variable change in the antibiotic susceptibility of Klebsiella pneumonia in this study is similar to what was observed in our study with test isolates of $E$. coli. This study did use a different method of characterizing resistance, the MIC method, whereas the Kirby-Bauer disk diffusion method was used in ours. The same general patterns were observed however, with a distribution of increased, decreased and stable antibiotic sensitivities. 
From observing the results from our study regarding changes in antibiotic resistance profiles after exposure to disinfection, and comparing these results to other studies using a variety of disinfection treatments, matrices, antibiotics, and bacteria, it can be deduced that there is a wide variation in antibiotic susceptibility response after exposure to stress. Although there were cases of increased susceptibility to antibiotics, there were also cases of decreased susceptibility. This study and the ones referenced above highlight the importance of completely removing antibiotic resistant bacteria from wastewater/water before discharging to the receiving environment or distribution to the public, to mitigate any health risk that exposure to the public may cause.

\subsection{Part 4: Significant susceptibility changes in post-disinfection $E$. coli picks causing reclassification of antibiotic resistance}

Many of the resistance classification changes were caused by a very subtle change in zone of inhibition diameter. For example, test isolate D had 3 observed classification changes for imipenem from intermediate to resistant, but the actual change in zone of inhibition diameter was less than $1 \mathrm{~mm}$. A recorded classification change like this could be caused by measurement error, but the Kirby Bauer disk diffusion ranges for susceptible, intermediate and resistant have been created to account for small measurement errors. In this study the same measuring instrument was used in the same lighting with the same person recording measurements throughout in order to maintain consistency and minimize errors. Also of note is the case of the control changing from susceptible to intermediate resistance to ceftriaxone. It was unexpected, as the control should not have any dormant antibiotic resistant genes 
that could be stimulated by exposure to disinfection treatment. It is possible, however, that this shift in resistance classification could be attributable to adaptations executed by the control, for example, up-regulating efflux pumps or reducing porin size. It is unlikely that the control contained genes that coded for, for example, an enzyme like beta-lactamase.

There were multiple changes in resistance classification that involved large decreases in zone of inhibition. For example, test isolate $\mathrm{C}$ went from susceptible to resistant to amoxicillin, with the measured diameter decreasing from $18.83 \pm 0.75$ $\mathrm{mm}$ to $0 \mathrm{~mm}$. This is a drastic increase in resistance to amoxicillin after exposure to stress from disinfection treatment.

Bacteria are able to respond to genotoxic stress such as disinfection treatment. This response can employ a variety of mechanisms such as, rearrange and mutate their genome, induce several phenotypic changes through differential regulation of genes, and sometimes acquire characteristics that can lead to better survival and adapt to changing environments. This response to genotoxic stress can be initiated by something called an SOS response, which is a broad regulatory network in most bacterial species used to address damage to DNA (Baharoglu \& Mazel, 2014). The sudden change in resistance classification after exposure to disinfection treatment observed in this study could be attributable to this mechanism. Potentially, when $E$. coli are exposed to stress their DNA regulation changes to defend itself, and possibly causes expression of genes that were dormant before. To confirm whether something like this had occurred, gene expression analysis would have had to be done. For example, if an E. coli isolate was susceptible to imipenem before 
disinfection and resistant to it post disinfection, it is possible it contained genes responsible for imipenem resistance that were not being expressed until induced by exposure to stress.

Overall, there were very few cases of classification change within the entire body of results, with only 16 observed classification changes in 1050 results (1.52\%). This shows that the large majority of the E. coli tested after disinfection did not drastically increase their resistance to the antibiotics used. Conversely, it is important to note that of 1050 results there was not a single case of an increased susceptibility classification change. 


\section{Conclusions}

This study investigated the prevalence of antibiotic resistant $E$. coli in secondary wastewater effluent and the effects of chlorine, PAA and low pressure UV on antibiotic resistant and susceptible $E$. coli with regards to their inactivation and changes in their Kirby Bauer resistance profiles. The following conclusions can be drawn from the results of this study:

1. Antibiotic resistant $E$. coli were very prevalent in secondary wastewater. The E. coli isolates were found to commonly be resistant to at least one antibiotic. $8 \%$ of the isolated E. coli were multidrug resistant. This reinforces what the current literature on this topic has concluded, and adds to the database of phenotypic antibiotic resistance analysis. This also supports the concept of wastewater treatment plants acting as a "hot spot" for antibiotic resistant bacteria, where they could potentially be exchanging genetic information that confers resistance to antibiotics.

2. At the disinfection doses used in this study, the antibiotic resistant E. coli did not survive exposure to chlorine or low pressure UV better than the control. The isolated E. coli did survive PAA better than the control, but this was attributed to them containing the catalase enzyme, not antibiotic resistance.

3. There was no relationship between greater resistance to antibiotics and greater survival of disinfection exposure. For example, the multidrug resistant test isolate D did not survive exposure to disinfection any better than the susceptible test isolate A. At the disinfection doses tested in this 
study, antibiotic resistant bacteria did not have any competitive advantage over susceptible bacteria.

4. There were few significant changes in zones of inhibition measured before and after disinfection for the control and the four test isolate E. coli, with all three disinfection treatments. However, the majority of zones of inhibition did not change after disinfection. There were a few cases (1.5\% of results) of very significant increases in resistance, causing reclassification of resistance category. There were no increases in susceptibility causing reclassification. This implies that exposure to disinfection can influence the expression and suppression of defensive mechanisms to antibiotics in E. coli.

5. Chlorine, PAA and low pressure UV all triggered similar proportions of increases, decreases and no change in antibiotic susceptibility. There were very few decreases in susceptibility to the carbapenem antibiotics observed. The other five antibiotics caused similar proportions of increases, decreases and no change in antibiotic susceptibility. The more resistant the E. coli isolate was, the less it seemed its resistance profile could be influenced.

Future work on this study could include sequencing the DNA of the $E$. coli isolates to determine what antibiotic genes may or may not have been present. The sequenced DNA could also be compared to the Kirby Bauer resistance profiles to reinforce their validity. This would help answer the question of whether or not disinfection can cause $E$. coli to turn on otherwise unused genes. The same experiment could be conducted using a wider range of doses for each disinfection treatment to see if that 
could cause different outcomes. It would also be worth investigating the regrowth of E. coli isolates after disinfection, and test their antibiotic resistance. 


\section{References}

A.W. Bauer, W. M. Kirby, J. C. Sherris, M. T. (1966). Antibiotic susceptibility testing by a standardized single disk method. The American Journal of Clinical Pathology, 45(4).

Arber, W. (2014). Horizontal Gene Transfer among Bacteria and Its Role in Biological Evolution. Life, 4, 217-224. https://doi.org/10.3390/life4020217

Aslan, A., Cole, Z., Bhattacharya, A., \& Oyibo, O. (2018). Presence of antibioticresistant Escherichia coli in wastewater treatment plant effluents utilized as water reuse for irrigation. Water (Switzerland), 10(6). https://doi.org/10.3390/w10060805

Baeza, S., Vejar, N., Gulppi, M., Azocar, M., Melo, F., Monsalve, A., ... Páez, M. A. (2013). New evidence on the role of catalase in Escherichia coli-mediated biocorrosion. Corrosion Science, 67, 32-41. https://doi.org/10.1016/j.corsci.2012.09.047

Baharoglu, Z., \& Mazel, D. (2014). SOS, the formidable strategy of bacteria against aggressions. FEMS Microbiology Reviews, 38(6), 1126-1145. https://doi.org/10.1111/1574-6976.12077

Bergeron, S., Boopathy, R., Nathaniel, R., Corbin, A., \& LaFleur, G. (2015). Presence of antibiotic resistant bacteria and antibiotic resistance genes in raw source water and treated drinking water. International Biodeterioration and Biodegradation, 102, 370-374. https://doi.org/10.1016/j.ibiod.2015.04.017

Blaak, H., De Kruijf, P., Hamidjaja, R. A., Van Hoek, A. H. A. M., De Roda Husman, A. M., \& Schets, F. M. (2014). Prevalence and characteristics of ESBL-producing E. coli in Dutch recreational waters influenced by wastewater treatment plants. 
Veterinary Microbiology, 171(3-4), 448-459.

https://doi.org/10.1016/j.vetmic.2014.03.007

Blair, J. M. A., Webber, M. A., Baylay, A. J., Ogbolu, D. O., \& Piddock, L. J. V. (2014).

Molecular mechanisms of antibiotic resistance. Nature Publishing Group, 13(1), 42-51. https://doi.org/10.1038/nrmicro3380

Bolton, J. R., Beck, S. E., Linden, K. G., Cres, C., \& Tr, C. (2016). Protocol for the Determination of Fluence ( UV Dose ) Using A Low-Pressure or Low-Pressure High-Output UV Lamp in Bench-Scale Collimated Beam Ultraviolet Experiments, (2003).

Bolton, J. R., Linden, K. G., \& Asce, M. (2003). Standardization of Methods for Fluence (UV Dose) Determination in Bench-Scale UV Experiments. Journal of Environmental Engineering, (March), 209-216.

Bouki, C., Venieri, D., \& Diamadopoulos, E. (2013). Detection and fate of antibiotic resistant bacteria in wastewater treatment plants: A review. Ecotoxicology and Environmental Safety, 91, 1-9. https://doi.org/10.1016/j.ecoenv.2013.01.016

Bush, K., Jacoby, G. A., \& Medeiros, A. A. (1995). Mini Review: A Functional Classification Scheme for Lactamases and Its Correlation with Molecular Structure, 39(6), 1211-1233.

Cantón, R., Akóva, M., Carmeli, Y., Giske, C. G., Glupczynski, Y., Gniadkowski, M., ... Cornaglia, G. (2012). Rapid evolution and spread of carbapenemases among Enterobacteriaceae in Europe. Clinical Microbiology and Infection, 18(5), 413431. https://doi.org/10.1111/j.1469-0691.2012.03821.x CDC. (2013). Antibiotic Resistance Threats. Cdc, 22-50. https://doi.org/CS239559-B 
Chopra, I., \& Roberts, M. (2001). Tetracycline Antibiotics : Mode of Action, Applications , Molecular Biology , and Epidemiology of Bacterial Resistance. Microbiology and Molecular Biology Reviews, 65(2), 232-260. https://doi.org/10.1128/MMBR.65.2.232

Collivignarelli, M. C., Abba, A., Benigna, I., Sorlini, S., \& Toretta, V. (2018). Overview of the Main Disinfection Processes for Wastewater and Drinking Water Treatment Plants. Sustainability, 10, 1-21. https://doi.org/10.3390/su10010086

Davies, J., \& Davies, D. (2010). Origins and Evolution of Antibiotic Resistance. Microbiology and Molecular Biology Reviews, 74(3), 417-433. https://doi.org/10.1128/MMBR.00016-10

Di Cesare, A., Fontaneto, D., Doppelbauer, J., \& Corno, G. (2016). Fitness and Recovery of Bacterial Communities and Antibiotic Resistance Genes in Urban Wastewaters Exposed to Classical Disinfection Treatments. Environmental Science and Technology, 50(18), 10153-10161. https://doi.org/10.1021/acs.est.6b02268

Etebu, E., \& Arikekpar, I. (2016). Antibiotics : Classification and mechanisms of action with emphasis on molecular perspectives. International Journal of Applied Microbiology and Biotechnology Research, 4, 90-101.

European Food Safety Authority, \& European Centre for Disease Prevention and Control. (2017). The European Union summary report on antimicrobial resistance in zoonotic and indicator bacteria from humans, animals and food in 2015. EFSA Journal, 15(January). https://doi.org/10.2903/j.efsa.2017.4694 
Feng, P. C. S., \& Hartman, P. A. (1982). Fluorogenic assays for immediate confirmation of Escherichia coli. Applied and Environmental Microbiology, 43(6), 1320-1329.

Ferro, G., Fiorentino, A., Alferez, M. C., Polo-López, M. I., Rizzo, L., \& FernándezIbáñez, P. (2015). Urban wastewater disinfection for agricultural reuse: effect of solar driven AOPs in the inactivation of a multidrug resistant E. coli strain. Applied Catalysis B: Environmental, 178, 65-73. https://doi.org/10.1016/j.apcatb.2014.10.043

Fiorentino, A., Ferro, G., Alferez, M. C., Polo-López, M. I., Fernández-Ibañez, P., \& Rizzo, L. (2015). Inactivation and regrowth of multidrug resistant bacteria in urban wastewater after disinfection by solar-driven and chlorination processes. Journal of Photochemistry and Photobiology B: Biology, 148, 43-50. https://doi.org/10.1016/j.jphotobiol.2015.03.029

Forsberg, K. J., Reyes, A., Wang, B., Selleck, E. M., Sommer, M. O. A., \& Dantas, G. (2012). The Shared Antibiotic Resistome of Soil Bacteria and Human Pathogens. Science, 337(August), 1107-1112.

Furuya, E. Y., \& Lowy, F. D. (2006). Antimicrobial-resistant bacteria in the community setting. Nature Reviews, 4(January). https://doi.org/10.1038/nrmicro1325

Gehr, R., Wagner, M., Veerasubramanian, P., \& Payment, P. (2003). Disinfection efficiency of peracetic acid, UV and ozone after enhanced primary treatment of municipal wastewater. Water Research, 37(19), 4573-4586. https://doi.org/10.1016/S0043-1354(03)00394-4 
Gothwal, R., \& Shashidhar, T. (2015). Antibiotic Pollution in the Environment: A Review. Clean - Soil, Air, Water, 43(4), 479-489. https://doi.org/10.1002/clen.201300989

Guo, C., Wang, K., Hou, S., Wan, L., Lv, J., Zhang, Y., ... Xu, J. (2017). H2O2 and/or TiO2photocatalysis under UV irradiation for the removal of antibiotic resistant bacteria and their antibiotic resistance genes. Journal of Hazardous Materials, 323, 710-718. https://doi.org/10.1016/j.jhazmat.2016.10.041

Guo, J., Li, J., Chen, H., Bond, P. L., \& Yuan, Z. (2017). Metagenomic analysis reveals wastewater treatment plants as hotspots of antibiotic resistance genes and mobile genetic elements. Water Research, 123, 468-478. https://doi.org/10.1016/j.watres.2017.07.002

Harris, S., Morris, C., Morris, D., Cormican, M., \& Cummins, E. (2014). Antimicrobial resistant Escherichia coli in the municipal wastewater system: Effect of hospital effluent and environmental fate. Science of the Total Environment, 468-469, 1078-1085. https://doi.org/10.1016/j.scitotenv.2013.09.017

Hijnen, W. A. M. Ã., Beerendonk, E. F., \& Medema, G. J. (2006). Inactivation credit of UV radiation for viruses, bacteria and protozoan ( oo ) cysts in water : A review. Water Research, 40, 3-22.

https://doi.org/10.1016/j.watres.2005.10.030

Hollis, A., \& Ahmed, Z. (2013). Preserving Antibiotics, Rationally. New England Journal of Medicine, 369(26), 2472-2474. https://doi.org/10.1056/nejmp1312654

Hua, G., \& Reckhow, D. A. (2007). Comparison of disinfection byproduct formation 
from chlorine and alternative disinfectants. Water Research, 41, 1667-1678. https://doi.org/10.1016/j.watres.2007.01.032

Huang, J. J., Xi, J. Y., Hu, H. Y., Tang, F., \& Pang, Y. C. (2013). Inactivation and regrowth of antibiotic-resistant bacteria by peracetic acid disinfection in the secondary effluent of a municipal wastewater treatment plant. Biomedical and Environmental Sciences : BES, 26(10), 865-868. https://doi.org/10.3967/bes2013.012

Igwaran, A., Iweriebor, B. C., \& Okoh, A. I. (2018). Molecular characterization and antimicrobial resistance pattern of Escherichia coli recovered from wastewater treatment plants in Eastern Cape South Africa. International Journal of Environmental Research and Public Health, 15(6). https://doi.org/10.3390/ijerph15061237

Jenks, P. J., Akalin, E., Bergan, T., Dornbusch, K., Howard, A. J., Hryniewicz, W., ... Williams, J. D. (1998). Susceptibility testing of Klebsiella spp.—an international collaborative study in quality assessment. Journal of Antimicrobial Chemotherapy, 42, 29-48.

Jensen, J. N. (2010). Disinfection model based on excess inactivation sites: Implications for linear disinfection curves and the Chick-Watson dilution coefficient. Environmental Science and Technology, 44(21), 8162-8168. https://doi.org/10.1021/es101818z

Jorgensen, J. H., \& Ferraro, M. J. (2009). Antimicrobial Susceptibility Testing: A Review of General Principles and Contemporary Practices. Medical Microbiology, 49, 1749-1755. https://doi.org/10.1086/647952 
Kenton, W. (2019). T-test Definition.

Kitis, M. (2004). Disinfection of wastewater with peracetic acid : a review. Environment International, 30, 47-55. https://doi.org/10.1016/S01604120(03)00147-8

Kollu, K., \& Örmeci, B. (2015). UV-induced self-aggregation of E. coli after low and medium pressure ultraviolet irradiation. Journal of Photochemistry and Photobiology B: Biology, 148, 310-321. https://doi.org/10.1016/j.jphotobiol.2015.04.013

Kumar, A., \& Pal, D. (2018). Antibiotic resistance and wastewater: Correlation, impact and critical human health challenges. Journal of Environmental Chemical Engineering, 6(1), 52-58. https://doi.org/10.1016/j.jece.2017.11.059

Kümmerer, K. (2009). Antibiotics in the aquatic environment - A review - Part I. Chemosphere, 75(4), 417-434. https://doi.org/10.1016/j.chemosphere.2008.11.086

Levy, S. B., \& Marshall, B. (2004). Antibacterial resistance worldwide: causes , challenges and responses. Nature Medicine, 10(12), 122-129. https://doi.org/10.1038/nm1145

Łuczkiewicz, A., Jankowska, K., Fudala-Ksiazek, S., \& Olańczuk-Neyman, K. (2010). Antimicrobial resistance of fecal indicators in municipal wastewater treatment plant. Water Research, 44(17), 5089-5097. https://doi.org/10.1016/j.watres.2010.08.007 McDonald, J. H. (2014). Handbook of Biological Statistics (Third). Baltimore, Maryland, U.S.A.: Sparky House Publishing. Retrieved from 
http://www.biostathandbook.com/permissions.html for

Metcalf \& Eddy. (2014). Wastewater Engineering: Treatment and resource recovery, fifth edition. (George Tchobanoglous, D. H. Stensel, R. Tsuchihashi, \& F. Burton, Eds.) (5th ed.). New York: McGraw-Hill Education.

Mezzanotte, V., Citterio, S., Antonelli, M., \& Nurizzo, C. (2007). Wastewater

Disinfection Alternatives : Chlorine, Ozone, Peracetic Acid, and UV Light. Water Environment Research, (December 2007). https://doi.org/10.2175/106143007X183763

Michael, I., Rizzo, L., McArdell, C. S., Manaia, C. M., Merlin, C., Schwartz, T., ... FattaKassinos, D. (2013). Urban wastewater treatment plants as hotspots for the release of antibiotics in the environment: A review. Water Research, 47(3), 957995. https://doi.org/10.1016/j.watres.2012.11.027

Mofidi, A. A., Meyer, E. A., Wallis, P. M., Chou, C. I., Meyer, B. P., Ramalingam, S., \& Coffey, B. M. (2002). The effect of UV light on the inactivation of Giardia lamblia and Giardia muris cysts as determined by animal infectivity assay ( P-2951-01 J. Water Research, 36, 2098-2108.

Munita, J. M., Arias, C. A., Unit, A. R., \& Santiago, A. De. (2016). Mechanisms of Antibiotic Resistance. Microbiol Spectr., 4(2), 1-37. https://doi.org/10.1128/microbiolspec.VMBF-0016-2015.Mechanisms Nordmann, P., \& Poirel, L. (2014). The difficult-to-control spread of carbapenemase producers among Enterobacteriaceae worldwide. Clinical Microbiology and Infection, 20(9), 821-830. https://doi.org/10.1111/1469-0691.12719 O'Neill, J. (2016). Tackling Drug-Resistant Infections Globally: Final Report and 
Recommendations. The Review on Antimicrobial Resistance. London, United Kingdom. https://doi.org/10.1016/j.jpha.2015.11.005

Odonkor, S. T., \& Addo, K. K. (2018). Prevalence of Multidrug-Resistant Escherichia coli Isolated from Drinking Water Sources. International Journal of Microbiology, 2018, 1-7. https://doi.org/10.1155/2018/7204013

Odonkor, S. T., \& Ampofo, J. K. (2013). Escherichia coli as an indicator of bacteriological quality of water : an overview. Microbiology Research, 4, 5-11. https://doi.org/10.4081/mr.2013.e2

Papp-Wallace, K. M., Endimiani, A., Taracila, M. A., \& Bonomo, R. A. (2011).

Carbapenems: Past, present, and future. Antimicrobial Agents and Chemotherapy, 55(11), 4943-4960. https://doi.org/10.1128/AAC.00296-11

Patel, J., Cockerill, F., \& Bradford, P. (2013). Performance Standards for Antimicrobial Susceptibility Testing; Twenty-Third Informational Supplement. Clinical and Laboratory Standards Institute (23rd ed.). Wayne, PA. https://doi.org/10.1126/science.273.5271.122

Pillay, L., \& Olaniran, A. O. (2016). Assessment of physicochemical parameters and prevalence of virulent and multiple-antibiotic-resistant Escherichia coli in treated effluent of two wastewater treatment plants and receiving aquatic milieu in Durban, South Africa. Environmental Monitoring and Assessment, 188(5). https://doi.org/10.1007/s10661-016-5232-4

Poirel, L., Brinas, L., Verlinde, A., Ide, L., \& Nordmann, P. (2005). BEL-1 , a Novel Clavulanic Acid-Inhibited Extended-Spectrum " ${ }_{\llcorner}$-Lactamase , and the Class 1 Integron In120 in Pseudomonas aeruginosa. Antimicrobial Agents and 
Chemotherapy, 49(9), 3743-3748. https://doi.org/10.1128/AAC.49.9.3743

Rebhun, M., Heller-grossman, L., \& Manka, J. (1993). Formation of disinfection byproducts during chlorination of secondary effluent and renovated water. Water Environment Research, 69(6). https://doi.org/10.2175/106143097X125902

Rijal, N. (2018). Spread Plate Technique: Principle, Procedure and Results. Retrieved February 8, 2019, from https://microbeonline.com/spread-plate-techniqueprinciple-procedure-results/

Rizzo, L., Manaia, C., Merlin, C., Schwartz, T., Dagot, C., Ploy, M. C., ... Fatta-Kassinos, D. (2013). Urban wastewater treatment plants as hotspots for antibiotic resistant bacteria and genes spread into the environment: A review. Science of the Total Environment, 447, 345-360.

https://doi.org/10.1016/j.scitotenv.2013.01.032

Rizzo, L., Sannino, D., Vaiano, V., Sacco, O., Scarpa, A., \& Pietrogiacomi, D. (2014). Effect of solar simulated N-doped TiO2photocatalysis on the inactivation and antibiotic resistance of an E. coli strain in biologically treated urban wastewater. Applied Catalysis B: Environmental, 144, 369-378. https://doi.org/10.1016/j.apcatb.2013.07.033

Rizzo, Luigi, Agovino, T., Nahim-Granados, S., Castro-Alférez, M., Fernández-Ibáñez, P., \& Polo-López, M. I. (2019). Tertiary treatment of urban wastewater by solar and UV-C driven advanced oxidation with peracetic acid: Effect on contaminants of emerging concern and antibiotic resistance. Water Research, 149, 272-281. https://doi.org/10.1016/j.watres.2018.11.031 
Rizzo, Luigi, Fiorentino, A., \& Anselmo, A. (2013). Advanced treatment of urban wastewater by UV radiation: Effect on antibiotics and antibiotic-resistant E. coli strains. Chemosphere, 92(2), 171-176.

https://doi.org/10.1016/j.chemosphere.2013.03.021

Rizzo, Luigi, Lofrano, G., Gago, C., Bredneva, T., Iannece, P., Pazos, M., ... Carotenuto, M. (2018). Antibiotic contaminated water treated by photo driven advanced oxidation processes: Ultraviolet/H202vs ultraviolet/peracetic acid. Journal of Cleaner Production, 205, 67-75. https://doi.org/10.1016/j.jclepro.2018.09.101

Sabaté, M., Prats, G., Moreno, E., Ballesté, E., Blanch, A. R., \& Andreu, A. (2008). Virulence and antimicrobial resistance profiles among Escherichia coli strains isolated from human and animal wastewater. Research in Microbiology, 159(4), 288-293. https://doi.org/10.1016/j.resmic.2008.02.001

Sharma, V. K., Johnson, N., Cizmas, L., McDonald, T. J., \& Kim, H. (2016). A review of the influence of treatment strategies on antibiotic resistant bacteria and antibiotic resistance genes. Chemosphere, 150, 702-714. https://doi.org/10.1016/j.chemosphere.2015.12.084

Standard Methods. (1999). Standard Methods for the Examination of Water and Wastewater Standard Methods for the Examination of Water and Wastewater.

Sullivan, B. A., Vance, C. C., Gentry, T. J., \& Karthikeyan, R. (2017). Effects of chlorination and ultraviolet light on environmental tetracycline-resistant bacteria and tet(W) in water. Journal of Environmental Chemical Engineering, 5(1), 777-784. https://doi.org/10.1016/j.jece.2016.12.052

Tchobanoglous, G., Burton, F. L., \& Stensel, H. D. (2003). Wastewater Engineering: 
Treatment and reuse (4th ed.). New York: Metcalf and Eddy, Inc.

Van Hoek, A. H. A. M., Mevius, D., Guerra, B., Mullany, P., Roberts, A. P., \& Aarts, H. J. M. (2011). Acquired antibiotic resistance genes- an overview. Frontiers in Microbiology, 2(203). https://doi.org/10.3389/fmicb.2011.00203

Venieri, D., Gounaki, I., Bikouvaraki, M., Binas, V., Zachopoulos, A., Kiriakidis, G., \& Mantzavinos, D. (2017). Solar photocatalysis as disinfection technique: Inactivation of Klebsiella pneumoniae in sewage and investigation of changes in antibiotic resistance profile. Journal of Environmental Management, 195, 140147. https://doi.org/10.1016/j.jenvman.2016.06.009

Ventola, C. L. (2015). The antibiotic resistance crisis. Part 1: causes and threats. P\&T: A Peer-Reviewed Journal for Formulary Management, 40(4). https://doi.org/Article

Wagner, M., Brumelis, D., \& Gehr, R. (2002). Disinfection of Wastewater by Hydrogen Peroxide or Peracetic Acid : Development of Procedures for Measurement of Residual Disinfectant and Application to a Physicochemically Treated Municipal Effluent. Water Environment Research, 74(February), 33-50.

https://doi.org/10.2175/106143002X139730

WHO. (2014). Antimicrobial resistance: Global Health Report on Surveillance. Bulletin of the World Health Organization, 1-256. https://doi.org/10.1007/s13312-014-0374-3

Zanotto, C., Bissa, M., Illiano, E., Mezzanotte, V., Marazzi, F., Turolla, A., ... Radaelli, A. (2016). Identification of antibiotic-resistant Escherichia coli isolated from a municipal wastewater treatment plant. Chemosphere, 164, 627-633. 
https://doi.org/10.1016/j.chemosphere.2016.08.040

Zhang, C. M., Xu, L. M., Wang, X. C., Zhuang, K., \& Liu, Q. Q. (2017). Effects of ultraviolet disinfection on antibiotic-resistant Escherichia coli from wastewater: inactivation, antibiotic resistance profiles and antibiotic resistance genes. Journal of Applied Microbiology, 123(1), 295-306. https://doi.org/10.1111/jam.13480 


\section{Appendix}

Table 7.1: Control strain zones of inhibition before and after disinfection treatment in millimeters

\begin{tabular}{|c|c|c|c|c|c|c|c|}
\hline Zone Measured & ERT & IPM & AMC & CRO & TET & AZM & CIP \\
\hline Before Disinfection & $\begin{array}{l}28.67 \\
\pm 1.03 \\
\end{array}$ & $\begin{array}{l}24.83 \\
\pm 0.75 \\
\end{array}$ & $\begin{array}{l}19.5 \pm \\
1.22\end{array}$ & $\begin{array}{l}27.17 \\
\pm 0.98 \\
\end{array}$ & $\begin{array}{l}20.83 \\
\pm 0.41 \\
\end{array}$ & $\begin{array}{l}21.83 \\
\pm 0.41 \\
\end{array}$ & $\begin{array}{l}31.67 \\
\pm 1.75 \\
\end{array}$ \\
\hline $\begin{array}{l}\text { After Chlorine } \\
\text { Exposure }\end{array}$ & $\begin{array}{l}30.6 \pm \\
1.07 \\
\end{array}$ & $\begin{array}{l}25.7 \pm \\
1.25\end{array}$ & $\begin{array}{l}19.95 \\
\pm 0.76 \\
\end{array}$ & $\begin{array}{l}28.6 \pm \\
2.07\end{array}$ & $\begin{array}{l}21.6 \pm \\
0.52\end{array}$ & $\begin{array}{l}22 \pm \\
0.82\end{array}$ & $\begin{array}{l}32.8 \pm \\
1.48\end{array}$ \\
\hline After PAA Exposure & $\begin{array}{l}30 \pm \\
1.83\end{array}$ & $\begin{array}{l}25.9 \pm \\
1.2\end{array}$ & $\begin{array}{l}19.8 \pm \\
0.92\end{array}$ & $\begin{array}{l}27.9 \pm \\
2.38\end{array}$ & $\begin{array}{l}20.9 \pm \\
0.88\end{array}$ & $\begin{array}{l}23 \pm \\
0.82\end{array}$ & $\begin{array}{l}32.5 \pm \\
0.85\end{array}$ \\
\hline $\begin{array}{l}\text { After Low-pressure } \\
\text { UV Exposure }\end{array}$ & $\begin{array}{l}30.2 \pm \\
1.55\end{array}$ & $\begin{array}{l}25.4 \pm \\
0.97\end{array}$ & $\begin{array}{l}20.1 \pm \\
0.88\end{array}$ & $\begin{array}{l}28.7 \pm \\
1.16\end{array}$ & $\begin{array}{l}20.9 \pm \\
0.74\end{array}$ & $\begin{array}{l}22.8 \pm \\
0.79\end{array}$ & $\begin{array}{l}33.5 \pm \\
1.27\end{array}$ \\
\hline
\end{tabular}

Table 7.2: Test isolate A Zones of inhibition before and after disinfection treatment in millimeters

\begin{tabular}{|c|c|c|c|c|c|c|c|}
\hline Zone Measured & ERT & IPM & AMC & CRO & TET & AZM & CIP \\
\hline Before Disinfection & $\begin{array}{l}28.5 \pm \\
0.55\end{array}$ & $\begin{array}{l}23.33 \\
\pm 0.52\end{array}$ & $\begin{array}{l}19 \pm \\
0.63\end{array}$ & $\begin{array}{l}25.5 \pm \\
0.84\end{array}$ & $\begin{array}{l}18.83 \\
\pm 0.98\end{array}$ & $\begin{array}{l}22 \pm \\
1.1\end{array}$ & $\begin{array}{l}30.5 \pm \\
0.55\end{array}$ \\
\hline $\begin{array}{l}\text { After Chlorine } \\
\text { Exposure }\end{array}$ & $\begin{array}{l}29.4 \pm \\
0.84 \\
\end{array}$ & $\begin{array}{l}23.3 \pm \\
0.95\end{array}$ & $\begin{array}{l}19.4 \pm \\
0.7 \\
\end{array}$ & $\begin{array}{l}26.2 \pm \\
1.69 \\
\end{array}$ & $\begin{array}{l}18.5 \pm \\
0.85\end{array}$ & $\begin{array}{l}21.8 \pm \\
1.32 \\
\end{array}$ & $\begin{array}{l}29.4 \pm \\
1.71\end{array}$ \\
\hline After PAA Exposure & $\begin{array}{l}27.9 \pm \\
0.74\end{array}$ & $\begin{array}{l}23 \pm \\
1.56\end{array}$ & $\begin{array}{l}18.8 \pm \\
0.79\end{array}$ & $\begin{array}{l}25.9 \pm \\
1.2\end{array}$ & $\begin{array}{l}17.9 \pm \\
1.1\end{array}$ & $\begin{array}{l}21.5 \pm \\
1.84\end{array}$ & $\begin{array}{l}28.9 \pm \\
2.08\end{array}$ \\
\hline $\begin{array}{l}\text { After Low-pressure } \\
\text { UV Exposure }\end{array}$ & $\begin{array}{l}29.2 \pm \\
0.63\end{array}$ & $\begin{array}{l}24 \pm \\
1.41\end{array}$ & $\begin{array}{l}19.4 \pm \\
0.7\end{array}$ & $\begin{array}{l}26.6 \pm \\
0.84\end{array}$ & $\begin{array}{l}19.9 \pm \\
3.32\end{array}$ & $\begin{array}{l}22.3 \pm \\
1.89\end{array}$ & $\begin{array}{l}30 \pm \\
0.67\end{array}$ \\
\hline
\end{tabular}


Table 7.3: Test isolate B Zones of inhibition before and after disinfection treatment in millimeters

\begin{tabular}{|l|l|l|l|l|l|l|l|}
\hline Zone Measured & ERT & IPM & AMC & CRO & TET & AZM & CIP \\
\hline Before Disinfection & $29.5 \pm$ & 25.67 & 21.33 & 28.17 & $21.5 \pm$ & $10.5 \pm$ & 14.33 \\
& 0.55 & \pm 0.82 & \pm 0.52 & \pm 1.47 & 0.55 & 1.05 & \pm 0.52 \\
\hline & $31.1 \pm$ & $26.2 \pm$ & $21.6 \pm$ & $29.5 \pm$ & $22.3 \pm$ & $10.2 \pm$ & $14.4 \pm$ \\
After Chlorine & 0.99 & 1.03 & 0.52 & 1.35 & 0.67 & 0.63 & 0.52 \\
Exposure & & & & & & & \\
\hline & & & & & & \\
After PAA Exposure & $29.7 \pm$ & $25.9 \pm$ & $20.5 \pm$ & $28 \pm$ & $21.8 \pm$ & $10 \pm 0$ & $13.9 \pm$ \\
& 0.67 & 1.6 & 0.53 & 0.94 & 0.92 & & 0.32 \\
\hline & & & & & & & \\
After Low-pressure & $30 \pm$ & $26.2 \pm$ & $21.7 \pm$ & $28.1 \pm$ & $22.4 \pm$ & $9.4 \pm$ & $14.3 \pm$ \\
UV Exposure & 0.82 & 0.63 & 0.67 & 1.1 & 1.78 & 1.07 & 0.48 \\
\hline
\end{tabular}

Table 7.4: Test isolate $C$ Zones of inhibition before and after disinfection treatment in millimeters

\begin{tabular}{|l|l|l|l|l|l|l|l|}
\hline Zone Measured & ERT & IPM & AMC & CRO & TET & AZM & CIP \\
\hline Before Disinfection & 27.33 & 23.67 & 18.83 & $9.17 \pm$ & $3.5 \pm$ & 10.33 & $0 \pm 0$ \\
& \pm 1.03 & \pm 0.52 & \pm 0.75 & 0.41 & 3.83 & \pm 0.52 & \\
\hline $\begin{array}{l}\text { After Chlorine } \\
\text { Exposure }\end{array}$ & $26.6 \pm$ & $24.3 \pm$ & $16.8 \pm$ & $7.1 \pm$ & $0.7 \pm$ & $8.1 \pm$ & $0 \pm 0$ \\
\hline & 1.96 & 0.95 & 6.07 & 3.81 & 2.21 & 4.28 & \\
After PAA Exposure & $28.2 \pm$ & $24.9 \pm$ & $18.8 \pm$ & $9 \pm$ & $6.3 \pm$ & $10.5 \pm$ & $0 \pm 0$ \\
& 0.63 & 0.57 & 0.63 & 0.47 & 2.21 & 0.53 & \\
\hline & & & 19.15 & $8.2 \pm$ & $6.3 \pm$ & $10.1 \pm$ & $0 \pm 0$ \\
After Low-pressure \\
UV Exposure
\end{tabular}


Table 7.5: Test isolate D Zones of inhibition before and after disinfection treatment in millimeters

\begin{tabular}{|l|l|l|l|l|l|l|l|}
\hline Zone Measured & ERT & IPM & AMC & CRO & TET & AZM & CIP \\
\hline Before Disinfection & $\begin{array}{l}23.67 \\
\pm 0.52\end{array}$ & $\begin{array}{l}19.92 \\
\pm 0.49\end{array}$ & $\begin{array}{l}2.33 \pm \\
3.61\end{array}$ & $\begin{array}{l}1.83 \pm \\
4.49\end{array}$ & $0 \pm 0$ & $0 \pm 0$ & $0 \pm 0$ \\
\hline $\begin{array}{l}\text { After Chlorine } \\
\text { Exposure }\end{array}$ & $\begin{array}{l}23.3 \pm \\
1.89\end{array}$ & $\begin{array}{l}20.7 \pm \\
0.86\end{array}$ & $0 \pm 0$ & $0 \pm 0$ & $0 \pm 0$ & $0 \pm 0$ & $0 \pm 0$ \\
\hline After PAA Exposure & $\begin{array}{l}23.9 \pm \\
0.57\end{array}$ & $\begin{array}{l}20.8 \pm \\
0.42\end{array}$ & $\begin{array}{l}4.2 \pm \\
3.61\end{array}$ & $0 \pm 0$ & $0 \pm 0$ & $0 \pm 0$ & $0 \pm 0$ \\
\hline $\begin{array}{l}\text { After Low-pressure } \\
\text { UV Exposure }\end{array}$ & $\begin{array}{l}23.8 \pm \\
0.42\end{array}$ & $\begin{array}{l}20.25 \\
\pm 0.75\end{array}$ & $\begin{array}{l}6.7 \pm \\
0.48\end{array}$ & $0 \pm 0$ & $0 \pm 0$ & $0 \pm 0$ & $0 \pm 0$ \\
\hline
\end{tabular}

Table 7.6: Zones of inhibition for $97 \mathrm{E}$. coli isolates against 7 antibiotics

\begin{tabular}{|c|c|c|c|c|c|c|c|c|}
\hline \multirow[t]{2}{*}{ E. coli Isolate } & \multirow{2}{*}{$\begin{array}{l}\text { Date } \\
\text { isolated }\end{array}$} & \multicolumn{6}{|c|}{ Zone of Inhibition (mm) } & \multirow[b]{2}{*}{ CIP } \\
\hline & & ERT & $\begin{array}{l}\text { IP } \\
\text { M }\end{array}$ & $\begin{array}{l}\text { A } \\
\text { MC }\end{array}$ & CRO & TET & AZM & \\
\hline Control & \multirow{22}{*}{ 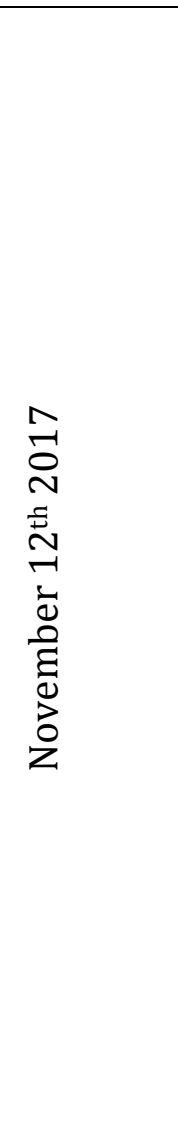 } & 28 & 23 & 19 & 26 & 22 & 22 & 27 \\
\hline EC002 & & 28 & 23 & 19 & 22 & 18 & 21 & 29 \\
\hline EC003 & & 28 & 24 & 20 & 26 & 19 & 23 & 31 \\
\hline EC004 & & 29 & 24 & 17 & 26 & 21 & 26 & 23 \\
\hline EC006 & & 28 & 26 & 21 & 26 & 19 & 25 & 24 \\
\hline EC007 & & 28 & 22 & 20 & 27 & 20 & 21 & 28 \\
\hline EC008 & & 28 & 23 & 19 & 26 & 18 & 19 & 29 \\
\hline EC009 & & 29 & 22 & 19 & 26 & 19 & 22 & 29 \\
\hline EC010 & & 28 & 25 & 20 & 27 & 21 & 25 & 31 \\
\hline EC011 & & 29 & 25 & 22 & 26 & 20 & 24 & 26 \\
\hline EC012 & & 29 & 23 & 18 & 25 & 19 & 10 & 24 \\
\hline EC013 & & 29 & 23 & 21 & 24 & 7 & 23 & 25 \\
\hline EC014 & & 28 & 23 & 19 & 24 & 21 & 22 & 27 \\
\hline EC015 & & 29 & 22 & 19 & 26 & 19 & 23 & 34 \\
\hline EC017 & & 29 & 25 & 19 & 27 & 19 & 22 & 35 \\
\hline EC018 & & 28 & 24 & 20 & 25 & 0 & 22 & 28 \\
\hline EC020 & & 28 & 26 & 20 & 26 & 21 & 19 & 28 \\
\hline EC021 & & 31 & 27 & 21 & 28 & 21 & 23 & 28 \\
\hline EC022 & & 27 & 22 & 18 & 24 & 19 & 21 & 27 \\
\hline EC023 & & 30 & 24 & 21 & 27 & 19 & 21 & 30 \\
\hline EC024 & & 29 & 23 & 20 & 26 & 20 & 20 & 27 \\
\hline EC025 & & 27 & 24 & 20 & 25 & 19 & 20 & 27 \\
\hline
\end{tabular}




\begin{tabular}{|c|c|c|c|c|c|c|c|c|}
\hline \multirow[t]{2}{*}{ E. coli Isolate } & \multirow{2}{*}{\begin{tabular}{|l} 
Date \\
isolated
\end{tabular}} & \multicolumn{6}{|c|}{ Zone of Inhibition (mm) } & \multirow[b]{2}{*}{ CIF } \\
\hline & & ERT & $\begin{array}{l}\text { IP } \\
\text { M }\end{array}$ & \begin{tabular}{|l|} 
A \\
MC
\end{tabular} & CRO & TET & AZM & \\
\hline EC026 & \multirow{23}{*}{ 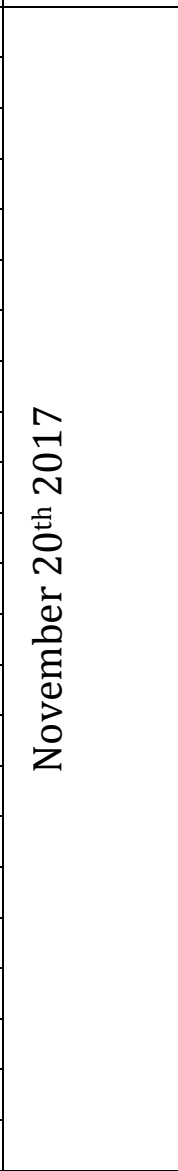 } & 29 & 27 & 19 & 29 & 6 & 24 & 34 \\
\hline EC027 & & 27 & 23 & 19 & 24 & 19 & 19 & 30 \\
\hline EC028 & & 28 & 24 & 19 & 27 & 0 & 25 & 24 \\
\hline EC029 & & 28 & 23 & 19 & 23 & 18 & 21 & 33 \\
\hline EC030 & & 27 & 24 & 18 & 25 & 18 & 21 & 25 \\
\hline EC031 & & 28 & 26 & 19 & 27 & 20 & 19 & 31 \\
\hline EC032 & & 29 & 26 & 18 & 27 & 18 & 20 & 25 \\
\hline EC033 & & 28 & 24 & 19 & 25 & 19 & 22 & 29 \\
\hline EC034 & & 28 & 25 & 20 & 26 & 19 & 20 & 25 \\
\hline EC035 & & 28 & 24 & 19 & 24 & 19 & 22 & 26 \\
\hline EC036 & & 27 & 23 & 18 & 25 & 20 & 19 & 32 \\
\hline EC037 & & 29 & 26 & 20 & 26 & 18 & 23 & 25 \\
\hline EC038 & & 27 & 23 & 22 & 28 & 22 & 22 & 31 \\
\hline EC039 & & 26 & 23 & 16 & 22 & 19 & 20 & 27 \\
\hline EC040 & & 27 & 23 & 18 & 24 & 18 & 22 & 27 \\
\hline EC041 & & 27 & 23 & 19 & 22 & 19 & 20 & 26 \\
\hline EC042 & & 26 & 23 & 18 & 25 & 19 & 18 & 31 \\
\hline EC043 & & 25 & 22 & 17 & 23 & 19 & 18 & 27 \\
\hline EC044 & & 27 & 25 & 19 & 27 & 19 & 11 & 29 \\
\hline EC045 & & 27 & 25 & 18 & 26 & 0 & 22 & 23 \\
\hline EC046 & & 27 & 24 & 20 & 23 & 19 & 20 & 28 \\
\hline EC047 & & 27 & 24 & 17 & 24 & 19 & 20 & 28 \\
\hline EC048 & & 27 & 25 & 20 & 27 & 21 & 22 & 30 \\
\hline EC049 & \multirow{15}{*}{ 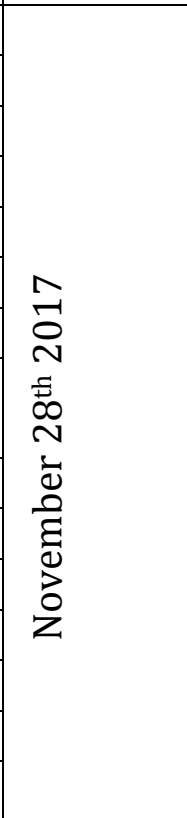 } & 23 & 23 & 17 & 7 & 0 & 6 & 0 \\
\hline EC050 & & 29 & 24 & 22 & 27 & 22 & 23 & 25 \\
\hline EC051 & & 26 & 23 & 19 & 26 & 21 & 27 & 30 \\
\hline EC052 & & 24 & 23 & 16 & 21 & 18 & 19 & 25 \\
\hline EC053 & & 26 & 22 & 19 & 25 & 20 & 24 & 21 \\
\hline EC054 & & 28 & 21 & 19 & 25 & 0 & 22 & 31 \\
\hline EC055 & & 27 & 22 & 20 & 27 & 19 & 24 & 31 \\
\hline EC056 & & 28 & 22 & 17 & 24 & $\begin{array}{l}\text { Error } \\
*\end{array}$ & 18 & 12 \\
\hline EC057 & & 27 & 22 & 18 & 26 & 17 & 21 & 27 \\
\hline EC058 & & 27 & 18 & 17 & 24 & 17 & 22 & 30 \\
\hline EC059 & & 29 & 25 & 18 & 27 & 19 & 17 & 31 \\
\hline EC060 & & 29 & 24 & 19 & 25 & 19 & 22 & 27 \\
\hline EC061 & & 29 & 25 & 21 & 27 & 0 & 24 & 24 \\
\hline EC062 & & 28 & 25 & 18 & 26 & 19 & 23 & 28 \\
\hline EC063 & & 26 & 26 & 13 & 26 & 0 & 21 & 29 \\
\hline
\end{tabular}




\begin{tabular}{|c|c|c|c|c|c|c|c|c|}
\hline \multirow[t]{2}{*}{ E. coli Isolate } & \multirow{2}{*}{$\begin{array}{l}\text { Date } \\
\text { isolated }\end{array}$} & \multicolumn{6}{|c|}{ Zone of Inhibition (mm) } & \multirow[b]{2}{*}{ CIP } \\
\hline & & ERT & \begin{tabular}{|l|} 
IP \\
M
\end{tabular} & $\begin{array}{l}\text { A } \\
\text { MC }\end{array}$ & CRO & TET & AZM & \\
\hline EC064 & \multirow{16}{*}{ 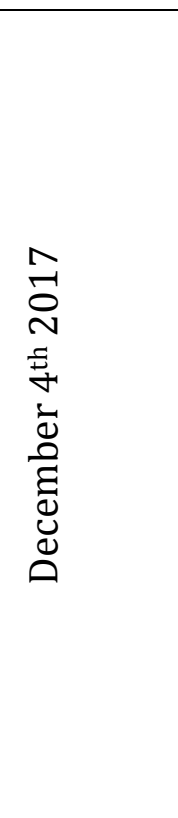 } & 28 & 23 & 18 & 25 & 18 & 22 & 29 \\
\hline EC065 & & 28 & 25 & 21 & 27 & 21 & 7 & 13 \\
\hline EC066 & & 27 & 22 & 18 & 26 & 0 & 24 & 30 \\
\hline EC067 & & 28 & 23 & 20 & 25 & 22 & 23 & 26 \\
\hline EC068 & & 26 & 22 & 16 & 23 & 19 & 22 & 28 \\
\hline EC069 & & 27 & 23 & 19 & 23 & 19 & 24 & 30 \\
\hline EC070 & & 27 & 23 & 20 & 27 & 25 & 26 & 27 \\
\hline EC071 & & 32 & 26 & 22 & 32 & 24 & 21 & 34 \\
\hline EC072 & & 27 & 22 & 18 & 24 & 12 & 25 & 24 \\
\hline EC073 & & 30 & 26 & 20 & 26 & 23 & 26 & 29 \\
\hline EC074 & & 32 & 25 & 20 & 30 & 20 & 30 & 32 \\
\hline EC075 & & 25 & 21 & 13 & 25 & 20 & 20 & 30 \\
\hline EC076 & & 27 & 22 & 18 & 25 & 20 & 22 & 29 \\
\hline EC077 & & 30 & 26 & 21 & 29 & 20 & 21 & 32 \\
\hline EC078 & & 27 & 24 & 19 & 26 & 18 & 23 & 31 \\
\hline EC079 & & 29 & 22 & 21 & 25 & 18 & 25 & 31 \\
\hline EC080 & \multirow{18}{*}{ 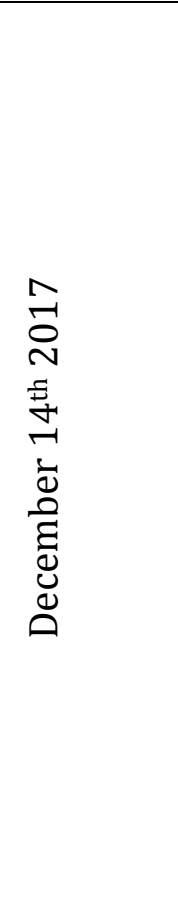 } & 26 & 23 & 21 & 26 & 19 & 22 & 26 \\
\hline EC081 & & 31 & 25 & 22 & 30 & 22 & 22 & 27 \\
\hline EC082 & & 34 & 25 & 21 & 28 & 24 & 25 & 31 \\
\hline EC083 & & 28 & 23 & 19 & 26 & 8 & 9 & 14 \\
\hline EC084 & & 26 & 24 & 17 & 6 & 7 & 11 & 0 \\
\hline EC085 & & 27 & 23 & 18 & 25 & 17 & 22 & 31 \\
\hline EC086 & & 23 & 25 & 20 & 21 & 18 & 22 & 25 \\
\hline EC087 & & 27 & 24 & 17 & 25 & 17 & 20 & 27 \\
\hline EC089 & & 26 & 24 & 22 & 30 & 28 & 24 & 35 \\
\hline EC090 & & 23 & 24 & 14 & 8 & 15 & 18 & 0 \\
\hline EC091 & & 26 & 24 & 20 & 26 & 16 & 20 & 27 \\
\hline EC092 & & 27 & 24 & 20 & 27 & 19 & 22 & 30 \\
\hline EC093 & & 27 & 25 & 19 & 26 & 19 & 21 & 33 \\
\hline EC094 & & 26 & 25 & 19 & 25 & 17 & 18 & 30 \\
\hline EC095 & & 27 & 23 & 19 & 25 & 18 & 20 & 29 \\
\hline EC096 & & 28 & 25 & 21 & 29 & 21 & 24 & 32 \\
\hline EC097 & & 26 & 23 & 14 & 22 & 6 & 17 & 30 \\
\hline EC098 & & 27 & 24 & 19 & 25 & 20 & 21 & 23 \\
\hline EC099 & \multirow{4}{*}{ 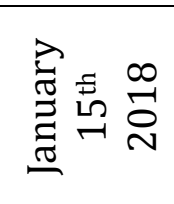 } & 26 & 23 & 29 & 25 & 20 & 23 & 26 \\
\hline EC100 & & 26 & 22 & 19 & 25 & 21 & 21 & 25 \\
\hline EC101 & & 23 & 21 & 0 & 0 & 0 & 0 & 0 \\
\hline EC102 & & 23 & 20 & 0 & 0 & 0 & 0 & 0 \\
\hline
\end{tabular}


Table 7.7: Free chlorine disinfection experiment data February 3rd 2018

\begin{tabular}{|c|c|c|c|c|}
\hline \multirow{3}{*}{$\begin{array}{l}\text { Sample Name } \\
\text { ATCC25922 Baseline } \\
\text { (Control) }\end{array}$} & \multirow{2}{*}{$\begin{array}{l}\begin{array}{l}\text { Volume of Sample Filtered } \\
\text { (microliters) }\end{array} \\
0.001\end{array}$} & \multicolumn{3}{|c|}{ CFU Recovery } \\
\hline & & 11 & 8 & 12 \\
\hline & 0.01 & 80 & 103 & 85 \\
\hline \multirow{3}{*}{$\begin{array}{l}\text { ATCC25922 Dose } \\
\text { (Control) }\end{array}$} & 1000 & 1 & 3 & 7 \\
\hline & 10000 & 31 & 27 & 39 \\
\hline & 76700 & 212 & & \\
\hline \multirow{2}{*}{$\begin{array}{l}\text { EC040 Baseline (Test } \\
\text { isolate A) }\end{array}$} & 0.001 & 24 & 22 & 17 \\
\hline & 0.01 & 103 & 117 & 110 \\
\hline \multirow{3}{*}{$\begin{array}{l}\text { EC040 Dose (Test } \\
\text { isolate } \mathrm{A} \text { ) }\end{array}$} & 1000 & 39 & 44 & 28 \\
\hline & 10000 & 264 & 275 & 275 \\
\hline & 76700 & TNTC & & \\
\hline \multirow{2}{*}{$\begin{array}{l}\text { EC065 Baseline (Test } \\
\text { isolate B) }\end{array}$} & 0.001 & 4 & 8 & 5 \\
\hline & 0.01 & 30 & 34 & 40 \\
\hline \multirow{3}{*}{$\begin{array}{l}\text { EC065 Dose (Test } \\
\text { isolate B) }\end{array}$} & 1000 & 1 & 1 & 0 \\
\hline & 10000 & 24 & 12 & 14 \\
\hline & 76700 & 150 & & \\
\hline \multirow{2}{*}{$\begin{array}{l}\text { EC084 Baseline (Test } \\
\text { isolate C) }\end{array}$} & 0.001 & 38 & 26 & 15 \\
\hline & 0.01 & 110 & 138 & 106 \\
\hline \multirow{3}{*}{$\begin{array}{l}\text { EC084 Dose (Test } \\
\text { isolate C) }\end{array}$} & 1000 & 15 & 17 & 6 \\
\hline & 10000 & 56 & 50 & 55 \\
\hline & 76700 & 300 & & \\
\hline \multirow{2}{*}{$\begin{array}{l}\text { EC101 Baseline (Test } \\
\text { isolate D) }\end{array}$} & 0.001 & 25 & 13 & 13 \\
\hline & 0.01 & 136 & 130 & 114 \\
\hline \multirow{3}{*}{$\begin{array}{l}\text { EC101 Dose (Test } \\
\text { isolate D) }\end{array}$} & 1000 & 6 & 10 & 6 \\
\hline & 10000 & 79 & 90 & 94 \\
\hline & 76700 & TNTC & & \\
\hline
\end{tabular}


Table 7.8: Free chlorine disinfection experiment data April 10th 2018

\begin{tabular}{|c|c|c|c|c|}
\hline \multirow{3}{*}{\begin{tabular}{|l|} 
Sample Name \\
$\begin{array}{l}\text { ATCC25922 Baseline } \\
\text { (Control) }\end{array}$
\end{tabular}} & \multirow{2}{*}{$\begin{array}{l}\begin{array}{l}\text { Volume of Sample Filtered } \\
\text { (microliters) }\end{array} \\
0.001\end{array}$} & \multicolumn{3}{|c|}{ CFU Recovery } \\
\hline & & 12 & 5 & 16 \\
\hline & 0.01 & 111 & 92 & 104 \\
\hline \multirow{3}{*}{$\begin{array}{l}\text { ATCC25922 Dose } \\
\text { (Control) }\end{array}$} & 1000 & 19 & 23 & 18 \\
\hline & 10000 & 276 & 244 & TNTC \\
\hline & 76700 & TNTC & & \\
\hline \multirow{2}{*}{$\begin{array}{l}\text { EC040 Baseline (Test } \\
\text { isolate A) }\end{array}$} & 0.001 & 8 & 7 & 10 \\
\hline & 0.01 & 87 & 77 & 89 \\
\hline \multirow{3}{*}{$\begin{array}{l}\text { EC040 Dose (Test } \\
\text { isolate A) }\end{array}$} & 1000 & 1 & 3 & 5 \\
\hline & 10000 & 117 & 35 & 64 \\
\hline & 76700 & TNTC & & \\
\hline \multirow{2}{*}{$\begin{array}{l}\text { EC065 Baseline (Test } \\
\text { isolate B) }\end{array}$} & 0.001 & 3 & 2 & 5 \\
\hline & 0.01 & 38 & 49 & 31 \\
\hline \multirow{3}{*}{$\begin{array}{l}\text { EC065 Dose (Test } \\
\text { isolate B) }\end{array}$} & 1000 & 5 & 8 & 10 \\
\hline & 10000 & 126 & 120 & 124 \\
\hline & 76700 & TNTC & & \\
\hline \multirow{2}{*}{$\begin{array}{l}\text { EC084 Baseline (Test } \\
\text { isolate C) }\end{array}$} & 0.001 & 6 & 13 & 8 \\
\hline & 0.01 & 70 & 70 & 80 \\
\hline \multirow{3}{*}{$\begin{array}{l}\text { EC084 Dose (Test } \\
\text { isolate C) }\end{array}$} & 1000 & 15 & 3 & 8 \\
\hline & 10000 & 71 & 60 & 73 \\
\hline & 76700 & TNTC & & \\
\hline \multirow{2}{*}{$\begin{array}{l}\text { EC101 Baseline (Test } \\
\text { isolate D) }\end{array}$} & 0.001 & 4 & 5 & 8 \\
\hline & 0.01 & 58 & 54 & 61 \\
\hline \multirow{3}{*}{$\begin{array}{l}\text { EC101 Dose (Test } \\
\text { isolate D) }\end{array}$} & 1000 & 1 & 1 & 3 \\
\hline & 10000 & 54 & 53 & 64 \\
\hline & 76700 & TNTC & & \\
\hline
\end{tabular}


Table 7.9: PAA disinfection experiment data February 26th 2018

\begin{tabular}{|c|c|c|c|c|}
\hline \multirow{3}{*}{$\begin{array}{l}\text { Sample Name } \\
\text { ATCC25922 Baseline } \\
\text { (Control) }\end{array}$} & \multirow{2}{*}{$\begin{array}{l}\text { Volume of Sample } \\
\text { Filtered (microliters) } \\
0.001\end{array}$} & \multicolumn{3}{|c|}{ CFU Recovery } \\
\hline & & 5 & 9 & 6 \\
\hline & 0.01 & 80 & 77 & 80 \\
\hline \multirow{3}{*}{$\begin{array}{l}\text { ATCC25922 Dose } \\
\text { (Control) }\end{array}$} & 10 & 1 & 0 & 4 \\
\hline & 100 & 26 & 22 & 61 \\
\hline & 1000 & 300 & 300 & TNTC \\
\hline \multirow{2}{*}{$\begin{array}{l}\text { EC040 Baseline (Test } \\
\text { isolate A) }\end{array}$} & 0.001 & 12 & 17 & 16 \\
\hline & 0.01 & 116 & 104 & 102 \\
\hline \multirow{3}{*}{$\begin{array}{l}\text { EC040 Dose (Test } \\
\text { isolate A) }\end{array}$} & 10 & 560 & 500 & 500 \\
\hline & 100 & TNTC & TNTC & TNTC \\
\hline & 1000 & TNTC & TNTC & TNTC \\
\hline \multirow{2}{*}{$\begin{array}{l}\text { EC065 Baseline (Test } \\
\text { isolate B) }\end{array}$} & 0.001 & 5 & 4 & 6 \\
\hline & 0.01 & 34 & 30 & 30 \\
\hline \multirow{3}{*}{$\begin{array}{l}\text { EC065 Dose (Test } \\
\text { isolate B) }\end{array}$} & 10 & 16 & 19 & 11 \\
\hline & 100 & 76 & 80 & 98 \\
\hline & 1000 & TNTC & TNTC & TNTC \\
\hline \multirow{2}{*}{$\begin{array}{l}\text { EC084 Baseline (Test } \\
\text { isolate C) }\end{array}$} & 0.001 & 9 & 5 & 10 \\
\hline & 0.01 & 78 & 83 & 51 \\
\hline \multirow{3}{*}{$\begin{array}{l}\text { EC084 Dose (Test } \\
\text { isolate C) }\end{array}$} & 10 & 448 & & \\
\hline & 100 & TNTC & TNTC & TNTC \\
\hline & 1000 & TNTC & TNTC & TNTC \\
\hline \multirow{2}{*}{$\begin{array}{l}\text { EC101 Baseline (Test } \\
\text { isolate D) }\end{array}$} & 0.001 & 2 & 2 & 0 \\
\hline & 0.01 & 8 & 12 & 7 \\
\hline \multirow{3}{*}{$\begin{array}{l}\text { EC101 Dose (Test } \\
\text { isolate D) }\end{array}$} & 10 & 12 & 21 & 13 \\
\hline & 100 & 72 & 99 & 112 \\
\hline & 1000 & TNTC & TNTC & TNTC \\
\hline
\end{tabular}


Table 7.10: PAA disinfection experiment data March 5th 2018

\begin{tabular}{|c|c|c|c|c|}
\hline \multirow{2}{*}{$\begin{array}{l}\text { ATCC25922 Baseline } \\
\text { (Control) }\end{array}$} & 0.001 & 9 & 10 & 12 \\
\hline & 0.01 & 94 & 81 & 95 \\
\hline \multirow{3}{*}{$\begin{array}{l}\text { ATCC25922 Dose } \\
\text { (Control) }\end{array}$} & 10 & 0 & 0 & 1 \\
\hline & 100 & 4 & 3 & 6 \\
\hline & 1000 & & 85 & 112 \\
\hline \multirow{2}{*}{$\begin{array}{l}\text { EC040 Baseline (Test } \\
\text { isolate A) }\end{array}$} & 0.001 & 12 & 8 & 22 \\
\hline & 0.01 & 100 & 117 & 100 \\
\hline \multirow{3}{*}{$\begin{array}{l}\text { EC040 Dose (Test } \\
\text { isolate } \mathrm{A} \text { ) }\end{array}$} & 0.1 & 188 & 200 & 178 \\
\hline & 1 & TNTC & TNTC & TNTC \\
\hline & 10 & TNTC & TNTC & TNTC \\
\hline \multirow{2}{*}{$\begin{array}{l}\text { EC065 Baseline (Test } \\
\text { isolate B) }\end{array}$} & 0.001 & 2 & 2 & 0 \\
\hline & 0.01 & 36 & 34 & 28 \\
\hline \multirow{3}{*}{$\begin{array}{l}\text { EC065 Dose (Test } \\
\text { isolate B) }\end{array}$} & 1 & 0 & 0 & 0 \\
\hline & 10 & 4 & 0 & 1 \\
\hline & 100 & 4 & 2 & 2 \\
\hline \multirow{2}{*}{$\begin{array}{l}\text { EC084 Baseline (Test } \\
\text { isolate C) }\end{array}$} & 0.001 & 5 & 5 & 4 \\
\hline & 0.01 & 69 & 72 & 72 \\
\hline \multirow{3}{*}{$\begin{array}{l}\text { EC084 Dose (Test } \\
\text { isolate C) }\end{array}$} & 0.1 & 44 & 37 & 41 \\
\hline & 1 & 380 & 236 & 180 \\
\hline & 10 & TNTC & TNTC & TNTC \\
\hline \multirow{2}{*}{$\begin{array}{l}\text { EC101 Baseline (Test } \\
\text { isolate D) }\end{array}$} & 0.001 & 13 & 5 & 3 \\
\hline & 0.01 & 79 & 64 & 72 \\
\hline \multirow{3}{*}{$\begin{array}{l}\text { EC101 Dose (Test } \\
\text { isolate D) }\end{array}$} & 1 & 1 & 4 & 2 \\
\hline & 10 & 49 & 42 & 52 \\
\hline & 100 & 113 & 158 & 176 \\
\hline
\end{tabular}


Table 7.11: Low pressure UV disinfection experiment data March 15th 2018

\begin{tabular}{|c|c|c|c|c|}
\hline \multirow{3}{*}{\begin{tabular}{|l|} 
Sample Name \\
ATCC25922 Baseline \\
(Control)
\end{tabular}} & \multirow{2}{*}{$\begin{array}{l}\text { Volume of Sample } \\
\text { Filtered (microliters) } \\
0.001\end{array}$} & \multicolumn{3}{|c|}{ CFU Recovery } \\
\hline & & 13 & 23 & 17 \\
\hline & 0.01 & 146 & 134 & 136 \\
\hline \multirow{3}{*}{$\begin{array}{l}\text { ATCC25922 Dose } \\
\text { (Control) }\end{array}$} & 100 & 3 & 4 & 0 \\
\hline & 1000 & 19 & 21 & 26 \\
\hline & 10000 & 204 & 224 & 184 \\
\hline \multirow{2}{*}{$\begin{array}{l}\text { EC040 Baseline (Test } \\
\text { isolate A) }\end{array}$} & 0.001 & 11 & 10 & 9 \\
\hline & 0.01 & 134 & 118 & 146 \\
\hline \multirow{3}{*}{$\begin{array}{l}\text { EC040 Dose (Test } \\
\text { isolate A) }\end{array}$} & 100 & 0 & 0 & 0 \\
\hline & 1000 & 0 & 0 & 1 \\
\hline & 10000 & 13 & 9 & 6 \\
\hline \multirow{2}{*}{$\begin{array}{l}\text { EC065 Baseline (Test } \\
\text { isolate B) }\end{array}$} & 0.001 & 3 & 3 & 4 \\
\hline & 0.01 & 34 & 45 & 37 \\
\hline \multirow{3}{*}{$\begin{array}{l}\text { EC065 Dose (Test } \\
\text { isolate B) }\end{array}$} & 100 & 0 & 0 & 0 \\
\hline & 1000 & 0 & 0 & 0 \\
\hline & 10000 & 5 & 12 & 12 \\
\hline \multirow{2}{*}{$\begin{array}{l}\text { EC084 Baseline (Test } \\
\text { isolate C) }\end{array}$} & 0.001 & 8 & 11 & 10 \\
\hline & 0.01 & 83 & 96 & 101 \\
\hline \multirow{3}{*}{$\begin{array}{l}\text { EC084 Dose (Test } \\
\text { isolate C) }\end{array}$} & 100 & 0 & 0 & 0 \\
\hline & 1000 & 1 & 2 & 5 \\
\hline & 10000 & 19 & 25 & 27 \\
\hline \multirow{2}{*}{$\begin{array}{l}\text { EC101 Baseline (Test } \\
\text { isolate D) }\end{array}$} & 0.001 & 8 & 5 & 6 \\
\hline & 0.01 & 84 & 75 & 69 \\
\hline \multirow{3}{*}{$\begin{array}{l}\text { EC101 Dose (Test } \\
\text { isolate D) }\end{array}$} & 100 & 1 & 0 & 1 \\
\hline & 1000 & 22 & 25 & 21 \\
\hline & 10000 & 186 & 190 & 170 \\
\hline
\end{tabular}


Table 7.12: Low pressure UV disinfection experiment data March 24th 2018

\begin{tabular}{|c|c|c|c|c|}
\hline \multirow{2}{*}{$\begin{array}{l}\text { ATCC25922 Baseline } \\
\text { (Control) }\end{array}$} & 0.001 & 9 & 9 & \\
\hline & 0.01 & 21 & 16 & \\
\hline \multirow{3}{*}{$\begin{array}{l}\text { ATCC25922 Dose } \\
\text { (Control) }\end{array}$} & 100 & 0 & 3 & 1 \\
\hline & 1000 & 21 & 12 & 26 \\
\hline & 10000 & 242 & 280 & 268 \\
\hline \multirow{2}{*}{$\begin{array}{l}\text { EC040 Baseline (Test } \\
\text { isolate A) }\end{array}$} & 0.001 & 33 & 22 & \\
\hline & 0.01 & 138 & 140 & \\
\hline \multirow{3}{*}{$\begin{array}{l}\text { EC040 Dose (Test } \\
\text { isolate } \mathrm{A} \text { ) }\end{array}$} & 1000 & 1 & 0 & 2 \\
\hline & 10000 & 12 & 17 & 31 \\
\hline & 67000 & TNTC & & \\
\hline \multirow{2}{*}{$\begin{array}{l}\text { EC065 Baseline (Test } \\
\text { isolate B) }\end{array}$} & 0.001 & 7 & 5 & \\
\hline & 0.01 & 42 & 49 & \\
\hline \multirow{3}{*}{$\begin{array}{l}\text { EC065 Dose (Test } \\
\text { isolate B) }\end{array}$} & 1000 & 3 & 3 & 4 \\
\hline & 10000 & 37 & 36 & 33 \\
\hline & 67000 & 150 & & \\
\hline \multirow{2}{*}{$\begin{array}{l}\text { EC084 Baseline (Test } \\
\text { isolate C) }\end{array}$} & 0.001 & 10 & 11 & 6 \\
\hline & 0.01 & 98 & 82 & 82 \\
\hline \multirow{3}{*}{$\begin{array}{l}\text { EC084 Dose (Test } \\
\text { isolate C) }\end{array}$} & 1000 & 1 & 1 & 5 \\
\hline & 10000 & 35 & 28 & 42 \\
\hline & 67000 & TNTC & & \\
\hline \multirow{2}{*}{$\begin{array}{l}\text { EC101 Baseline (Test } \\
\text { isolate D) }\end{array}$} & 0.001 & 8 & 8 & 15 \\
\hline & 0.01 & 73 & 71 & 90 \\
\hline \multirow{3}{*}{$\begin{array}{l}\text { EC101 Dose (Test } \\
\text { isolate D) }\end{array}$} & 100 & 4 & 2 & 0 \\
\hline & 1000 & 28 & 53 & 39 \\
\hline & 10000 & TNTC & TNTC & TNTC \\
\hline
\end{tabular}


Table 7.13: Kirby Bauer resistance profiles of control and test isolates pre and post free chlorine disinfection February 3rd 2018

\begin{tabular}{|c|c|c|c|c|c|c|c|c|c|c|c|c|c|c|c|}
\hline Pre Disinfection & \multicolumn{7}{|c|}{ Zone of Inhibition (mm) } & \multirow{2}{*}{\begin{tabular}{|c|}
$\begin{array}{c}\text { Post } \\
\text { Disinfection }\end{array}$ \\
Sample Name \\
\end{tabular}} & \multicolumn{7}{|c|}{ Zone of Inhibition (mm) } \\
\hline Sample Name & ERT & TIPM & AMC & CRO & TET & AZM & CIP & & ERT & IPM & AMC & CRO & TET & AZM & CIP \\
\hline \multirow{5}{*}{ ATCC 25922 (Control) } & \multirow{5}{*}{29} & \multirow{5}{*}{25} & \multirow{5}{*}{22} & \multirow{5}{*}{27} & \multirow{5}{*}{21} & \multirow{5}{*}{22} & \multirow{5}{*}{31} & ATCC25922-1 & 30 & 26 & 20 & 29 & 22 & 21 & 33 \\
\hline & & & & & & & & ATCC25922- 2 & 30 & 24 & 20 & 29 & 22 & Error & 31 \\
\hline & & & & & & & & ATCC25922- 3 & 30 & 24 & 20 & 28 & 21 & 23 & 30 \\
\hline & & & & & & & & ATCC25922- 4 & 29 & 25 & 18 & 23 & 21 & 22 & 33 \\
\hline & & & & & & & & ATCC25922- 5 & 30 & 27 & 20 & 30 & 22 & 21 & 32 \\
\hline \multirow{5}{*}{ EC040 (Test isolate A) } & \multirow{5}{*}{29} & \multirow{5}{*}{24} & \multirow{5}{*}{20} & \multirow{5}{*}{25} & \multirow{5}{*}{18} & \multirow{5}{*}{21} & \multirow{5}{*}{31} & EC040- 1 & 30 & 24 & 20 & 28 & 20 & 23 & 30 \\
\hline & & & & & & & & ECO40- 2 & 30 & 23 & 19 & 27 & 19 & 24 & 28 \\
\hline & & & & & & & & ECO40- 3 & 30 & 23 & 19 & 26 & 19 & 22 & 29 \\
\hline & & & & & & & & EC040- 4 & 28 & 23 & 20 & 27 & 18 & 21 & 32 \\
\hline & & & & & & & & EC040- 5 & 29 & 21 & 19 & 22 & 18 & 22 & 26 \\
\hline \multirow{5}{*}{ EC065 (Test isolate B) } & \multirow{5}{*}{30} & \multirow{5}{*}{25} & \multirow{5}{*}{22} & \multirow{5}{*}{26} & \multirow{5}{*}{21} & \multirow{5}{*}{10} & \multirow{5}{*}{15} & EC065- 1 & 32 & 26 & 22 & 31 & 23 & 10 & 15 \\
\hline & & & & & & & & EC065- 2 & 33 & 27 & 22 & 31 & 23 & 11 & 15 \\
\hline & & & & & & & & EC065- 3 & 30 & 26 & 21 & 29 & 22 & 11 & 14 \\
\hline & & & & & & & & EC065- 4 & 32 & 24 & 22 & 28 & 22 & 11 & 15 \\
\hline & & & & & & & & EC065- 5 & 31 & 27 & 22 & 30 & 23 & 10 & 14 \\
\hline \multirow{5}{*}{ EC084 (Test isolate C) } & & & & & & & & EC084- 1 & 26 & 24 & 18 & 0 & 0 & 10 & 0 \\
\hline & & & & & & & & EC084- 2 & 23 & 26 & 0 & 9 & 0 & 0 & 0 \\
\hline & 28 & 24 & 18 & 9 & 7 & 11 & 0 & EC084- 3 & 30 & 25 & 20 & 10 & 0 & 10 & 0 \\
\hline & & & & & & & & EC084- 4 & 25 & 23 & 15 & 0 & 0 & 0 & 0 \\
\hline & & & & & & & & EC084- 5 & 28 & 25 & 20 & 9 & 0 & 11 & 0 \\
\hline & & & & & & & & EC101-1 & 18 & 19 & 0 & 0 & 0 & 0 & 0 \\
\hline & & & & & & & & EC101- 2 & 24 & 21 & 0 & 0 & 0 & 0 & 0 \\
\hline EC101 (Test isolate D) & 23 & 19 & 0 & 0 & 0 & 0 & 0 & EC101- 3 & 24 & 22 & 0 & 0 & 0 & 0 & 0 \\
\hline & & & & & & & & EC101- 4 & 24 & 21 - 21 & 0 & 0 & 0 & 0 & 0 \\
\hline & & & & & & & & EC101- 5 & 23 & 20 & 0 & 0 & 0 & 0 & 0 \\
\hline
\end{tabular}


Table 7.14: Kirby Bauer resistance profiles of control and test isolates pre and post free chlorine disinfection April $10^{\text {th }} 2018$

\begin{tabular}{|c|c|c|c|c|c|c|c|c|c|c|c|c|c|c|c|}
\hline Pre Disinfection & \multicolumn{7}{|c|}{ Zone of Inhibition (mm) } & \multirow{2}{*}{\begin{tabular}{|c|}
$\begin{array}{c}\text { Post } \\
\text { Disinfection }\end{array}$ \\
Sample Name \\
\end{tabular}} & \multicolumn{7}{|c|}{ Zone of Inhibition (mm) } \\
\hline Sample Name & ERT & IPM & AMC & CRO & TET & AZM & CIP & & ERT & IPM & AMC & CRO & TET & AZM & CIP \\
\hline \multirow{5}{*}{ ATCC 25922 (Control) } & \multirow{5}{*}{30} & \multirow{5}{*}{26} & \multirow{5}{*}{19} & \multirow{5}{*}{27} & \multirow{5}{*}{21} & \multirow{5}{*}{22} & \multirow{5}{*}{30} & ATCC25922-1 & 30 & 26 & 20 & 30 & 21 & 22 & 35 \\
\hline & & & & & & & & ATCC25922- 2 & 32 & 26 & 21 & 29 & 22 & 23 & 34 \\
\hline & & & & & & & & ATCC25922- 3 & 32 & 25 & 20 & 30 & 22 & 23 & 33 \\
\hline & & & & & & & & ATCC25922- 4 & 32 & 26 & 21 & 29 & 21 & 22 & 33 \\
\hline & & & & & & & & ATCC25922- 5 & 31 & 28 & 20 & 29 & 22 & 22 & 34 \\
\hline \multirow{5}{*}{ EC040 (Test isolate A) } & \multirow{5}{*}{28} & \multirow{5}{*}{23} & \multirow{5}{*}{19} & \multirow{5}{*}{26} & \multirow{5}{*}{20} & \multirow{5}{*}{22} & \multirow{5}{*}{30} & EC040- 1 & 29 & 23 & 20 & 27 & 19 & 21 & 30 \\
\hline & & & & & & & & EC040- 2 & 30 & 24 & 20 & 27 & 19 & 22 & 31 \\
\hline & & & & & & & & EC040- 3 & 28 & 24 & 20 & 26 & 18 & 20 & 30 \\
\hline & & & & & & & & EC040- 4 & 30 & 24 & 18 & 25 & 18 & 20 & 28 \\
\hline & & & & & & & & EC040- 5 & 30 & 24 & 19 & 27 & 17 & 23 & 30 \\
\hline \multirow{5}{*}{ EC065 (Test isolate B) } & \multirow{5}{*}{30} & \multirow{5}{*}{27} & \multirow{5}{*}{21} & \multirow{5}{*}{30} & \multirow{5}{*}{22} & \multirow{5}{*}{11} & \multirow{5}{*}{15} & EC065- 1 & 30 & 27 & 22 & 29 & 22 & 10 & 14 \\
\hline & & & & & & & & EC065- 2 & 31 & 27 & 22 & 31 & 23 & 9 & 14 \\
\hline & & & & & & & & EC065- 3 & 31 & 27 & 21 & 30 & 22 & 10 & 15 \\
\hline & & & & & & & & EC065- 4 & 31 & 26 & 21 & 29 & 21 & 10 & 14 \\
\hline & & & & & & & & EC065- 5 & 30 & 25 & 21 & 27 & 22 & 10 & 14 \\
\hline \multirow{5}{*}{ EC084 (Test isolate C) } & & & & & & & & EC084- 1 & 28 & 24 & 19 & 9 & 0 & 10 & 0 \\
\hline & & & & & & & & EC084- 2 & 27 & 24 & 19 & 9 & 0 & 10 & 0 \\
\hline & 27 & 23 & 19 & 9 & 0 & 10 & 0 & EC084- 3 & 27 & 23 & 19 & 9 & 0 & 10 & 0 \\
\hline & & & & & & & & EC084- 4 & 25 & 24 & 19 & 7 & 0 & 10 & 0 \\
\hline & & & & & & & & EC084- 5 & 27 & 25 & 19 & 9 & 7 & 10 & 0 \\
\hline & & & & & & & & EC101- 1 & 24 & 21 & 0 & 0 & 0 & 0 & 0 \\
\hline & & & & & & & & EC101- 2 & 24 & 21 & 0 & 0 & 0 & 0 & 0 \\
\hline EC101 (Test isolate D) & 24 & 20 & 0 & 11 & 0 & 0 & 0 & EC101-3 & 24 & 20 & 0 & 0 & 0 & 0 & 0 \\
\hline & & & & & & & & EC101- 4 & 24 & 22 & 0 & 0 & 0 & 0 & 0 \\
\hline & & & & & & & & EC101- 5 & 24 & 21 & 0 & 0 & 0 & 0 & 0 \\
\hline
\end{tabular}


Table 7.15: Kirby Bauer resistance profiles of control and test isolates pre and post PAA disinfection February $26^{\text {th }} 2018$

\begin{tabular}{|c|c|c|c|c|c|c|c|c|c|c|c|c|c|c|c|}
\hline Pre Disinfection & \multicolumn{7}{|c|}{ Zone of Inhibition (mm) } & \multirow{2}{*}{\begin{tabular}{|c|}
$\begin{array}{c}\text { Post } \\
\text { Disinfection }\end{array}$ \\
Sample Name \\
\end{tabular}} & \multicolumn{7}{|c|}{ Zone of Inhibition (mm) } \\
\hline Sample Name & ERT & IPM & AMC & CRO & TET & AZM & CIP & & ERT & IPM & AMC & CRO & TET & AZM & $\mathrm{CIP}$ \\
\hline \multirow{5}{*}{ ATCC 25922 (Control) } & \multirow{5}{*}{29} & \multirow{5}{*}{24} & \multirow{5}{*}{19} & \multirow{5}{*}{26} & \multirow{5}{*}{21} & \multirow{5}{*}{22} & \multirow{5}{*}{31} & ATCC25922-1 & 30 & 25 & 20 & 28 & 21 & 23 & 33 \\
\hline & & & & & & & & ATCC25922- 2 & 32 & 26 & 21 & 29 & 21 & 23 & 32 \\
\hline & & & & & & & & ATCC25922-3 & 31 & 25 & 20 & 28 & 21 & 24 & 33 \\
\hline & & & & & & & & ATCC25922- 4 & 30 & 25 & 19 & 27 & 20 & 22 & 32 \\
\hline & & & & & & & & ATCC25922- 5 & 26 & 24 & 18 & 22 & 20 & 22 & 32 \\
\hline \multirow{5}{*}{ EC040 (Test isolate A) } & \multirow{5}{*}{$29 \mid$} & \multirow{5}{*}{23} & \multirow{5}{*}{19} & \multirow{5}{*}{26} & \multirow{5}{*}{18} & \multirow{5}{*}{24} & \multirow{5}{*}{30} & EC040- 1 & 28 & 25 & 19 & 25 & 17 & 19 & 30 \\
\hline & & & & & & & & ECO40- 2 & 28 & 23 & 19 & 26 & 17 & 22 & 28 \\
\hline & & & & & & & & EC040- 3 & 28 & 23 & 19 & 25 & 17 & 21 & 30 \\
\hline & & & & & & & & EC040- 4 & 27 & 22 & 17 & 24 & 17 & 20 & 25 \\
\hline & & & & & & & & EC040- 5 & 27 & 21 & 18 & 25 & 17 & 19 & 28 \\
\hline \multirow{5}{*}{ EC065 (Test isolate B) } & \multirow{5}{*}{$29 \mid$} & \multirow{5}{*}{25} & \multirow{5}{*}{21} & \multirow{5}{*}{29} & \multirow{5}{*}{21} & \multirow{5}{*}{11} & \multirow{5}{*}{14} & EC065- 1 & 28 & 25 & 20 & 26 & 20 & 10 & 13 \\
\hline & & & & & & & & EC065- 2 & 30 & 27 & 21 & 29 & 21 & 10 & 14 \\
\hline & & & & & & & & EC065- 3 & 30 & 26 & 20 & 27 & 22 & 10 & 14 \\
\hline & & & & & & & & EC065- 4 & 30 & 22 & 21 & 28 & 22 & 10 & 14 \\
\hline & & & & & & & & EC065- 5 & 30 & 25 & 20 & 28 & 21 & 10 & 14 \\
\hline \multirow{5}{*}{ EC084 (Test isolate C) } & & & & & & & & EC084- 1 & 28 & 24 & 19 & 9 & 7 & 11 & 0 \\
\hline & & & & & & & & EC084- 2 & 28 & 24 & 18 & 8 & 7 & 10 & 0 \\
\hline & 27 & 24 & 19 & 9 & 7 & 10 & 0 & EC084- 3 & 28 & 25 & 19 & 10 & 7 & 10 & 0 \\
\hline & & & & & & & & EC084- 4 & 29 & 25 & 18 & 9 & 7 & 11 & 0 \\
\hline & & & & & & & & EC084- 5 & 28 & 25 & 20 & 9 & 7 & 11 & 0 \\
\hline & & & & & & & & EC101- 1 & 23 & 21 & 7 & 0 & 0 & 0 & 0 \\
\hline & & & & & & & & EC101- 2 & 23 & 21 & 0 & 0 & 0 & 0 & 0 \\
\hline EC101 (Test isolate D) & 23 & 20 & 0 & 0 & 0 & 0 & 0 & EC101-3 & 24 & 21 & 0 & 0 & 0 & 0 & 0 \\
\hline & & & & & & & & EC101- 4 & 24 & 21 & 0 & 0 & 0 & 0 & 0 \\
\hline & & & & & & & & EC101- 5 & 25 & 21 & 0 & 0 & 0 & 0 & 0 \\
\hline
\end{tabular}


Table 7.16: Kirby Bauer resistance profiles of control and test isolates pre and post PAA disinfection March $5^{\text {th }} 2018$

\begin{tabular}{|c|c|c|c|c|c|c|c|c|c|c|c|c|c|c|c|}
\hline Pre Disinfection & \multicolumn{7}{|c|}{ Zone of Inhibition (mm) } & \multirow{2}{*}{\begin{tabular}{|c|}
$\begin{array}{c}\text { Post } \\
\text { Disinfection }\end{array}$ \\
Sample Name \\
\end{tabular}} & \multicolumn{7}{|c|}{ Zone of Inhibition (mm) } \\
\hline Sample Name & ERT & IPM & AMC & CRO & TET & AZM & $\mathrm{CIP}$ & & ERT & IPM & AMC & CRO & TET & AZM & $\mathrm{ClP}$ \\
\hline \multirow{5}{*}{ ATCC 25922 (Control) } & \multirow{5}{*}{29} & \multirow{5}{*}{25} & \multirow{5}{*}{19} & \multirow{5}{*}{27} & \multirow{5}{*}{21} & \multirow{5}{*}{22} & & ATCC25922- 1 & $\sqrt{30}$ & 28 & 20 & 30 & 21 & 24 & 33 \\
\hline & & & & & & & \multirow{4}{*}{32} & ATCC25922- 2 & 32 & 27 & 21 & 30 & 23 & 24 & 34 \\
\hline & & & & & & & & ATCC25922- 3 & 30 & 27 & 20 & 28 & 21 & 23 & 32 \\
\hline & & & & & & & & ATCC25922- 4 & 31 & 26 & 20 & 30 & 21 & 23 & 31 \\
\hline & & & & & & & & ATCC25922- 5 & 28 & 26 & 19 & 27 & 20 & 22 & 33 \\
\hline \multirow{5}{*}{ EC040 (Test isolate A) } & \multirow{5}{*}{28} & \multirow{5}{*}{24} & \multirow{5}{*}{18} & \multirow{5}{*}{24} & \multirow{5}{*}{18} & \multirow{5}{*}{22} & \multirow{5}{*}{31} & ECO40- 1 & 29 & 21 & 20 & 27 & 20 & 23 & 31 \\
\hline & & & & & & & & ECO40- 2 & 28 & 25 & 19 & 28 & 19 & 25 & 32 \\
\hline & & & & & & & & ECO40- 3 & 29 & 22 & 19 & 26 & 19 & 22 & 30 \\
\hline & & & & & & & & ECO40- 4 & 28 & 25 & 19 & 27 & 18 & 22 & 27 \\
\hline & & & & & & & & ECO40- 5 & 27 & 23 & 19 & 26 & 18 & 22 & 28 \\
\hline \multirow{5}{*}{ EC065 (Test isolate B) } & \multirow{5}{*}{30} & \multirow{5}{*}{25} & \multirow{5}{*}{21} & \multirow{5}{*}{27} & \multirow{5}{*}{21} & \multirow{5}{*}{12} & \multirow{5}{*}{14} & EC065- 1 & 30 & 27 & 21 & 29 & 22 & 10 & 14 \\
\hline & & & & & & & & EC065- 2 & 30 & 26 & 20 & 28 & 23 & 10 & 14 \\
\hline & & & & & & & & EC065- 3 & 30 & 27 & 21 & 28 & 23 & 10 & 14 \\
\hline & & & & & & & & EC065- 4 & 29 & 27 & 20 & 28 & 22 & 10 & 14 \\
\hline & & & & & & & & EC065- 5 & 30 & 27 & 21 & 29 & 22 & 10 & 14 \\
\hline \multirow{5}{*}{ EC084 (Test isolate C) } & & & & & & & & EC084- 1 & 29 & 25 & 19 & 9 & 0 & 11 & 0 \\
\hline & & & & & & & & EC084- 2 & 28 & 26 & 19 & 9 & 7 & 10 & 0 \\
\hline & 26 & 23 & 18 & 9 & 0 & 11 & 0 & EC084- 3 & 29 & 25 & 19 & 9 & 7 & 10 & 0 \\
\hline & & & & & & & & EC084- 4 & 27 & 25 & 18 & 9 & 7 & 10 & 0 \\
\hline & & & & & & & & EC084- 5 & 28 & 25 & 19 & 9 & 7 & 11 & 0 \\
\hline & & & & & & & & EC101- 1 & 24 & 20 & 7 & 0 & Error & 0 & 0 \\
\hline & & & & & & & & EC101- 2 & 24 & 21 & 7 & 0 & 0 & 0 & 0 \\
\hline EC101 (Test isolate D) & 24 & 20 & 0 & 0 & 0 & 0 & 0 & EC101- 3 & 24 & 21 & 7 & 0 & 0 & 0 & 0 \\
\hline & & & & & & & & EC101- 4 & 24 & 21 & 7 & 0 & 0 & 0 & 0 \\
\hline & & & & & & & & EC101- 5 & 24 & 20 & 7 & 0 & 0 & 0 & 0 \\
\hline
\end{tabular}


Table 7.17: Kirby Bauer resistance profiles of control and test isolates pre and post low pressure UV disinfection March $15^{\text {th }} 2018$

\begin{tabular}{|c|c|c|c|c|c|c|c|c|c|c|c|c|c|c|c|}
\hline Pre Disinfection & \multicolumn{7}{|c|}{ Zone of Inhibition (mm) } & \begin{tabular}{c|} 
Post \\
Disinfection
\end{tabular} & \multicolumn{7}{|c|}{ Zone of Inhibition (mm) } \\
\hline Sample Name & ERT & IPM & AMC & CRO & TET & AZM & $\mathrm{CIP}$ & Sample Name & ERT & IPM & AMC & CRO & TET & AZM & $\mathrm{CIP}$ \\
\hline \multirow{5}{*}{ ATCC 25922 (Control) } & \multirow{5}{*}{27} & \multirow{5}{*}{24} & \multirow{5}{*}{19} & \multirow{5}{*}{27} & \multirow{5}{*}{20} & \multirow{5}{*}{21} & \multirow{5}{*}{31} & ATCC25922-1 & 28 & 24 & 19 & 26 & 20 & 22 & 31 \\
\hline & & & & & & & & ATCC25922- 2 & 29 & 25 & 20 & 29 & 21 & 23 & 32 \\
\hline & & & & & & & & ATCC25922-3 & 28 & 24 & 19 & 29 & 20 & 24 & 34 \\
\hline & & & & & & & & ATCC25922-4 & 31 & 26 & 20 & 29 & 21 & 24 & 35 \\
\hline & & & & & & & & ATCC25922- 5 & 29 & 25 & 19 & 28 & 21 & 22 & 34 \\
\hline \multirow{5}{*}{ EC040 (Test isolate A) } & \multirow{5}{*}{28} & \multirow{5}{*}{24} & \multirow{5}{*}{19} & \multirow{5}{*}{26} & \multirow{5}{*}{20} & \multirow{5}{*}{21} & \multirow{5}{*}{31} & EC040- 1 & 30 & 23 & 18 & 26 & 18 & 19 & 30 \\
\hline & & & & & & & & EC040- 2 & 29 & 23 & 19 & 26 & 19 & 22 & 30 \\
\hline & & & & & & & & EC040- 3 & 29 & 23 & 20 & 28 & 20 & 21 & 31 \\
\hline & & & & & & & & EC040- 4 & 29 & 23 & 19 & 26 & 19 & 22 & 30 \\
\hline & & & & & & & & EC040- 5 & 28 & 25 & 19 & 25 & 18 & 20 & 29 \\
\hline \multirow{5}{*}{ EC065 (Test isolate B) } & \multirow{5}{*}{29} & \multirow{5}{*}{26} & \multirow{5}{*}{22} & \multirow{5}{*}{28} & \multirow{5}{*}{22} & \multirow{5}{*}{10} & \multirow{5}{*}{14} & EC065- 1 & 29 & 26 & 20 & 28 & 21 & 9 & 15 \\
\hline & & & & & & & & EC065- 2 & 30 & 27 & 22 & 28 & 22 & 7 & 14 \\
\hline & & & & & & & & EC065- 3 & 29 & 26 & 21 & 27 & 21 & 10 & 14 \\
\hline & & & & & & & & EC065- 4 & 30 & 26 & 22 & 27 & 21 & 9 & 14 \\
\hline & & & & & & & & EC065- 5 & 29 & 25 & 22 & 26 & 22 & 10 & 14 \\
\hline \multirow{5}{*}{ EC084 (Test isolate C) } & \multirow{5}{*}{27} & & & & & & & EC084- 1 & 27 & 24 & 19 & 9 & 7 & 11 & 0 \\
\hline & & & & & & & & EC084- 2 & 29 & 24 & 19 & 8 & 7 & 11 & 0 \\
\hline & & 24 & 19 & 9 & 7 & 10 & 0 & EC084- 3 & 27 & 24 & 19 & 8 & 7 & 9 & 0 \\
\hline & & & & & & & & EC084- 4 & 28 & 24 & 20 & 8 & 7 & 9 & 0 \\
\hline & & & & & & & & EC084- 5 & 29 & 24 & 19 & 8 & 7 & 10 & 0 \\
\hline & & & & & & & & EC101- 1 & 23 & 19 & 7 & 0 & 0 & 0 & 0 \\
\hline & & & & & & & & EC101- 2 & 24 & 21 & 7 & 0 & 0 & 0 & 0 \\
\hline EC101 (Test isolate D) & 24 & 20 & 7 & 0 & 0 & 0 & 0 & EC101- 3 & 24 & 21 & 7 & 0 & 0 & 0 & 0 \\
\hline & & & & & & & & EC101- 4 & 24 & 21 & 7 & 0 & 0 & 0 & 0 \\
\hline & & & & & & & & EC101- 5 & 24 & 20 & 7 & 0 & 0 & 0 & 0 \\
\hline
\end{tabular}


Table 7.18: Kirby Bauer resistance profiles of control and test isolates pre and post low pressure UV disinfection March $24^{\text {th }} 2018$

\begin{tabular}{|c|c|c|c|c|c|c|c|c|c|c|c|c|c|c|c|}
\hline \multirow{2}{*}{\begin{tabular}{|c|} 
Pre Disinfection \\
Sample Name
\end{tabular}} & \multicolumn{7}{|c|}{ Zone of Inhibition (mm) } & \multirow{2}{*}{\begin{tabular}{|l|} 
Post \\
Disinfection \\
Sample Name \\
\end{tabular}} & \multicolumn{7}{|c|}{ Zone of Inhibition (mm) } \\
\hline & ERT & IPM & AMC & CRO & TET & AZM & $\mathrm{CIP}$ & & ERT & IPM & AMC & $\overline{C R O}$ & TET & AZM & $\mathrm{CIP}$ \\
\hline \multirow{5}{*}{ ATCC 25922} & \multirow{5}{*}{28} & \multirow{5}{*}{25} & \multirow{5}{*}{19} & \multirow{5}{*}{29} & \multirow{5}{*}{21} & \multirow{5}{*}{22} & \multirow{5}{*}{35} & ATCC25922-1 & 32 & 27 & 21 & 30 & 22 & 23 & 34 \\
\hline & & & & & & & & ATCC25922- 2 & 32 & 26 & 21 & 29 & 21 & 22 & 33 \\
\hline & & & & & & & & ATCC25922-3 & 31 & 25 & 21 & 28 & 20 & 23 & 34 \\
\hline & & & & & & & & ATCC25922-4 & 31 & 26 & 20 & 30 & 22 & 23 & 33 \\
\hline & & & & & & & & ATCC25922- 5 & 31 & 26 & 21 & 29 & 21 & 22 & 35 \\
\hline \multirow{5}{*}{ EC040 } & \multirow{5}{*}{29} & \multirow{5}{*}{23} & \multirow{5}{*}{19} & \multirow{5}{*}{26} & \multirow{5}{*}{19} & \multirow{5}{*}{22} & \multirow{5}{*}{30} & EC040- 1 & 29 & 26 & 20 & 27 & 20 & 24 & 30 \\
\hline & & & & & & & & EC040- 2 & 30 & 26 & 20 & 27 & 19 & 24 & 30 \\
\hline & & & & & & & & EC040- 3 & 30 & 24 & 20 & 27 & 20 & 25 & 30 \\
\hline & & & & & & & & EC040- 4 & 29 & 25 & 20 & 27 & 29 & 23 & 29 \\
\hline & & & & & & & & EC040- 5 & 29 & 22 & 19 & 27 & 18 & 23 & 31 \\
\hline \multirow{5}{*}{ EC065 } & \multirow{5}{*}{29} & \multirow{5}{*}{26} & \multirow{5}{*}{21} & \multirow{5}{*}{29} & \multirow{5}{*}{22} & \multirow{5}{*}{9} & \multirow{5}{*}{14} & EC065- 1 & 30 & 27 & 22 & 29 & 23 & 10 & 15 \\
\hline & & & & & & & & EC065- 2 & 30 & 26 & 22 & 29 & 27 & 9 & 14 \\
\hline & & & & & & & & EC065- 3 & 31 & 26 & 22 & 29 & 22 & 10 & 15 \\
\hline & & & & & & & & EC065- 4 & 31 & 26 & 22 & 29 & 23 & 9 & 14 \\
\hline & & & & & & & & EC065- 5 & 31 & 27 & 22 & 29 & 22 & 11 & 14 \\
\hline & & & & & & & & EC084- 1 & 27 & 23 & 19 & 8 & 7 & 11 & 0 \\
\hline & & & & & & & & EC084- 2 & 28 & 24 & 19 & 9 & 7 & 10 & 0 \\
\hline EC084 & 29 & 24 & 20 & 10 & 0 & 10 & 0 & EC084- 3 & 28 & 25 & 20 & 8 & 0 & 10 & 0 \\
\hline & & & & & & & & EC084- 4 & 28 & 24 & 19 & 7 & 7 & 10 & 0 \\
\hline & & & & & & & & EC084- 5 & 28 & 24 & 19 & 9 & 7 & 10 & 0 \\
\hline & & & & & & & & EC101- 1 & 24 & 21 & 7 & 0 & 0 & 0 & 0 \\
\hline & & & & & & & & EC101- 2 & 24 & 21 & 7 & 0 & 0 & 0 & 0 \\
\hline EC101 & 24 & 21 & 7 & 0 & 0 & 0 & 0 & EC101- 3 & 24 & 19 & 6 & 0 & 0 & 0 & 0 \\
\hline & & & & & & & & EC101- 4 & 24 & 21 & 6 & 0 & 0 & 0 & 0 \\
\hline & & & & & & & & EC101- 5 & 23 & 20 & 6 & 0 & 0 & 0 & 0 \\
\hline
\end{tabular}


Table 7.19: Secondary wastewater effluent water quality data obtained from the Robert O. Pickard Environmental Center before disinfection (BD) and after disinfection (AD)

\begin{tabular}{|c|c|c|c|c|c|c|c|c|}
\hline $\begin{array}{c}\text { Sample } \\
\text { Date }\end{array}$ & $\begin{array}{c}\text { TSS- } \\
\text { AD } \\
\text { (mg/L) }\end{array}$ & $\begin{array}{c}\text { CBOD- } \\
\text { AD } \\
\text { (mg/L) }\end{array}$ & $\begin{array}{c}\text { COD - } \\
\text { AD } \\
(\mathrm{mg} / \mathrm{L})\end{array}$ & $\begin{array}{c}\text { Total } \\
\text { Phosphate } \\
\text { - AD } \\
\text { (mg/L) }\end{array}$ & $\begin{array}{c}\text { Reactive } \\
\text { phosphate } \\
\text { - AD } \\
\text { (mg/L) }\end{array}$ & $\begin{array}{c}\mathrm{PH}- \\
\mathrm{AD} \\
\text { (pH } \\
\text { units) }\end{array}$ & $\begin{array}{c}\text { SCBOD } \\
-A D \\
(\mathrm{mg} / \mathrm{L})\end{array}$ & $\begin{array}{c}\text { SCOD - } \\
\text { AD } \\
(\mathrm{mg} / \mathrm{L})\end{array}$ \\
\hline 31-Oct-17 & 8 & 4 & 25 & 0.37 & 0.16 & 7.76 & 2 & 29 \\
\hline $\begin{array}{c}\text { 02-Nov- } \\
17\end{array}$ & 9 & 5 & 40 & 0.59 & 0.34 & 7.74 & \multicolumn{2}{|c|}{$\begin{array}{l}\text { Analysis not } \\
\text { performed }\end{array}$} \\
\hline $\begin{array}{c}\text { 04-Nov- } \\
17\end{array}$ & 10 & 5 & 54 & 0.52 & 0.23 & 7.83 & \multicolumn{2}{|c|}{$\begin{array}{c}\text { Analysis not } \\
\text { performed }\end{array}$} \\
\hline $\begin{array}{c}\text { 06-Nov- } \\
17\end{array}$ & 7 & 5 & 81 & 0.46 & 0.24 & 7.46 & 3 & 36 \\
\hline $\begin{array}{c}\text { 08-Nov- } \\
17\end{array}$ & 7 & 13 & 115 & 0.51 & 0.35 & 7.52 & \multicolumn{2}{|c|}{$\begin{array}{l}\text { Analysis not } \\
\text { performed }\end{array}$} \\
\hline $\begin{array}{c}\text { 10-Nov- } \\
17\end{array}$ & 6 & 21 & 78 & 0.5 & 0.27 & 7.62 & \multicolumn{2}{|c|}{$\begin{array}{c}\text { Analysis not } \\
\text { performed }\end{array}$} \\
\hline $\begin{array}{c}12-N o v- \\
17^{*}\end{array}$ & 5 & 19 & 75 & 0.58 & 0.33 & 7.53 & \multicolumn{2}{|c|}{$\begin{array}{l}\text { Analysis not } \\
\text { performed }\end{array}$} \\
\hline $\begin{array}{c}\text { 14-Nov- } \\
17\end{array}$ & 4 & 15 & 50 & 0.47 & 0.32 & 7.56 & 15 & 46 \\
\hline $\begin{array}{c}\text { 16-Nov- } \\
17\end{array}$ & 5 & 22 & 75 & 0.54 & 0.36 & 7.77 & \multicolumn{2}{|c|}{$\begin{array}{c}\text { Analysis not } \\
\text { performed }\end{array}$} \\
\hline $\begin{array}{c}\text { 18-Nov- } \\
17\end{array}$ & 7 & 12 & 62 & 0.55 & 0.37 & 7.58 & \multicolumn{2}{|c|}{$\begin{array}{l}\text { Analysis not } \\
\text { performed }\end{array}$} \\
\hline $\begin{array}{c}20-N o v- \\
17^{*}\end{array}$ & 4 & 22 & 49 & 0.39 & 0.23 & 7.44 & 9 & 46 \\
\hline $\begin{array}{c}\text { 22-Nov- } \\
17\end{array}$ & 36 & 12 & 73 & 0.82 & 0.61 & 7.64 & \multicolumn{2}{|c|}{$\begin{array}{c}\text { Analysis not } \\
\text { performed }\end{array}$} \\
\hline $\begin{array}{c}\text { 24-Nov- } \\
17\end{array}$ & 4 & 8 & 53 & 0.77 & 0.55 & 7.47 & \multicolumn{2}{|c|}{$\begin{array}{l}\text { Analysis not } \\
\text { performed }\end{array}$} \\
\hline $\begin{array}{c}26-N o v- \\
17\end{array}$ & 4 & 7 & 60 & 0.48 & 0.32 & 7.57 & \multicolumn{2}{|c|}{$\begin{array}{l}\text { Analysis not } \\
\text { performed }\end{array}$} \\
\hline $\begin{array}{c}28-N o v- \\
17^{*}\end{array}$ & 4 & 11 & 60 & 0.42 & 0.26 & 7.48 & 4 & 39 \\
\hline $\begin{array}{c}\text { 30-Nov- } \\
17\end{array}$ & 5 & 5 & 54 & 0.52 & 0.3 & 7.48 & \multicolumn{2}{|c|}{$\begin{array}{l}\text { Analysis not } \\
\text { performed }\end{array}$} \\
\hline 02-Dec-17 & 5 & 5 & 58 & 0.55 & 0.34 & 7.51 & \multicolumn{2}{|c|}{$\begin{array}{l}\text { Analysis not } \\
\text { performed }\end{array}$} \\
\hline $\begin{array}{c}\text { 04-Dec- } \\
17^{*}\end{array}$ & 3 & 3 & 64 & 0.44 & 0.22 & 7.54 & 6 & 61 \\
\hline 06-Dec-17 & 4 & 5 & 28 & 0.45 & 0.25 & 7.64 & \multicolumn{2}{|c|}{$\begin{array}{c}\text { Analysis not } \\
\text { performed }\end{array}$} \\
\hline 08-Dec-17 & 7 & 4 & 41 & 0.71 & 0.45 & 7.58 & \multicolumn{2}{|c|}{ Analysis not } \\
\hline
\end{tabular}




\begin{tabular}{|c|c|c|c|c|c|c|c|c|}
\hline $\begin{array}{c}\text { Sample } \\
\text { Date }\end{array}$ & $\begin{array}{c}\text { TSS- } \\
\text { AD } \\
\text { (mg/L) }\end{array}$ & $\begin{array}{c}\text { CBOD- } \\
\text { AD } \\
(\mathrm{mg} / \mathrm{L})\end{array}$ & $\begin{array}{c}\text { COD - } \\
\text { AD } \\
(\mathrm{mg} / \mathrm{L})\end{array}$ & $\begin{array}{c}\text { Total } \\
\text { Phosphate } \\
\text { - AD } \\
\text { (mg/L) }\end{array}$ & $\begin{array}{c}\text { Reactive } \\
\text { phosphate } \\
\text { - AD } \\
\text { (mg/L) }\end{array}$ & $\begin{array}{c}\mathrm{PH}- \\
\mathrm{AD} \\
\text { (pH } \\
\text { units) }\end{array}$ & $\begin{array}{c}\text { SCBOD } \\
-A D \\
(\mathrm{mg} / \mathrm{L})\end{array}$ & $\begin{array}{c}\text { SCOD - } \\
\text { AD } \\
(\mathrm{mg} / \mathrm{L})\end{array}$ \\
\hline & & & & & & & \multicolumn{2}{|c|}{ performed } \\
\hline 10-Dec-17 & 5 & 4 & 35 & 0.54 & 0.34 & 7.4 & \multicolumn{2}{|c|}{$\begin{array}{c}\text { Analysis not } \\
\text { performed }\end{array}$} \\
\hline 12-Dec-17 & 4 & 33 & 114 & 0.61 & 0.48 & 7.42 & 4 & 55 \\
\hline $\begin{array}{c}\text { 14-Dec- } \\
17^{*}\end{array}$ & 4 & 4 & 66 & 0.68 & 0.48 & 7.5 & \multicolumn{2}{|c|}{$\begin{array}{l}\text { Analysis not } \\
\text { performed }\end{array}$} \\
\hline 16-Dec-17 & 4 & 3 & 55 & 0.74 & 0.51 & 7.41 & \multicolumn{2}{|c|}{$\begin{array}{l}\text { Analysis not } \\
\text { performed }\end{array}$} \\
\hline 18-Dec-17 & 5 & 11 & 59 & 0.52 & 0.38 & 7.44 & 2 & 46 \\
\hline 20-Dec-17 & 4 & 4 & 68 & 0.63 & 0.44 & 7.42 & \multicolumn{2}{|c|}{$\begin{array}{l}\text { Analysis not } \\
\text { performed }\end{array}$} \\
\hline 24-Dec-17 & 5 & 5 & 65 & 0.6 & 0.39 & 7.99 & \multicolumn{2}{|c|}{$\begin{array}{l}\text { Analysis not } \\
\text { performed }\end{array}$} \\
\hline 26-Dec-17 & 3 & 8 & 67 & 0.64 & 0.44 & 7.78 & 3 & 35 \\
\hline 28-Dec-17 & 4 & 3 & 52 & 0.42 & 0.26 & 7.66 & \multicolumn{2}{|c|}{$\begin{array}{c}\text { Analysis not } \\
\text { performed }\end{array}$} \\
\hline 30-Dec-17 & 5 & 3 & 68 & 0.5 & 0.27 & 7.91 & \multicolumn{2}{|c|}{$\begin{array}{l}\text { Analysis not } \\
\text { performed }\end{array}$} \\
\hline 01-Jan-18 & 17 & 3 & 64 & 0.45 & 0.19 & 7.88 & 3 & 50 \\
\hline 03-Jan-18 & 6 & 5 & 78 & 0.42 & 0.2 & 7.85 & \multicolumn{2}{|c|}{$\begin{array}{c}\text { Analysis not } \\
\text { performed }\end{array}$} \\
\hline 05-Jan-18 & 6 & 5 & 71 & 0.75 & 0.45 & 7.78 & \multicolumn{2}{|c|}{$\begin{array}{c}\text { Analysis not } \\
\text { performed }\end{array}$} \\
\hline 07-Jan-18 & 7 & 7 & 67 & 0.57 & 0.27 & 7.76 & \multicolumn{2}{|c|}{$\begin{array}{c}\text { Analysis not } \\
\text { performed }\end{array}$} \\
\hline 09-Jan-18 & 11 & 12 & 84 & 0.63 & 0.27 & 7.85 & 4 & 63 \\
\hline 11-Jan-18 & 4 & 5 & 80 & 0.68 & 0.31 & 7.82 & \multicolumn{2}{|c|}{$\begin{array}{c}\text { Analysis not } \\
\text { performed }\end{array}$} \\
\hline 13-Jan-18 & 8 & 5 & 48 & 0.59 & 0.25 & 7.87 & \multicolumn{2}{|c|}{$\begin{array}{c}\text { Analysis not } \\
\text { performed }\end{array}$} \\
\hline $\begin{array}{c}\text { 15-Jan- } \\
18^{*}\end{array}$ & 5 & 4 & 57 & 0.41 & 0.15 & 7.92 & 3 & 51 \\
\hline 17-Jan-18 & 5 & 4 & 55 & 0.51 & 0.25 & 7.89 & \multicolumn{2}{|c|}{$\begin{array}{l}\text { Analysis not } \\
\text { performed }\end{array}$} \\
\hline 19-Jan-18 & 7 & 4 & 56 & 0.59 & 0.29 & 7.89 & \multicolumn{2}{|c|}{$\begin{array}{l}\text { Analysis not } \\
\text { performed }\end{array}$} \\
\hline 21-Jan-18 & 5 & 8 & 53 & 0.6 & 0.39 & 7.87 & \multicolumn{2}{|c|}{$\begin{array}{l}\text { Analysis not } \\
\text { performed }\end{array}$} \\
\hline 23-Jan-18 & 6 & 6 & 74 & 0.53 & 0.29 & 7.84 & 4 & 65 \\
\hline 25-Jan-18 & 14 & 6 & 72 & 0.65 & 0.28 & 7.7 & \multicolumn{2}{|c|}{ Analysis not } \\
\hline
\end{tabular}




\begin{tabular}{|c|c|c|c|c|c|c|c|c|}
\hline $\begin{array}{c}\text { Sample } \\
\text { Date }\end{array}$ & $\begin{array}{c}\text { TSS- } \\
\text { AD } \\
\text { (mg/L) }\end{array}$ & $\begin{array}{c}\text { CBOD- } \\
\text { AD } \\
\text { (mg/L) }\end{array}$ & $\begin{array}{c}\text { COD - } \\
\text { AD } \\
(\mathrm{mg} / \mathrm{L})\end{array}$ & $\begin{array}{c}\text { Total } \\
\text { Phosphate } \\
-A D \\
\text { (mg/L) }\end{array}$ & $\begin{array}{c}\text { Reactive } \\
\text { phosphate } \\
\text { - AD } \\
\text { (mg/L) }\end{array}$ & $\begin{array}{c}\mathrm{PH}- \\
\mathrm{AD} \\
\text { (pH } \\
\text { units) }\end{array}$ & $\begin{array}{c}\text { SCBOD } \\
\text {-AD } \\
\text { (mg/L) }\end{array}$ & $\begin{array}{c}\text { SCOD } \\
\text { AD } \\
(\mathrm{mg} / \mathrm{L})\end{array}$ \\
\hline & & & & & & & \multicolumn{2}{|c|}{ performed } \\
\hline 27-Jan-18 & 5 & 5 & 58 & 0.56 & 0.26 & 7.86 & \multicolumn{2}{|c|}{$\begin{array}{c}\text { Analysis not } \\
\text { performed }\end{array}$} \\
\hline 29-Jan-18 & 7 & 12 & 62 & 0.64 & 0.29 & 7.82 & 4 & 21 \\
\hline 31-Jan-18 & 4 & 8 & 68 & 0.67 & 0.39 & 7.92 & \multicolumn{2}{|c|}{$\begin{array}{c}\text { Analysis not } \\
\text { performed }\end{array}$} \\
\hline
\end{tabular}

* Days grab samples were obtained from the weir of the secondary clarifier and $E$. coli were isolated from 